Universidade de São Paulo

Faculdade de Saúde Pública

\title{
Programa Saúde na Escola: Análise da gestão local, ações de alimentação e nutrição e estado nutricional dos escolares brasileiros.
}

\author{
Ana Carolina Feldenheimer da Silva
}

Tese de doutorado apresentada ao Programa de Pós-Graduação em Nutrição e Saúde Pública para obtenção do título de Doutor em ciências.

Orientadora: Profa. Associada Patricia Constante Jaime

São Paulo

2014 


\section{Programa Saúde na Escola: Análise da gestão local, ações de alimentação e nutrição e estado nutricional dos escolares brasileiros.}

Ana Carolina Feldenheimer da Silva

Tese de doutorado apresentada ao Programa de Pós-Graduação em Nutrição e Saúde Pública para obtenção do título de Doutor em ciências.

Orientadora: Profa. Associada Patricia Constante Jaime 
É expressamente proibida a comercialização deste documento, tanto na sua forma impressa como eletrônica. Sua reprodução total ou parcial é permitida exclusivamente para fins acadêmicos e científicos desde que reprodução figure a identificação do autor, título, instituição e ano da tese. 


\section{Dedicatória}

Dedico este trabalho ao meu anjo da guarda, que por 30 anos pude chamar de pai e que hoje me acompanha às vezes de perto, às vezes de longe. Mas que nunca me deixa só na caminhada desta vida... 


\section{Agradecimentos}

Agradeço à minha orientadora e amiga Patricia Jaime, primeiro pelo convite para ser sua orientanda e, por acreditar no meu trabalho não apenas como no desenvolvimento desta tese, mas também como parte da equipe de gestão federal da Política Nacional de Alimentação.

Aos Professores que compuseram a minha banca: Prof. Oswaldo Tanaka, Prof ${ }^{\mathrm{a}}$. Deborah Malta, Prof. Daniel Bandoni e Prof ${ }^{\mathrm{a}}$. Natacha Toral, tanto pelas contribuições no processo da pré-banca como na disponibilidade em aceitar o convite para testemunhar este importante momento do meu percurso acadêmico.

À todos os professores que passaram pela minha vida, desde a préescola, e em especial aos Professores da Faculdade de Saúde Pública da USP, que ajudaram a construir minha vida acadêmica, desde a graduação até a final deste doutorado. Muito do sei sobre nutrição e saúde pública aprendi com estes profissionais e considero a minha formação acadêmica de ótima qualidade.

Aos funcionários da FSP, em especial a Alessandra Blaya, e todo o pessoal da graduação e da pós-graduação, que sempre foram prestativos e me ajudaram quando necessário.

Ao Ministério da Saúde, no qual pude trabalhar por mais de 5 anos, e onde aprendi muito sobre a gestão federal e pude dar a minha contribuição para a contribuição do SUS que queremos e da maneira que acreditamos. À minha "ex-equipe" da CGAN: Renata, Lorena, Mara e Bruna, que me acompanharam neste período do doutorado e que me ensinaram que confiar vale mais do que apenas ordenar e que juntas nossas habilidades se multiplicam.

Aos gestores e trabalhadores da Atenção Básica e do Programa Saúde na Escola, que diariamente produzem saúde e saber, em suas trincheiras, localizadas nas quase 50 mil Unidades Básicas de Saúde deste Brasil. 
Aos meus novos colegas de trabalho da OPAS: Guto, Samia, Lauana, Isabella e Janaína, que apesar de não terem compartilhado toda esta caminhada, me acolheram de braços abertos na Organização, facilitando a minha transição e ao Dr Oscar Suriel, meu atual chefe, que compreende as minhas ausências por conta do fim deste trabalho.

Agradeço enormemente a família na qual eu nasci e fui acolhida pelos meus pais: Monika e Pedro, que sempre me deram a melhor educação possível, me apoiaram na minha trajetória acadêmica, incentivaram meus estudos e que sempre foram exemplos de seres humanos. Aos meus irmãos: Moacir, Mário e Daniel, que me ensinaram a importância de compartilhar e do amor fraternal, às minhas cunhadas por cuidarem dos meus irmãos e aumentarem a nossa família, aos meus sobrinhos: Enzo e Heloísa, por me ensinarem o que é o amor incondicional, às minhas avós que são exemplo de mulheres guerreiras, amo muito todos vocês!

Agradeço à vida que sempre foi muito generosa em me oferecer ótimas amigas-irmãs, algumas com mais tempo de estrada: Dani von, Katia e Renata, muitas que conheci por conta da minha escolha profissional: Carla, Giorgia; As que compartilharam a experiência na CGAN: Marcinha, Natacha, Gisele; As que dividem, mesmo que temporariamente o teto, mas eternamente os mesmo ideais: Kelly e Jana; e a Kimielle, que embora não more lá em casa, está sempre presente, topando qualquer roubada e garantindo sempre as melhores conversas e risadas. Agradeço as meninas da FSP: Ana Paula, Lara e Dani Canella, que para além de amigas, dividiram comigo as agruras e as alegrias de fazer um doutorado e sempre me ajudaram com a burocracia da Universidade, diminuindo minhas distâncias. Todas são mulheres extraordinárias que moram no meu coração e que mesmo longe estão sempre presentes.

À Val, minha terapeuta e amiga, que me acompanha há muitos anos e que sempre me ajuda a caminhar em busca da minha autonomia e felicidade. 
"Há um tempo em que é preci so abandonar as roupas usadas, que já tem a forma do nosso corpo, e esqu ecer os nossos caminhos, que nos l evam sempre aos mesmos lugares. É o tempo da travessia: e, se não ousarmos fazê la, teremos ficado, para sempre, à margem de nós mesmos." Fernando Pessoa 


\section{RESUMO}

Silva, ACF. Alimentação e nutrição no Programa Saúde da Escola: gestão local e estado nutricional dos escolares. [Tese para a obtenção do título de doutora em Nutrição em Saúde Pública]. São Paulo: Faculdade de Saúde Pública da USP; 2014.

Introdução: A escola é um espaço privilegiado para o desenvolvimento de ações de promoção da saúde e melhoria das condições de bem-estar dos educandos. O Programa Saúde na Escola - PSE, criado em 2007, é uma iniciativa intersetorial, entre Ministérios da Saúde e da Educação que objetiva implementar ações de diagnóstico, atenção, prevenção e promoção à saúde dos escolares, em escolas públicas brasileiras. O acompanhamento do estado nutricional de crianças e adolescentes é uma das atividades previstas para o PSE e é acompanhado sistematicamente pela Atenção Básica - AB dos SUS por meio do Sistema de Vigilância Alimentar e Nutricional - SISVAN. Objetivo: Realizar um diagnóstico da estruturação do Programa nos municípios brasileiros, com foco nas ações de alimentação e nutrição e avaliar a evolução do estado nutricional de crianças e adolescentes com idades entre 7 e 18 anos, atendidos pela Atenção Básica e verificar qual o momento mais oportuno para a realização de intervenções que objetivem o adequado desenvolvimento do crescimento, e consequentemente, do estado nutricional em crianças e adolescentes. Metodologia: A tese está organizada em duas seções, sendo a primeira composta por um estudo transversal, com levantamento direto de dados com os gestores municipais do PSE do setor saúde, por meio de formulário eletrônico, com questões sobre a gestão do programa, estrutura do município e organização das ações de alimentação e nutrição e; a segunda seção é um estudo longitudinal de avaliação da tendência de variação do estado nutricional de escolares entre 7 e 18 anos, frequentadores da $A B$, com dados registrados no SISVAN, entre os anos de 2008 e 2012, com avaliação da média de escore-Z do indicador de I MC para-a-idade, em comparação com as curvas de referência da Organização Mundial da Saúde propostas em 2007. Resultados: Para a análise do Programa foi proposto um modelo lógico de avaliação, baseado nos componentes do PSE. Dentre os principais achados, destaca-se: Os municípios ( $n=380$ ), que responderam o formulário possuem um número médio de 45 escolas e contam em média com 11 equipes de Saúde da 
Família. Cerca de 59\% dos municípios realizaram diagnóstico prévio para implantação do programa e apenas $62,8 \%$ dos municípios pactuaram as ações do PSE no Conselho Municipal de Saúde. Cerca de metade dos gestores do programa $(53,6 \%)$ são enfermeiros. Para potencializar as ações no ambiente escolar quase dois terços dos gestores municipais alegam contar com o auxílio de outros parceiros para a execução das ações. No que se refere às ações de alimentação e nutrição desenvolvidas nos municípios: $93,6 \%$ tem no seu quadro de funcionários nutricionistas, sendo que cerca de $70 \%$ possuem um nutricionista na alimentação escolar, 43,9\% contam com equipes de NASF e em 84,3\% das equipes de Núcleos de Apoio à Saúde da Família há um nutricionista. Dos respondentes, cerca de 62,5\% realizaram a Semana Saúde na Escola no ano de 2012 e 90\% declararam ser esta uma ação que fortalece o PSE no município. Na análise temporal do estado nutricional dos escolares, observou-se que em todas as idades a média do escore $Z$ do IMC para a idade está acima de zero, sendo sempre maior do que o valor de referência. Ao longo das idades essa média apresenta crescimento entre as crianças com idades entre 7 e 10 anos, com uma pequena queda entre 10 e 14 anos e com uma tendência ascendente após os 15 anos para ambos os sexos. A tendência de aumento dos valores também é observada ano a ano. Entre o período analisado (anos de 2008 a 2012) ocorre um incremento constante nesta média, sendo este um reflexo do incremento do peso corporal destas crianças e adolescentes. $O$ comportamento do escore-Z deveria ser constante e em uma população saudável a distribuição seria praticamente igual ao das curvas de referência. Conclusão: $\mathrm{O}$ PSE possui ferramentas que lhe conferem capacidade de enfrentar os desafios em saúde e as ações devem ser planejadas e discutidas de maneira a propiciar um ambiente de práticas e hábitos saudáveis. O Estado Nutricional apresenta uma tendência de aumento anual do IMC médio dos escolares, reforçando os diferentes estudos que mostram o aumento do excesso de peso em todas as fases do curso da vida. O melhor momento para a intervenção entre crianças e adolescentes é o intervalo entre os 10 e 14 anos, onde há uma tendência de declive na curva de IMC para a idade.

Descritores: Avaliação de Programas e Projetos de Saúde; Vigilância Nutricional; Avaliação Nutricional; Criança; Adolescente; Escolares. 
SUMMARY

Silva, ACF. Feeding and nutrition in the Program Health of the School: local management and nutritional status of the students. [Thesis for the attainment of the title of doctor in Nutrition in Public Health]. São Paulo: School of Public Health USP; 2014.

Introduction: The school is a privileged space for the development of health actions and promotion as well as the improvement of the students health conditions. The Program Health in the School - PSE, created in 2007, is an intersectoral initiative, between Education and Health department that objectives to implement action of diagnosis, attention, prevention and promotion of the students health, in Brazilian public schools. The monitoring of the nutritional status of children and adolescents is one of the activities planned for the PSE and systematically followed by Primary Care - PC of SUS through the Food and Nutrition Surveillance System - SISVAN. Objective: Realize a diagnosis of the structure of the Program in the cities, with focus to the actions of feeding and nutrition and to evaluate the evolution of the nutritional status of children and adolescents (ages between 7 and 18 years), taken care by the PC and to verify the most opportune moment for the accomplishment of interventions that objectify the adequate development of growth in children and adolescents. Methodology: The thesis is organized in two sections of results, the first presents a transversal study, with direct survey of data answered by the municipal managers of the PSE of the sector health, through an electronic form, with questions about the management of the program, structure of the city and organization of actions; the second section is a longitudinal study of evaluation of the trend of variation of the nutritional state of adolescent children and (public-target of the PSE), assisted by the basic attention to the health, with data registered in the SISVAN, with evaluation of the average of the Z-score of the IMC for-the-age, in comparison with the curves of reference of the World Health Organization proposed in 2007. Results: For the analysis of the Program it has been considered a logical model of evaluation, based on the components of PSE. Among the main findings, we detach: The cities that had answered the form possess an average number of 45 schools and count with in average on 11 teams of Health of the Family. About $59 \%$ of the cities made a previous diagnosis for implementation of the program and only $62.8 \%$ of the cities 
had agreed to the actions of the PSE in the City council of Health. About half of the managers of the program (53.6\%) are nurses. To potentiate the actions in the school environment almost two third parts of the municipal managers allege to count with the aid of other partners for the execution of the actions. In what the actions of developed feeding and nutrition are mentioned in cities $93.6 \%$ has nutritionists among their employees, and about $70 \%$ of them has a nutritionist who cares for the feeding program at the school. 43.9\% count on NASF teams and in $84,3 \%$ of the NASF teams there is a nutritionist. Of the respondents, about $62,5 \%$ had carried through the Health Week in the School in the year of 2012 and 90\% had declared to be this an action that fortifies the action of the PSE in the city. In the secular analysis of the nutritional state of the pertaining to school, we can always observe that in all ages the average of the score $Z$ of the IMC for the age is above of zero, being ever bigger than the value of reference. To long of the ages this average presents growth between the children with ages between 7 and 10 years, with a small fall between 10 and 14 years and with an ascending trend after the 15 years for both girls and boys. The trend of increase of the values also is observed year after year. During the analyzed period (years of 2008 the 2012) occurs a constant increment in this average, being this a consequence of the increment of the corporal weight of these children and adolescents. The behavior of Z-score would have to be constant and in a healthful population the distribution would practically be equal to the one of the reference curves. Conclusion: The PSE offers tools that confers it ability to face the health challenges and the actions must be planned and discussed in order to provide an environment of healthy practices and habits. The Nutritional Status shows a trend of annual increases in mean BMl in schoolchildren, reinforcing the different studies showing the increase of overweight at all stages of the life course and bringing more alert about this specific age group. The best time to an intervention among children and adolescents is in the interval between 10 and 14 years, where there is a trend of decline in the BMl curve for age.

Describers: Program Evaluation; Nutritional Surveillance; Nutrition Assessment; Child; Adolescence; Schoolchildren. 


\section{ÍNDICE}

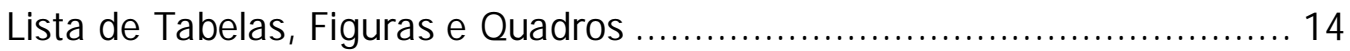

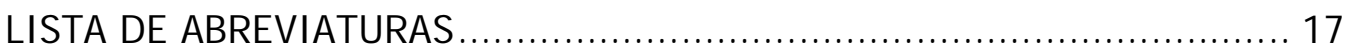

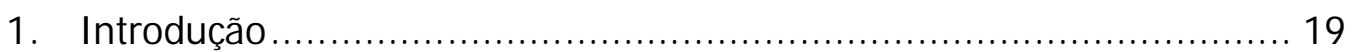

1.1 Condições de saúde e nutrição de crianças e adolescentes brasileiras .. 20

1.2 Determinantes do estado nutricional de crianças e adolescentes ...... 29

1.3 O modelo de atenção à saúde no Brasil - A Atenção Básica à Saúde e sua inserção nas Redes de Atenção à Saúde ......................................... 33

1.4 A escola como espaço de saúde e parte integrante do território da

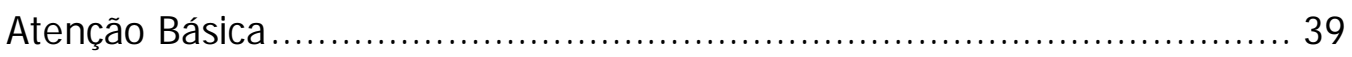

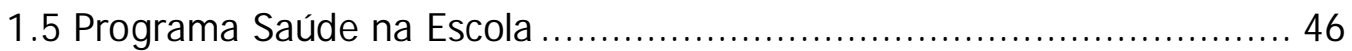

1.6 Ações de alimentação e nutrição no contexto escolar .......................... 49

1.7 A importância da avalição dos Programas em Saúde.......................... 51

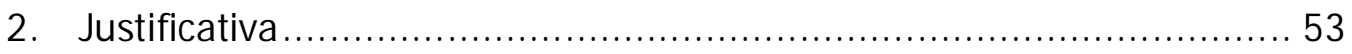

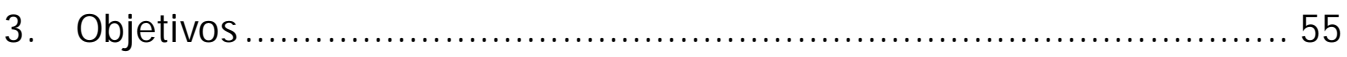

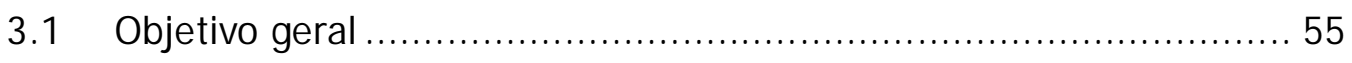

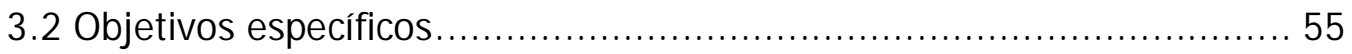

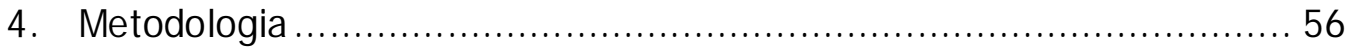

4.1 Análise da implantação municipal do Programa Saúde na Escola ...... 57

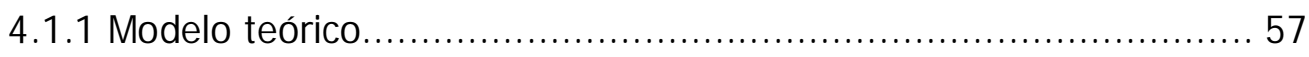

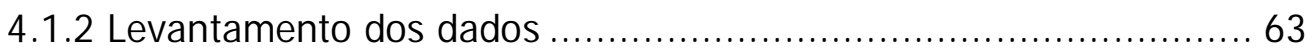

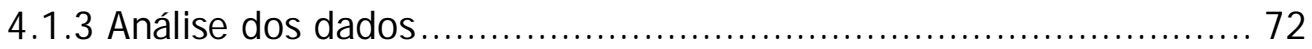

4.2 Análise longitudinal do estado nutricional de crianças e adolescentes com

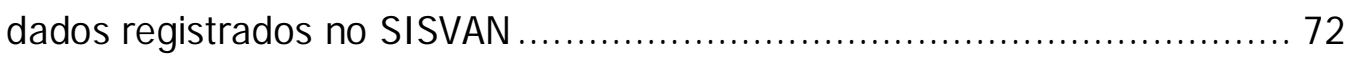

4.2.1 O Sistema de Vigilância Alimentar e Nutricional - SISVAN............ 72

4.2.2 Obtenção dos dados e variáveis estudadas............................... 73

4.2.3 Classificação do estado nutricional.......................................... 73

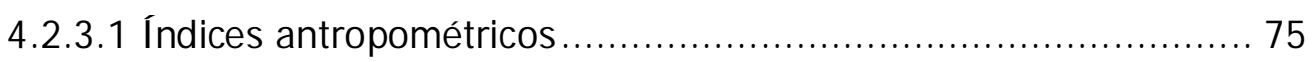

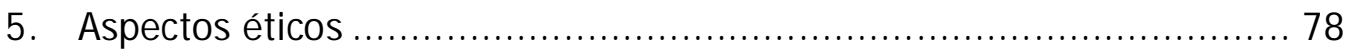


6. Resultados

6. 1 Análise da implantação do Programa Saúde na Escola nos municípios brasileiros. 79

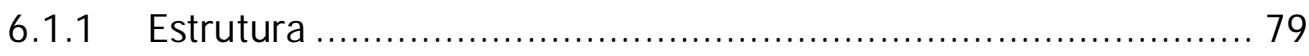

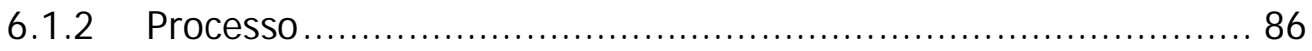

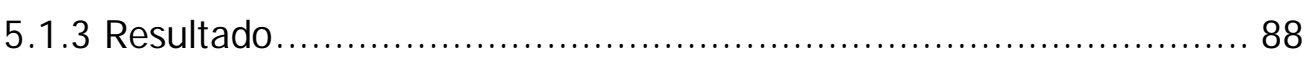

6.2 Avaliação da evolução do estado nutricional de crianças e adolescentes

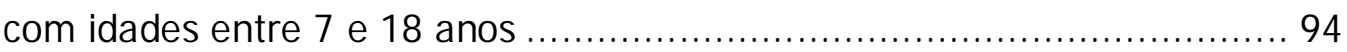

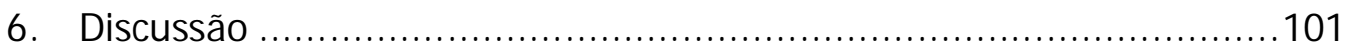

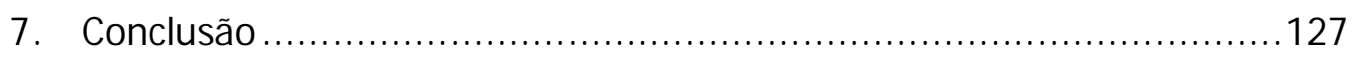

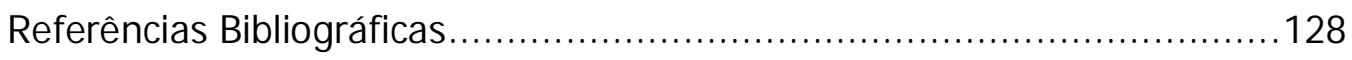

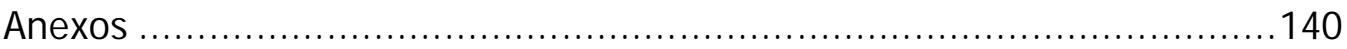

Anexo A: Lista de Portarias e Decreto do Programa Saúde na Escola ......... 141 Anexo B: Parecer do Comitê de Ética em Pesquisa - COEP da Faculdade de Saúde Pública da Universidade de São Paulo........................................ 145

Anexo C: Convite para participação no estudo.....................................146 Anexo D: Formulário eletrônico disponibilizado aos gestores municipais do

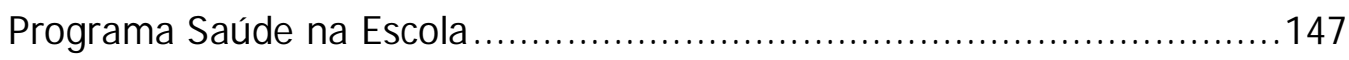
Anexo E: Medianas dos valores de peso e altur a, segundo sexo e ano, comparados com os valores de referência da OMS - 2007 e Pesquisa de

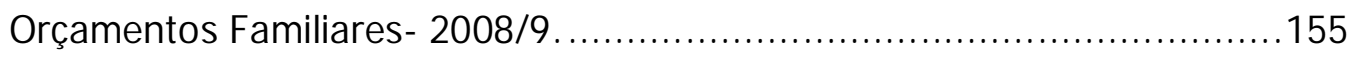

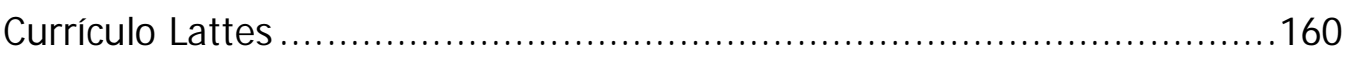




\section{Lista de Tabelas, Figuras e Quadros}

\section{LISTA DE TABELAS}

Tabela 1 Distribuição dos municípios segundo características demográficas, 83 educacionais e de estruturação da Atenção Básica. Brasil, 2014.

Tabela 2 Distribuição da força de trabalho e atuação do nutricionista nos 84 municípios do Programa Saúde na Escola. Brasil, 2014.

Tabela 3 Distribuição da conformação dos Grupos de trabalho e materiais 86 de apoio para desenvolvimento das ações do PSE. Brasil, 2014.

Tabela 4 Caracterização do processo de trabalho do Grupo de Trabalho 88 Intersetorial para realização das atividades do Programa Saúde na Escola. Brasil, 2014.

Tabela 5 Distribuição das ações de alimentação e nutrição do Componente I 91 - Avaliação do estado nutricional dos escolares do PSE, e atuação das equipes no território. Brasil, 2014.

Tabela 6 Distribuição das ações de alimentação e nutriçãa do Componente II - Ações de promoção da saúde e prevenção das doenças e agravos. Brasil, 2014.

Tabela 7 Distribuição das atividades realizadas na Semana Saúde na 95 Escola no ano de 2012. Brasil, 2014.

Tabela 8 Distribuição de número de registros avaliados do SISVAN-Web, 96 segundo sexo e ano. Brasil, 2014.

Tabela 9 Distribuição da mediana da altura de indivíduos do sexo 155 masculino, segundo idade. SISVAN (anos 2008 a 2012), Pesquisa Nacional de Orçamentos Familiares e Valores da População de referência proposta pela OMS. Brasil, 2014.

Tabela 10 e. SISVAN (anos 2008 a 2012), Pesquisa Nacional de Orçamentos 155 Familiares e Valores da População de referência proposta pela OMS. Brasil, 2014.

Tabela 11 Distribuição da mediana de peso de indivíduos do sexo masculino, 156 segundo idade. SI SVAN (anos 2008 a 2012), Pesquisa Nacional de Orçamentos Familiares e Valores da População de referência proposta pela OMS. Brasil, 2014.

Tabela 12 Distribuição da mediana de peso de indivíduos do sexo feminino, 156 segundo idade. SISVAN (anos 2008 a 2012), Pesquisa Nacional de Orçamentos Familiares e Valores da População de referência proposta pela OMS. Brasil, 2014.

Tabela 13 Distribuição percentual de desvios nutricionais (baixo peso, 157 sobrepeso e obesidade) segundo idade e sexo, de indivíduos acompanhados SISVAN no ano de 2008. Brasil, 2014.

Tabela 14 Distribuição percentual de desvios nutricionais (baixo peso, 157 sobrepeso e obesidade) segundo idade e sexo, de indivíduos acompanhados SISVAN no ano de 2009. Brasil, 2014. 
Tabela 15 Distribuição percentual de desvios nutricionais (baixo peso, 158 sobrepeso e obesidade) segundo idade e sexo, de indivíduos acompanhados SISVAN no ano de 2010. Brasil, 2014.

Tabela 16 Distribuição percentual de desvios nutricionais (baixo peso, 158 sobrepeso e obesidade) segundo idade e sexo, de indivíduos acompanhados SISVAN no ano de 2011. Brasil, 2014.

Tabela 17 Distribuição percentual de desvios nutricionais (baixo peso, 159 sobrepeso e obesidade) segundo idade e sexo, de indivíduos acompanhados SISVAN no ano de 2012. Brasil, 2014.

\section{LISTA DE FI GURAS}

Figura 1 Evolução percentual do estado nutricional de crianças de 5 a 924 anos de idade, segundo sexo e classificação do estado nutricional. Brasil, 1974 a 2009.

Figura 2 Distribuição percentual do estado nutricional de crianças entre 5 e 25 9 anos, segundo sexo, macrorregiões brasileiras e Brasil. Brasil, 2012.

Figura 3 Distribuição percentual da evolução do estado nutricional de adolescentes entre 10 a 19 anos segundo IMC-para-idade, macrorregião e sexo. Brasil, 2012.

Figura 4 Distribuição percentual do estado nutricional de adolescentes entre 10 e 19 anos, segundo sexo, macrorregiões brasileiras e Brasil. Brasil, 2012.

Figura 5 Distribuição percentual de escolares frequentando o 9o ano do ensino fundamental, segundo consumo frequente de alimentos marcadores de alimentação saudável e não saudável, por sexo, PeNSE, 2012.

Figura 6 Componentes conceituais na avaliação de programas.

Figura 7 Modelo de avaliação normativa proposto do GRIS (1992)

Figura 8 Adaptação do Modelo de avaliação normativa proposto pelo GRIS (1992) para avaliação do Programa Saúde na Escola.

Figura 9 Mediana da altura, de indivíduos do sexo masculino, com idades entre 7 e 18 anos com dados registrados no SISVAN-Web, comparado com POF 2008/9 e com OMS 2007. Brasil, 2014.

Figura 10 Mediana da altura, de indivíduos do sexo feminino, com idades entre 7 e 18 anos com dados registrados no SISVAN-Web, comparado com POF 2008/9 e com OMS 2007. Brasil, 2014.

Figura 11 Mediana do peso, de indivíduos do sexo masculino, com idades entre 7 e 18 anos com dados registrados no SISVAN-Web,, comparado com POF 2008/9 e com OMS 2007. Brasil, 2014.

Figura 12 Mediana do peso, de indivíduos do sexo feminino, com idades entre 7 e 18 anos com dados registrados no SISVAN-Web, comparado com POF 2008/9 e com OMS 2007. Brasil, 2014.

Figura 13 Variação dos valores médios de escore-Z do Índice de Massa 100 Corporal para a Idade, de indivíduos de ambos os sexos, com idades entre 7 e 18 anos, acompanhados pelo SISVAN, no período de 2008 a 2012. Brasil, 2014. 
Figura 14 Variação dos valores médios de escore-Z do Índice de Massa 101 Corporal para a Idade, de indivíduos do sexo masculino, com idades entre 7 e 18 anos, acompanhados pelo SISVAN, no período de 2008 a 2012. Brasil, 2014.

Figura 15 Variação dos valores médios de escore-Z do índice de Massa 101 Corporal para a Idade, de indivíduos do sexo feminino, com idades entre 7 e 18 anos, acompanhados pelo SISVAN, no período de 2008 a 2012. Brasil, 2014.

\section{LISTA DE QUADROS}

Quadro 1 Evolução da adesão municipal do Programa Saúde na Escola no 48 período de 2008 a 2013, número de equipes de Atenção Básica vinculadas ao Programa e número de escolares envolvidos nas ações. Brasil, 2014.

Quadro 2 Componentes do modelo teórico adotado para avaliar a 67 implantação das ações do Programa Saúde na Escola nos municípios brasileiros.

Quadro 3 Relação dos Índices antropométricos utilizados e valores limites 75 em escores $Z$. 


\section{LISTA DE ABREVIATURAS}

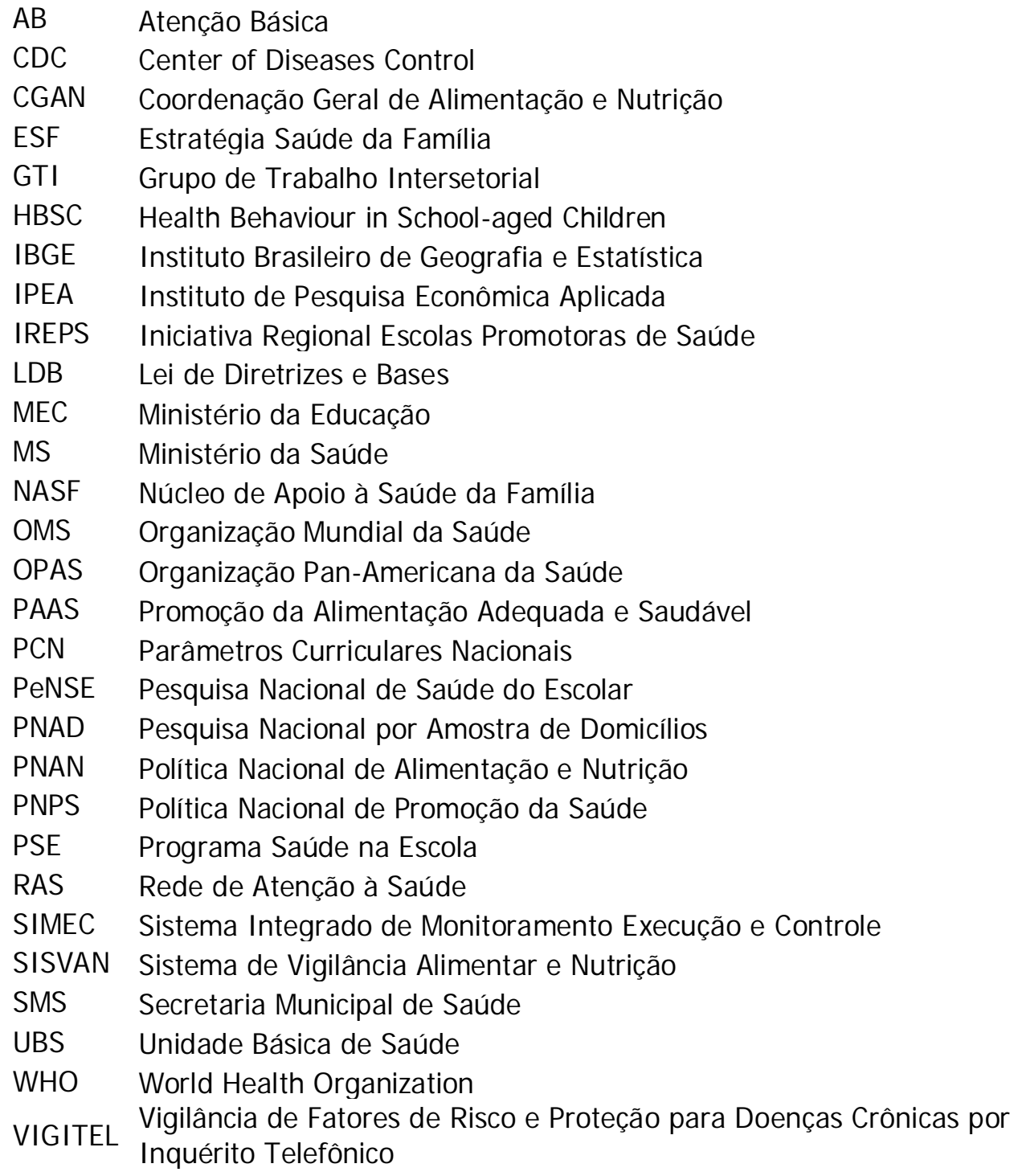




\section{Apresentação}

Esta tese é resultado de um estudo dedicado a conhecer melhor o estado da arte da implantação de um programa governamental, proposto pela esfera federal, de articulação intersetorial, que tem como missão articular e fortalecer as ações de saúde dentro do ambiente escolar. O Programa em questão: Programa Saúde na Escola é uma iniciativa nacional relativamente nova, em fase de estruturação e pouco explorado na literatura. Por outro lado, a avaliação do estado nutricional de crianças e adolescentes brasileiros, é uma temática que vem sendo objeto dos pesquisadores do campo da alimentação e nutrição há mais de três décadas, com estudos locais e nacionais. Aliado a isto, soma-se a necessidade de estudos focados na avaliação de programas, com enfoque na gestão dos mesmos e nas ações temáticas desenvolvidas, que aqui são representadas pelas ações de alimentação e nutrição desenvolvidos nos diferentes pontos das Redes de Atenção à Saúde. O trabalho apresentado está embasado tanto na constatação da mudança do perfil nutricional de crianças e jovens como no reconhecimento da capacidade de programas voltados para a melhoria da saúde das populações de fazer frente aos atuais desafios em saúde pública. 


\section{In trodução}

Segundo dados do Censo populacional realizado em 2010 (IBGE, 2010a)

o Brasil tem aproximadamente 200 milhões de habitantes e destes cerca de $13 \%$, se encontram na faixa etária dos 5 aos 19 anos, resultando em mais de 26 milhões de crianças e adolescentes em idade escolar. Crianças e adolescentes de 6 a 19 anos são classificados como escolares por ser esta a fase do curso da vida em que se passa a maior parte do tempo na escola, período este que engloba praticamente toda a infância e a adolescência sendo caraterizado por um intenso desenvolvimento físico, cognitivo, emocional, por adaptações sociais e por mudanças nos hábitos alimentares (Demory-Luce, 2004).

O Instituto de Pesquisa Econômica Aplicada - IPEA, divulgou que em 2007, 97,6\% das crianças brasileiras de 7 a 14 anos frequentavam a escola (IPEA, 2009). Segundo dados da Pesquisa Nacional por Amostra de Domicílios PNAD de 2011, no Brasil, o acesso à escola era de 97,4\% para a população de 6 a 14 anos e de 87,7\% na faixa etária de 15 a 19 anos de idade (IBGE, 2012). No Brasil a educação básica é um direito assegurado pela Constituição Federal

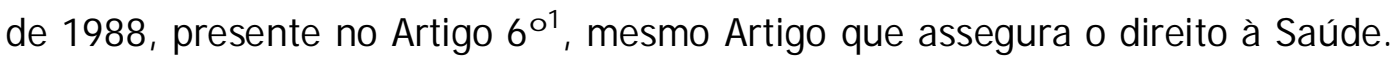
A educação básica no Brasil hoje é dividida em 3 ciclos (Brasil, 1996): Educação Infantil, Ensino Fundamental e Médio. O Ensino Fundamental compreende a educação do $1^{\text {으 ao }}$ 9o ano que deve ocorrer entre os 6 e 14 anos

\footnotetext{
1 Art. 6o São direitos sociais a educação, a saúde, a alimentação, o trabalho, a moradia, o lazer, a segurança, a previdência social, a proteção à maternidade e à infância, a assistência aos desamparados, na forma desta Constituição. (Redação dada pela Emenda Constitucional no 64, de 2010). Constituição da República Federativa do Brasil de 1988.
} 
de idade e o ensino médio, divido em três anos, compreende o período subsequente, dos 15 aos 17 anos.

\subsection{Condições de saúde e nutrição de crianças e adolescentes brasileiras}

As condições de vida e saúde da população estão relacionadas a diferentes fatores que causam interferências desde a vida intra-utrerina (Barker, 1995), sendo afetadas por elementos diversos e grande parte desta influencia é exercida pelo ambiente e pelas condições na qual cada indivíduo está inserido (OAKES, 2008). A infância e adolescência são importantes períodos de crescimento e desenvolvimento, além de serem fases de preparação para a idade adulta que é a fase mais longa da vida dos indivíduos.

Graham e Power (2004) apontam a adolescência como um período crítico para a determinação de hábitos saudáveis e comportamentos relacionados à saúde, que perduram pela vida adulta, como o consumo de álcool, o tabagismo, hábitos alimentares e a prática da atividade física. As principais inequidades em saúde dos adultos são iniciadas e desenvolvidas durante a fase da adolescência.

Para conhecer e monitorar o estado de saúde dos escolares, o Ministério da Saúde em parceria com o Instituto Brasileiro de Geografia e Estatística (IBGE) realizam a Pesquisa Nacional de Saúde do Escolar - PeNSE, que tem como objetivo conhecer a frequência dos fatores de risco e proteção à saúde dos adolescentes a fim de orientar intervenções em saúde adequadas ao adolescente e avaliar o impacto das políticas públicas, contribuindo para o 
monitoramento da saúde do escolar. O inquérito foi realizado nos anos de 2009 e 2012, com alunos do 9o ano (8ª série) de escolas públicas e particulares de todos os estados brasileiros. Na edição de 2009 foram entrevistados apenas adolescentes residentes nas capitais brasileiras, mas em 2012 o inquérito ampliou a sua abrangência geográfica, com representatividade para Brasil, regiões, capitais e não capitais.

No ano 2012, a estimativa de escolares frequentando o 9o ano do ensino fundamental era de 3.153 .314 , sendo estes $47,8 \%$ do sexo masculino e $52,2 \%$ do sexo feminino. Na PeNSE 86,0\% dos entrevistados tinham idades entre 13 e 15 anos no momento da pesquisa, sendo que a maioria (45,5\%) com 14 anos. Com relação à dependência administrativa da escola: $82,8 \%$ estudavam em escolas públicas e 17,2\%, em privadas. O Censo escolar, realizado em 2012, revelou que entre os estudantes matriculados na educação básica, 16,5\% frequentavam a rede privada e $83,5 \%$ a rede pública de ensino (IBGE, 2013).

Com relação à cor ou raça, $36,8 \%$ se declararam brancos, $42,2 \%$ pardos e $13,4 \%$ pretos. Com relação à estrutura familiar, $62,1 \%$ dos escolares viviam com o pai e a mãe e $28,5 \%$ residiam apenas com as mães e $4 \%$ residiam apenas com o pai. A escolaridade da mãe também foi inquirida como uma proxy da renda familiar. Um terço dos estudantes (34,5\%) tinham mães com escolaridade que ia de nenhuma a menos do que o ensino fundamental completo e 8,9\% eram filhos de mães que tinham o nível superior completo. Ao se comparar a escolaridade da mãe e o tipo de escola (pública e privada) percebe-se a disparidade entre as mães que completaram o ensino superior, 
que era de $28,7 \%$ entre os frequentadores de escola privada e $4,8 \%$ os da escola pública (Brasil, 2013).

Evidências sugerem que alguns mecanismos podem ser acionados para compensar ou diminuir o efeito de alguns determinantes, incluindo as diferenças socioeconômicas. Pesquisas com jovens apontam que o acúmulo de diferentes fatores de proteção tem a capacidade de potencializar as intervenções e de reduzir os riscos de injúrias na saúde das crianças e jovens, até nas situações mais adversas (BLUM et al., 2001; SCALES, 1999). Um ambiente protetor tem grande impacto sobre este público quando se refere à promoção da saúde e prevenção de agravos. Segundo os dados da PeNSE, parte das escolas brasileiras necessitam de melhorias para poderem oferecer todas as condições esperadas que as qualifiquem como ambientes promotores de saúde.

O estado nutricional de crianças e adolescentes brasileiros é sistematicamente acompanhado por sistemas de informação da Atenção Básica do Sistema Único de Saúde - SUS como o Sistema de Vigilância Alimentar e Nutricional (SISVAN) e por inquéritos nacionais periódicos realizados desde a década de 70 como o ENDEF (Estudo Nacional da Despesa Familiar) em 197475 e as Pesquisas Nacionais de Orçamentos Familiares (POF) em 2003 e 2008. A PeNSE também contribuiu para a caracterização da população brasileira, ampliando sobremaneira o conhecimento acerca das características de saúde da população adolescente brasileira (IBGE, 2013). As informações oriundas dos sistemas de informação aliada aos inquéritos servem de subsídios para as instâncias executivas e legislativas, os conselhos de saúde e os demais agentes 
relacionados ao setor, com informaç̧ões confiáveis para a orientação e a avaliação das políticas de saúde, principalmente aquelas destinadas às crianças e jovens.

O Brasil passa por uma importante mudança no perfil nutricional de sua população, com quedas consideráveis dos índices de desnutrição e aumento rápido e significativo do excesso de peso, o que pode ser observado também entre os escolares (BATISTA FILHO e RISSIN, 2003). Com a série histórica de acompanhamento do estado nutricional observa-se claramente esta mudança. De acordo com a Figura 1, na década de 1970 cerca de 30\% dos meninos e $25 \%$ das meninas com idade entre 5 e 9 anos apresentavam déficit de altura. Depois de três décadas os valores de déficit de altura apresentaram um grande declive, atingindo cerca de $7 \%$ dos meninos e $6 \%$ das meninas.

Por outro lado, a outra face da má-nutrição, o excesso de peso, mais do que triplicou entre as crianças nas últimas três décadas, com prevalências que variavam entre 8 e $10 \%$ entre os sexos em 1974-75 e alcançaram prevalências de mais de $34 \%$ entre os meninos e cerca de $32 \%$ entre as meninas em 2008 09. Esses valores indicam que atualmente, uma em cada três crianças nesta faixa etária está com o peso acima do considerado como adequado para a sua idade e sexo.

A obesidade - o extremo do excesso de peso - aumentou quase seis vezes entre os meninos e 6,5 vezes entre as meninas, o que é uma velocidade de crescimento alta por se tratar de um agravo crônico e com sérias consequências para a vida adulta, como o desenvolvimento precoce de doenças crônicas não transmissíveis como diabetes e hipertensão além do aumento do 
risco cardiovascular na idade adulta e uma criança que apresenta excesso de peso na infância tem o dobro de chance de ser um adulto com sobrepeso ou obesidade (FISBERG, 1995).

Figura 1: Evolução percentual do estado nutricional de crianças de 5 a 9 anos de idade, segundo sexo e dassificação do estado nutricional. Brasil, 1974 a 2009.

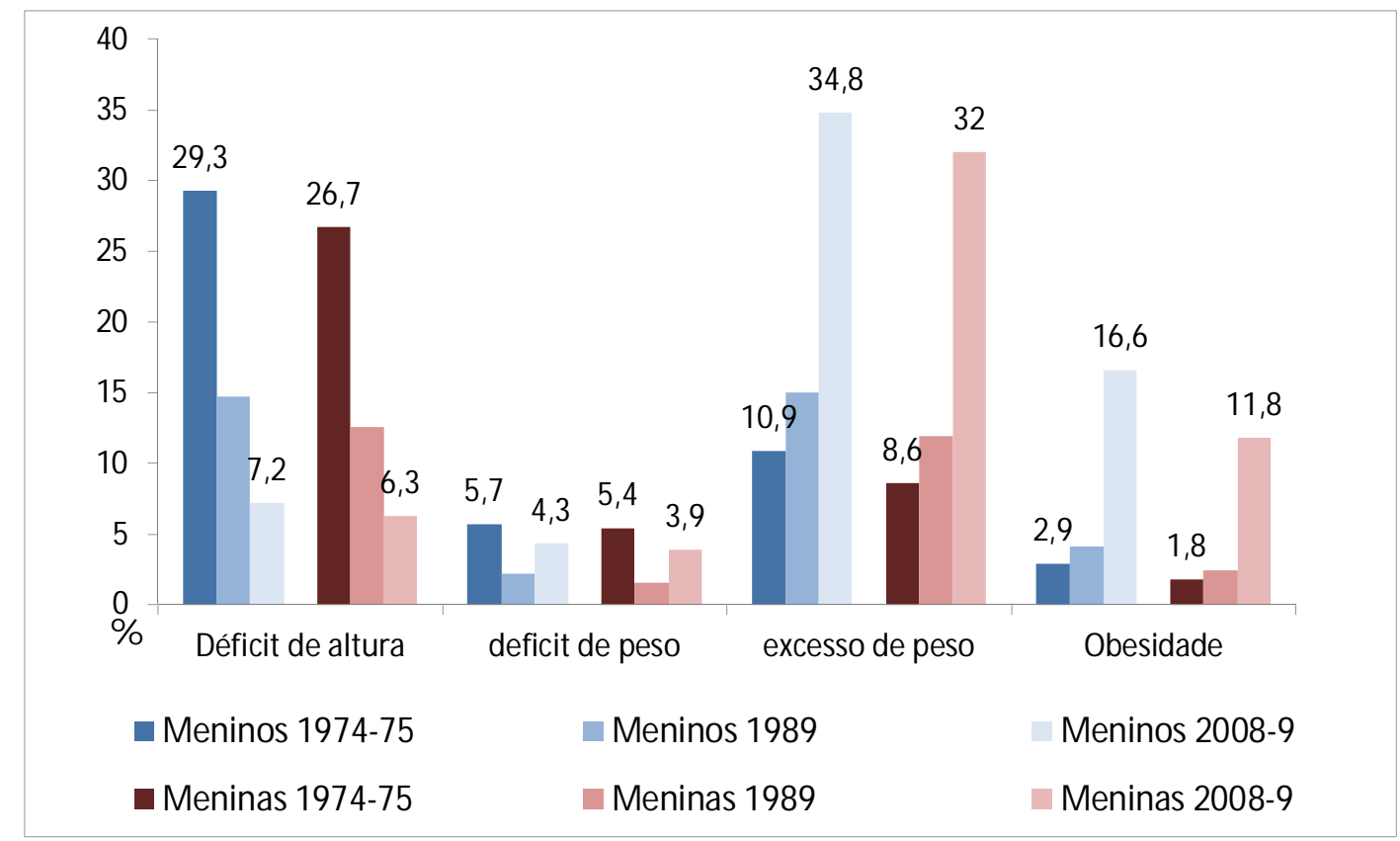

Fonte: IBGE, 2010 - POF 2008-2009.

Os dados do estado nutricional oriundos do SISVAN referentes ao ano de 2012, com 3.277.893 registros de crianças com idade entre 5 e 10 anos (1.654.569 meninas e 1.623.324 meninos) reforçam os dados encontrados nos inquéritos nacionais, conforme a Figura 2. 
Figura 2: Distribuição percentual do estado nutricional de crianças entre 5 e 9 anos, segundo sexo, macrorregiões brasileiras e Brasil. Brasil, 2012.

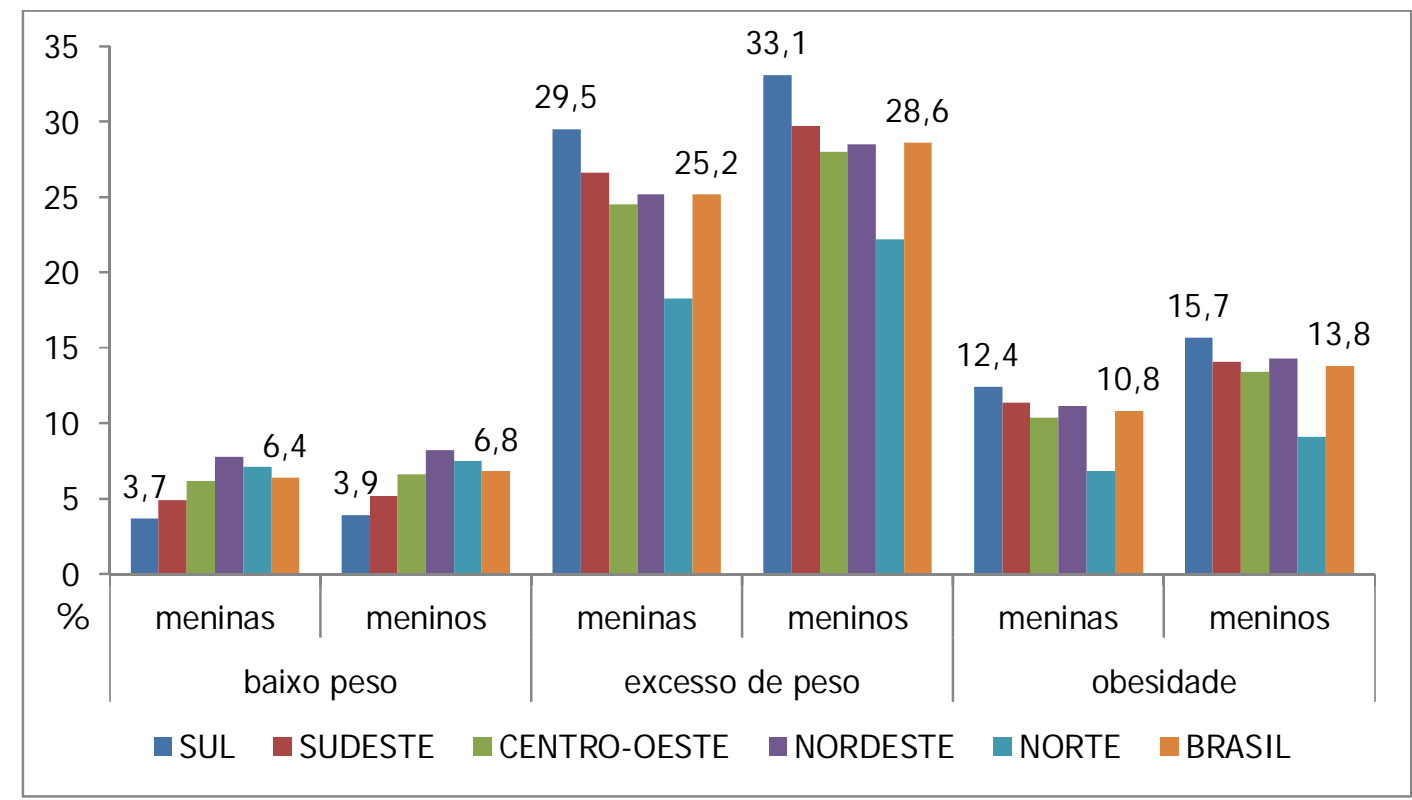

Fonte: SISVAN Web, 2012.

A Figura 2 apresenta o estado nutricional, classificado de acordo com o Índice de Massa Corporal - IMC-para-idade, de meninas e meninos entre 5 e 9 anos segundo as cinco regiões brasileiras e para o Brasil em 2012 . Pode-se observar que em todas as regiões o baixo peso se encontra com prevalências inferiores a $10 \%$, sendo que os valores mais altos são encontrados entre os meninos residentes na região nordeste $(8,2 \%)$ e os mais baixos entre as meninas residentes na região Sul $(3,7 \%)$. Em relação ao excesso de peso (sobrepeso e obesidade), observa-se que as maiores prevalências são encontradas na região Sul (cerca de 30\%), sendo 33,1\% em meninos e $29,5 \%$ em meninas. Ao analisar apenas a prevalência de obesidade, as maiores também estão na região Sul, com $12,4 \%$ das meninas e $15,7 \%$ classificados como obesos. Por outro lado, a região Norte apresenta as menores taxas tanto para o excesso de peso como para a obesidade, sendo $18,3 \%$ das meninas e 
$22,2 \%$ dos meninos classificados com excesso de peso e 6,8\% das meninas e 9,1\% dos meninos com obesidade.

Ao se analisar a tendência temporal do estado nutricional de adolescentes, com idades entre 10 e 19 anos nas últimas décadas, observa-se uma tendência semelhante à encontrada nas demais faixas etárias, conforme descrito na Figura 3. Na década de 1970, cerca de $10 \%$ dos adolescentes do sexo masculino e $5 \%$ das adolescentes apresentavam déficit de peso e menos de $1 \%$ apresentavam obesidade. Esse cenário apresentou uma grande reversão com queda no déficit de peso e aumento do excesso de peso e da obesidade. $\mathrm{O}$ excesso de peso quintuplicou (5,8 vezes) entre os adolescentes do sexo masculino e mais do que dobrou ( 2,5 vezes) entre as adolescentes. A obesidade cresce com uma velocidade maior do que o excesso de peso, sendo o seu aumento entre os adolescentes do sexo masculino de 14,8 vezes e entre as adolescentes de 5,7 vezes. Esses dados apresentam um cenário importante uma vez que tanto o aumento do excesso de peso bem como a magnitude desse aumento apontam para um importante problema de saúde pública nesta faixa etária. 
Figura 3: Distribuição percentual da evolução do estado nutricional de adolescentes entre 10 a 19 anos segundo IMC-para-idade, macrorregião e sexo. Brasil, 2012.

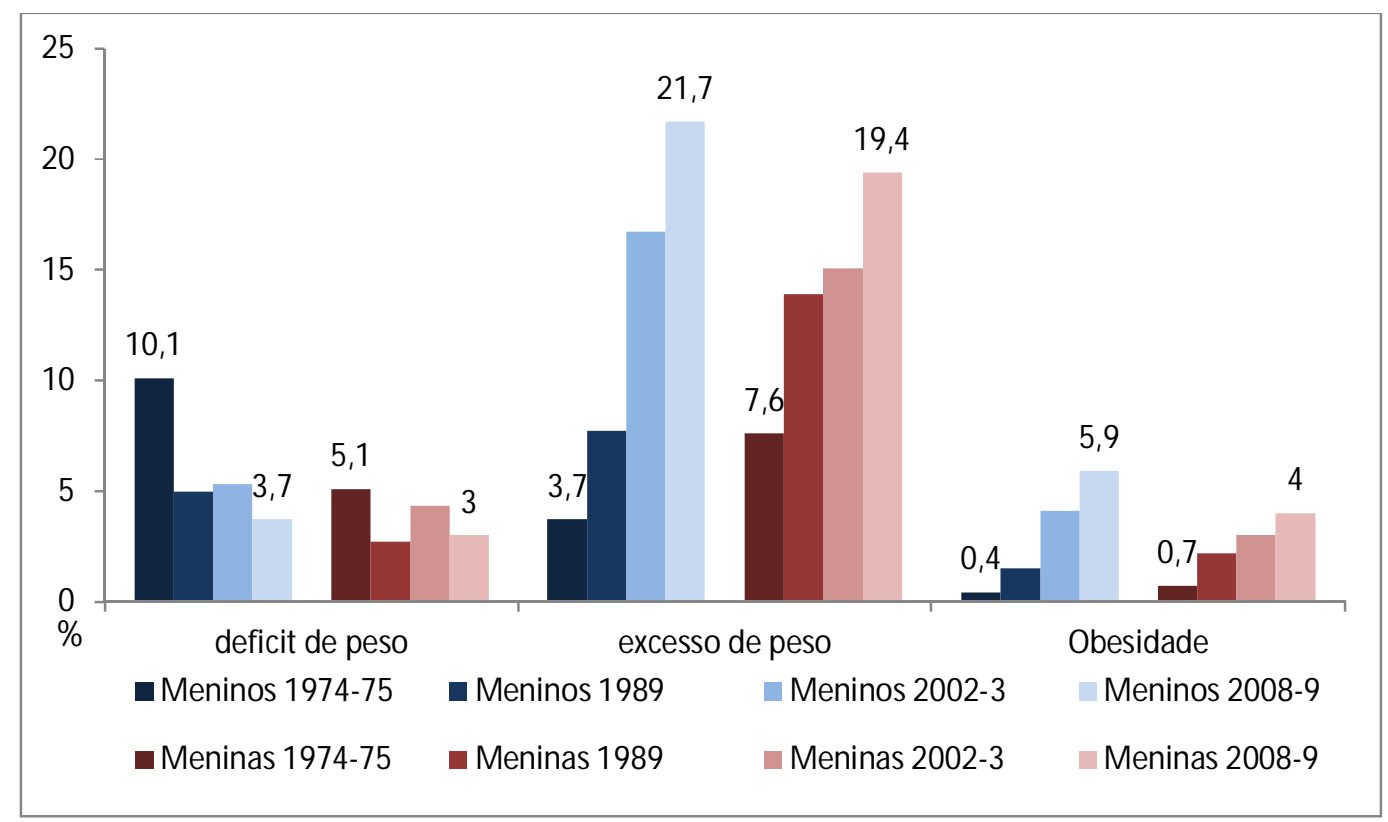

Fonte: IBGE, 2010 - POF 2008-2009.

Os dados do estado nutricional de adolescentes encontrados no SISVAN referentes ao ano de 2012, quando foram acompanhados $4.281 .922^{2}$ pela Atenção Básica do SUS, revelam que o estado nutricional desta faixa etária possui semelhanças com o estado nutricional das crianças. Segundo a Figura 4 o baixo peso tem prevalência maior entre os adolescentes do sexo masculino residentes na região Norte enquanto o excesso de peso e a obesidade tem maiores prevalências na região Sul do Brasil.

\footnotetext{
${ }^{2}$ Dados referentes ao relatório público do SISVAN, acessado em 7/03/2014. http://dabsistemas.saude.gov.br/sistemas/sisvan/relatorios_publicos/relatorio-acomp-nutri. view.php
} 
Figura 4: Distribuição percentual do estado nutricional de adolescentes entre 10 e 19 anos, segundo sexo, macrorregiões brasileiras e Brasil. Brasil, 2012.

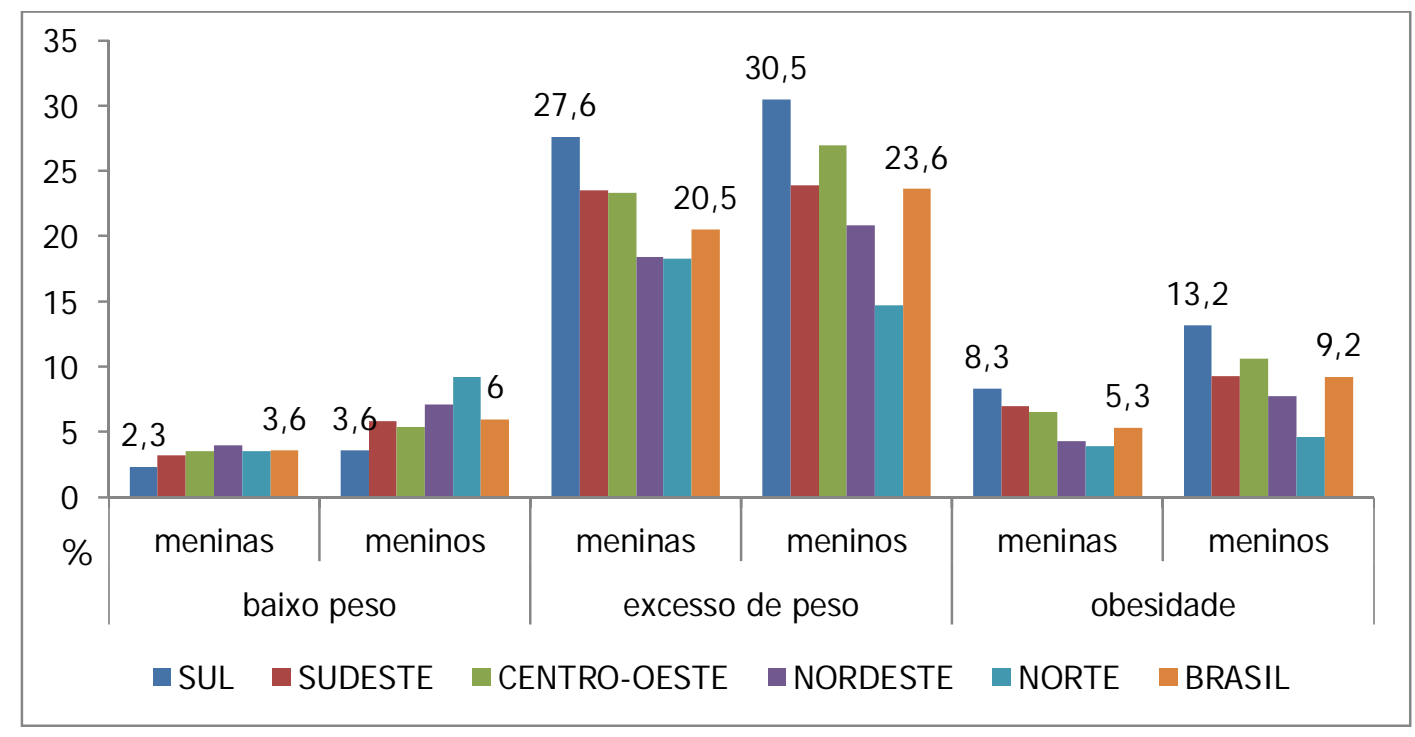

Fonte: SISVAN Web, 2012.

O estado nutricional dos adolescentes foi avaliado através da mensuração do peso e altura e pelo indicador de IMC-para-idade. Dentre os adolescentes do sexo masculino o baixo peso estava presente $6,0 \%$ enquanto $o$ índice para o sexo feminino era de 3,6\%. O Excesso de peso afetava cerca de um quarto dos meninos $(23,6 \%)$ sendo que $14,4 \%$ apresentavam sobrepeso e 9,2\% obesidade e entre as adolescentes o cenário não é diferente $20,5 \%$ com excesso de peso ( $15,2 \%$ sobrepeso e $5,3 \%$ obesidade).

A PeNSE 2009 avaliou o estado nutricional de 58.971 adolescentes, destes $2,9 \%$ apresentaram déficit estatural, 2,9\% baixo peso para idade e aluta. Com relação ao excesso de peso, $23,0 \%$ dos adolescentes estavam nesta classificação e 7,3\% foram classificados com obesidade de 7,3\%. Ao se comparar os índices entre os sexos, verificamos que o déficit de altura estava presente em 3,2\% dos representantes do sexo masculino e 2,6\% do feminino. 
O excesso de peso e a obesidade perfaziam, entre os meninos: $24,0 \% 8,7 \%$ e as meninas $22,1 \%$ e $6,05 \%$, respectivamente (Araújo, 2010). Observa-se, a partir dos dados referentes ao estado nutricional de crianças e adolescentes, tanto aqueles oriundos de inquéritos como os provenientes do SISVAN, que as crianças e adolescentes do sexo masculino apresentam, constantemente, maiores frequências desvios nutricionais, tanto quando se avalia desnutrição como no sobrepeso e obesidade, evidenciando que os meninos apresentam maior risco nutricional, quando comparados com as meninas.

\subsection{Determinantes do estado nutricional de crianças e}

\section{adolescentes}

O estado nutricional de um indivíduo é o resultado do balanço entre o consumo e o gasto energético. Na fase escolar há uma variação grande desses dois fatores por conta do intenso crescimento e desenvolvimento físico e cognitivo das crianças e dos adolescentes. Essa população apresenta necessidades nutricionais diferenciadas em relação a idade adulta (DEMORYLUCE et al., 2004).

Na maioria das vezes, as recomendações nutricionais no período da infância para a adolescência não são seguidas entre os jovens, levando por um lado a deficiências de vitaminas e minerais e, por outro ao aumento do consumo energético e de alimentos ricos em açúcar e gordura que irão contribuir para aumentar o risco de ganho de peso excessivo. Entre os comportamentos com potencial para influenciar negativamente o equilíbrio energético ou induzir efeitos adversos à saúde estão incluídos: omitir refeições 
(principalmente o café-da-manhã), baixa frequência ou abandono das atividades esportivas, o aumento do uso do computador, aumento do consumo de lanches hipercalóricos e o alto consumo de refrigerantes (WINDLE et al., 2004). A exposição a fatores de risco comportamentais como alimentação inadequada, sedentarismo, tabagismo e consumo de álcool, tem, com frequência, início na adolescência. Estes fatores estão associados ao desenvolvimento da maioria das doenças crônicas não transmissíveis, como as doenças cardiovasculares, diabetes e câncer, que lideram as causas de óbito na vida adulta no País e no mundo (SRI NIVASAN et al., 1996).

Estudo feito por ENES e SLATER (2010) concluiu que as mudanças ocorridas nos padrões alimentares nas últimas décadas, como o aumento do consumo de açúcares simples, alimentos industrializados e ingestão insuficiente de frutas e hortaliças, estão diretamente associadas ao ganho de peso dos adolescentes. Além disso, a redução progressiva da prática de atividade física combinada ao maior tempo dedicado às atividades de baixa intensidade, como assistir televisão, usar computador e jogar videogame, também tem contribuído para o aumento de peso dos jovens.

Os resultados da PeNSE 2012 mostraram que o percentual de escolares frequentando o 9 o ano do ensino fundamental que costumavam comer enquanto assistiam à TV ou estudavam foi de aproximadamente $64,0 \%$, não havendo diferença relevante por sexo e dependência administrativa da escola. A Região Sudeste $(67,9 \%)$ apresentou a maior proporção desse hábito entre os adolescentes. A Figura 5 apresenta o percentual de escolares do 90 ano e 0 consumo frequente ( 5 ou mais dias na semana) de alimentos marcadores de 
uma alimentação saudável e não saudável. Dentre os alimentos considerados saudáveis, o mais consumido é o feijão, seguido do leite. Menos da metade dos entrevistados apresentam um consumo frequente de frutas e hortaliças. Quase metade das meninas afirmou consumir guloseimas regularmente e cerca de um terço dos entrevistados, de ambos os sexos, consomem regularmente biscoitos doces e salgados e cerca de $40 \%$ dos escolares consumiam refrigerantes 5 ou mais vezes na semana (IBGE, 2013).

Figura 5: Distribuição percentual de escolares frequentando o 90 ano do ensino fundamental, segundo consumo frequente de alimentos marcadores de alimentação saudável e não saudável, por sexo, PeNSE, 2012.

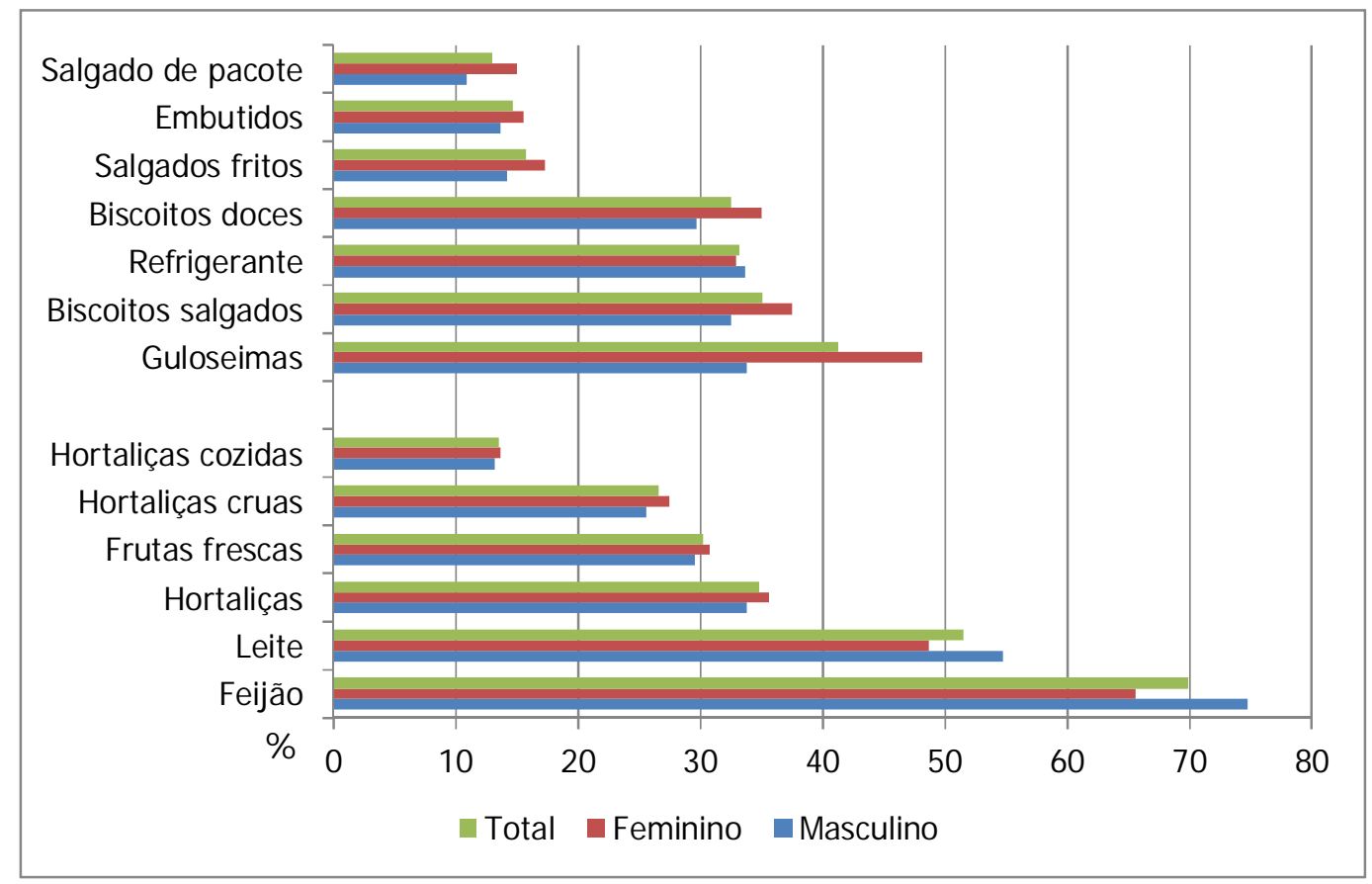

Fonte: IBGE, 2013 - Pesquisa Nacional do Escolar.

Na PeNSE a atividade física foi avaliada e categorizada de acordo com o tempo despendido nas atividades físicas, verificou-se que $43,1 \%$ dos escolares eram ativos (300 minutos ou mais de atividade física), apenas 49,2\% 
realizaram dois dias ou mais de educação física na escola e 79,5\% dos assistiam duas ou mais horas de TV por dia.

Durante a fase escolar é importante observar as diferenças etárias, entendendo que este período é composto por particularidades que são diferentes ao se comparar uma criança no início do ensino fundamental, com cerca de seis anos com um adolescente completando o ensino médio, ingressando na idade adulta. As desigualdades em saúde tendem a aumentar com o aumento da idade e os fatores de risco para doenças crônicas também são maiores, com o avanço da idade (BRENER et al., 2007). É comum que na infância sejam realizadas intervenções em saúde com êxito, mas estes resultados podem ser perdidos ou minimizados se as ações não forem continuadas e focadas para as diferentes fases do desenvolvimento (UNICEF, 2011).

As diferenças também são explicitadas quando observa-se as mudanças por gênero: meninos tendem ser mais agressivos, sujeitos às agressões e violências geradas por causas externas e uso de álcool enquanto as meninas tendem a tratar a saúde de forma mais emotiva e reservada, sendo mais propensas a desenvolver questões relacionadas à saúde mental (HURRELMANN e RICHTER, 2006). As ações em saúde, focada nos escolares, devem sair do enfoque da negligência e partir para uma intervenção oportuna, com desfechos positivos para toda a vida.

Segundo OAKES (2008) determinantes macrossociais são fatores que estão além do indivíduo e, portanto, os desfechos individuais de saúde não estão diretamente relacionados a esses fatores, embora exerçam influência. 
Para mudar a condição de saúde de uma população atuando nos determinantes "macro", são necessárias mudanças culturais e intervenções baseadas em políticas e programas de saúde pública. Fatores como amizades, famílias, escolas, bairros estão em um nível mais proximal do indivíduo e por esse motivo podem não ser encarados como fenômenos macrossociais embora sofram influências tanto dos determinantes macrossociais como individuais.

\subsection{O modelo de atenção à saúde no Brasil - A Atenção Básica à Saúde e sua inserção nas Redes de Atenção à Saúde}

A proposta atual de organização da atenção à saúde no país, nos seus diferentes níveis de complexidade, é baseada no modelo de Redes de Atenção à Saúde - RAS, que são arranjos organizacionais que se colocam como uma solução para a atual condição de saúde da população brasileira, caracterizada por uma transição epidemiológica tardia, que contempla um cenário de aumento das doenças crônicas, coexistindo com as doenças infecciosas. As Redes preveem que o cuidado necessita de uma longitudinalidade, entendendo que a organização dos senviços compreendem um determinado território e uma população adscrita, uma oferta de serviços compostos por diferentes níveis de complexidade, um componente logístico que auxilie o caminhar do usuário pelos diferentes serviços e suas possibilidades e um sistema de regulação, com

normas e protocolos que organizam a oferta e a procura pelos serviços de saúde. Uma RAS pode ser composta por Linhas de Cuidado, que facilitam o 
percurso do usuário de acordo com o seu agravo e as tecnologias disponíveis (SILVA, 2013).

A Atenção Básica (AB) no Brasil é considerada o primeiro, e preferencial, ponto de acesso à atenção dentro do sistema de saúde, além de ser ordenadora da Rede e coordenadora do cuidado. A AB tem um papel predominante na garantia da integralidade do cuidado em saúde da população, entendendo o cuidado como as ações de promoção, prevenção, cura e reabilitação. Atualmente, no Brasil, a AB é organizada através da Política Nacional de Atenção Básica - PNAB (Portaria no 2.488/GM de 21/10/2011). Segundo a PNAB-2011: "A atenção básica caracteriza-se por um conjunto de ações de saúde, no âmbito individual e coletivo, que abrange a promoção e a proteção da saúde, a prevenção de agravos, o diagnóstico, o tratamento, a reabilitação, a redução de danos e a manutenção da saúde com o objetivo de desenvolver uma atenção integral que impacte na situação de saúde e autonomia das pessoas e nos determinantes e condicionantes de saúde das coletividades. É desenvolvida por meio do exercício de práticas de cuidado e gestão, democráticas e participativas, sob forma de trabalho em equipe, dirigidas a populações de territórios definidos, pelas quais assume a responsabilidade sanitária, considerando a dinamicidade existente no território em que vivem essas populações. Utiliza tecnologias de cuidado complexas e variadas que devem auxiliar no manejo das demandas e necessidades de saúde de maior frequência e relevância em seu território, observando critérios de risco, vulnerabilidade, resiliência e o imperativo ético de que toda demanda, necessidade de saúde ou sofrimento devem ser acolhidos" (BRASI L, 2012a). 
A Estratégia de Saúde da Família - ESF, modelo proposto há mais de 15 anos, conta com equipe mínima composta por médico especialista em saúde da família ou generalista, enfermeiro, auxiliar de enfermagem e agentes comunitários de saúde - ACS. Essas equipes são alocadas em uma Unidade Básica de Saúde - UBS e suas atividades são realizadas tanto na UBS como em outras localidades como nos domicílios dos usuários. Dentre as atividades desenvolvidas pelas equipes são prioritárias a territorialização e busca ativa das famílias que estão sob responsabilidade de cada equipe. De acordo com os dados do Departamento de Atenção Básica - DAB em outubro de $2013^{3}, 5.327$ municípios brasileiros tem ao menos uma Equipe de Saúde da Família, atendendo cerca de 108,8 milhões de brasileiros $(56,1 \%)$. E, baseado nos pressupostos de STARFIELD (2004), tem como prinápios: universalidade, porta de entrada preferencial; longitudinalidade do cuidado, vínculo e responsabilização; integralidade, integração demanda programada versus espontânea e coordenação do cuidado na rede de senviços; formação e capacitação dos profissionais de saúde; planejamento e programação e participação popular.

De acordo com a PNAB-2011 no processo de trabalho da AB, estão previstos: "Realizar atenção à saúde na Unidade Básica de Saúde, no domicílio, em locais do território (salões comunitários, escolas, creches, praças etc.) e em outros espaços que comportem a ação planejada", tendo como atribuições comuns a todos os profissionais: "Realizar o cuidado da saúde da população

\footnotetext{
${ }^{3}$ Dados disponíveis em http://dab.saude.gov.br/dab/historico_cobertura_sf/historico_cobertura_sf_relatorio.php, acessados em 26 de dezembro de 2013.
} 
adscrita, prioritariamente no âmbito da unidade de saúde, e, quando necessário, no domicílio e nos demais espaços comunitários (escolas, associações, entre outros)" (BRASI L, 2012a).

As Equipes de $A B$ têm suas ações apoiada pelas equipes do Núcleo de Apoio à Saúde da Família - NASF, equipes multiprofissionais, criadas em 2008, com o intuito de aumentar a resolutividade das equipes de AB. Segundo a PNAB - 2011: “Os NASF devem buscar contribuir para a integralidade do cuidado aos usuários do Sistema Único de Saúde - SUS principalmente por intermédio da ampliação da clínica, auxiliando no aumento da capacidade de análise e de intervenção sobre problemas e necessidades de saúde, tanto em termos clínicos quanto sanitários. São exemplos de ações de apoio desenvolvidas pelos profissionais dos NASF: discussão de casos, atendimento conjunto ou não, interconsulta, construção conjunta de projetos terapêuticos, educação permanente, intervenções no território e na saúde de grupos populacionais e da coletividade, ações intersetoriais, ações de prevenção e promoção da saúde, discussão do processo de trabalho das equipes, etc".

O SUS tem como uma de suas principais atividades as ações de Vigilância à Saúde, que tem como função básica reorganizar e reorientar as ações de vigilância epidemiológica, no sentido de contemplar os problemas de saúde e condições de vida em sua amplitude. Segundo FRACOLLI et al. (2008) a vigilância em saúde deve contemplar as características de um dado território com informações demográficas, socioeconômicas, político-culturais, epidemiológicas e sanitárias. Este conjunto de informações permite que as equipes de saúde tracem o perfil epidemiológico e as necessidades de saúde 
das populações, permitindo o planejamento e a definição de prioridades. Descrita como um campo de atuação do SUS, Artigo 6o da Lei no 8.080, de 19/09/1990, a vigilância em saúde tem um papel importante ao fornecer subsídios para que gestores e profissionais possam, de acordo o conhecimento de sua realidade local, qualificar a atenção às pessoas por meio de ações de promoção, proteção e recuperação da saúde (AREAZZA e MORAES, 2010).

De pose das informaç̧ões, podem ser tomadas decisões que vão desde o acompanhamento de processos contínuos, análise de possíveis riscos, qualificação do cuidado com a articulação entre a promoção, prevenção e cura, além da articulação intersetorial, que potencializa as ações em saúde. Os dados oriundos da vigilância podem racionalizar os recursos e as atividades não apenas da Atenção Básica, mas de todos os pontos da RAS.

A Vigilância Alimentar e Nutricional compõe o rol de especialidades dentro do campo da vigilância à saúde. Segundo COUTINHO et al. (2009) “A Vigilância Alimentar e Nutricional -VAN corresponde à descrição contínua e à predição de tendências das condições de alimentação e nutrição da população, assim como de seus fatores determinantes. Abrange atividades de rotina, coletas e análises de dados e informações para descrever as condições alimentares e nutricionais da população. A partir do SISVAN, são embasadas decisões políticas no sentido de auxiliar no planejamento, monitoramento e gerenciamento de programas relacionados com a melhoria dos padrões de consumo alimentar e nutricionais da população".

O SISVAN foi proposto em 1976, mas apenas em 1990, foi estabelecido nacionalmente. O sistema tem como um de seus objetivos, auxiliar gestores 
públicos na gestão de políticas de Alimentação e Nutrição, através do planejamento, acompanhamento e avaliação dos programas ligados ao tema (COUTINHO et al., 2009). Desde janeiro de 2008 a AB dispõe de um sistema informatizado para coleta e processamento dos dados, o SISVAN-Web, disponível via Internet para todas as UBS e Equipes de Saúde da Família para registro dos dados de acompanhamento do estado nutricional e marcadores do consumo alimentar dos usuários da $A B$ que procuram as UBS por demanda espontânea ou não. O registro pode ser feito para todas as fases do curso da vida: crianças, adolescentes, adultos, idosos e gestantes, incluindo os beneficiários de Programas intersetoriais como o Programa Bolsa Família e o PSE (BRASIL, 2011).

A Política Nacional de Alimentação e Nutrição (PNAN), publicada inicialmente em 1999 e revista em 2011 tem entre suas diretrizes a VAN e a entende como uma atividade essencial na atenção à saúde da população, compondo o processo do cuidado à saúde, auxiliando na organização e no planejamento das prioridades da atenção, auxiliando na tomada de decisões e na identificação de prioridades de acordo com o perfil de saúde e nutrição das populações, o "processo de organização e gestão dos cuidados relativos à alimentação e nutrição na RAS deverá ser iniciado pelo diagnóstico da situação alimentar e nutricional da população adscrita aos serviços e equipes de Atenção Básica" (BRASI L, 2012b). 


\subsection{A escola como espaço de saúde e parte integrante do território da Atenção Básica}

As ações das Equipes de $A B$, definidas pela PNAB determinam que as ações em saúde devem ser desenvolvidas para além do espaço da UBS e, por sua vez, compreender todo o território de responsabilidades das equipes ali presentes. A escola é um equipamento social localizado no território de responsabilidade das equipes de saúde e as ações de promoção à saúde e Promoção da alimentação adequada e saudável podem ser realizadas no ambiente escolar com êxito. "A promoção à saúde é um tema que deve ser aplicado transversalmente no currículo escolar e deve ser abordado pelos educadores dentro do conteúdo programático das disciplinas escolares e as ações podem ser aplicadas dentro e fora das salas de aula, com práticas diferenciadas" (BRASI L, 2012a). O ambiente escolar deve ser protetor para as escolhas saudáveis, garantindo em seu espaço a promoção da saúde principalmente pela oferta de alimentação saudável e práticas corporais adequadas e interessantes para os escolares (SOARES et al., 2008).

O entendimento da escola como ambiente para a prática de ações de atenção, prevenção e promoção à saúde é uma prática que ocorre desde o final do século XIX. No início as ações eram centradas em três eixos: polícia médica, sanitarismo e puericultura, onde, segundo LMA (1985) o exerácio da polícia médica "se deu pela inspetoria das condições de saúde dos envolvidos com o ensino"; O sanitarismo, "pela prescrição a respeito da salubridade dos locais de 
ensino" e a puericultura, "pela difusão de regras de viver para professores e alunos".

Ao longo das últimas décadas a saúde escolar no Brasil sofreu mudanças, partindo de um modelo assistencial, evoluindo para um modelo de prevenção e promoção, entendendo a escola como um espaço composto não só do ambiente como do entorno no qual está inserido. A promoção à saúde no ambiente escolar segue os preceitos apresentados na Carta de Otawa, creditando no indivíduo o controle de sua saúde e a redução dos fatores de risco e o favorecimento de ambientes saudáveis (FIGUEI REDO et al., 2010).

A promoção à saúde é elencada como um dos principais alicerces das políticas de saúde, nos distintos ambientes, incluindo o ambiente escolar com influências nas últimas décadas de documentos internacionais como: Carta de Ottawa (1986), Declaração de Adelaide (1988), Declaração de Sundsvall (1991), Declaração de Bogotá (1992), Conferência do Caribe (1993), Declaração de Jacarta (1997), Declaração do México (2000), Declaração de Bangcoc (2005), Declaração de Nairobi (2009) e a Declaração de Helsinque (2013) que prevê a "Saúde em todas as políticas". A promoção à saúde é entendida como uma ação localizada para além da atuação isolada do setor saúde, atuando na moradia, educação, alimentação, renda, entre outros fatores, e para que ela aconteça necessita da articulação e parceria dos fatores envolvidos. A promoção à saúde é uma estratégia encontrada para enfrentar os diversos problemas de saúde dos indivíduos e dos espaços que estes habitam com a articulação dos conhecimentos técnicos e populares além da mobilização de recursos públicos e privados (MOURA et al, 2007). 
A Carta de Ottawa (1986) define Promoção da Saúde como "o processo de capacitação da comunidade para atuar na melhoria da qualidade de vida e saúde, incluindo uma maior participação no controle do processo". Um ambiente pode ser considerado promotor de saúde quando desenvolve atividades que facilitam esse processo.

A estratégia que define a criação de ambientes favoráveis à saúde pode ser colocada em prática em escolas públicas e particulares. O ambiente escolar é considerado promotor de saúde quando se fortalece como um espaço saudável para viver, aprender e trabalhar (OMS, 1998).

As escolas fazem parte dos locais onde as ações de promoção da saúde têm sido propostas, procurando-se fortalecer a ação e o protagonismo do nível local, incentivando a intersetorialidade e a participação social (BÓGUS, 2004). Ações de alimentação e nutrição podem servir de forma efetiva nas abordagens iniciais para o estabelecimento de uma escola promotora da saúde, envolvendo toda a comunidade escolar (SOARES et al., 2008).

De acordo com a Organização Mundial da Saúde - OMS (1998), para que as escolas se fortaleçam na questão de promoção da saúde, é necessário que as mesmas incluam alguns componentes em seu cotidiano, entre eles: educação em saúde no espaço escolar, escola presente em meio ambiente saudável, envolvimento da comunidade e das famílias na promoção da saúde e, entre outros, que a escola tenha um programa adequado de nutrição e alimentação.

As evidências apontam para o impacto das iniquidades em saúde e seus efeitos nas condições de vida da população, com aumento do risco para os 
desfechos negativos. Algumas dessas iniquidades podem ser reduzidas quando ações são desenvolvidas nos ambientes, e o ambiente escolar tem um papel importante nesta equação. Crianças e adolescentes, em idade escolar, compõem um grupo vulnerável que muitas vezes são negligenciados nas estatísticas de saúde e frequentemente os adolescentes são tratados e entendidos no grupo dos adultos. Dados do Estudo HBSC - 2009/10 (Health Behaviour in School-Aged Children (HBSC) Study) - realizado em países da Europa e América Norte, apontam para uma melhoria nas condições de saúde dos escolares nos últimos anos, mas ainda há muito que fazer para que seja alcançado o potencial máximo de desenvolvimento destes indivíduos (WHO, 2012).

Há mundialmente uma série de iniciativas e recomendações para o desenvolvimento de ações da saúde no contexto escolar. As "Escolas promotoras de saúde" são uma iniciativa mundial que iniciou as suas atividades com a Rede Europeia de Escolas Promotoras de Saúde, articulada pela Organização Mundial da Saúde (OMS) em 1992 e estimula o desenvolvimento de ações voltadas a atenção e a promoção da saúde no contexto escolar nos países. Em 1998, o Comitê de especialistas da Organização Mundial de Saúde OMS, baseado nos documentos guia para a Promoção da saúde como a Carta de Ottawa e a declaração de J acarta para a Promoção da Saúde, propôs um documento voltado para os países com abordagem nacional, regional e local com vistas à melhoria das atividades de Promoção à saúde no ambiente escolar. O documento aponta 5 grandes barreiras: Visão e planejamento estratégico inadequados; Inadequado entendimento e aceitação dos 
Programas; Falta de responsáveis e prestações de contas; Coordenação e colaboração inadequada entre os responsáveis pelas ações de saúde nas escolas; Falta de infraestrutura para os programas (incluindo financeiro, recursos humanos, material e organizacional) (WHO, 2006a; WHO; 2006b). Para avançar na superação dos entraves locais, a iniciativa está embasada nas seguintes estratégias: Realização de pesquisas para melhorar os programas de saúde escolar; Capacitação para a melhoria dos programas de saúde escolar; Fortalecimento das capacidades nacionais; Criação de redes e alianças para o desenvolvimento de escolas promotoras da saúde.

Nas Américas, a Organização Pan-Americana de Saúde (OPAS) desenvolve desde 1995 a IREPS que objetiva o fortalecimento dos países na capacidade de promover a saúde no ambiente escolar. A IREPS prevê a articulação entre a saúde e a educação, tendo a escola como protagonista ao elencar as suas necessidades de saúde e busca de estratégias para resolvê-los. A iniciativa é uma estratégia de promoção à saúde baseada em três componentes: 1) Educação para a saúde com enfoque integral, incluindo o desenvolvimento de habilidades para a vida; 2) Criação e manutenção de ambientes físicos e psicossociais saudáveis e, 3) Oferta de senviços de saúde, alimentação saudável e vida ativa (IPPOUTO-SHEPHERD et al., 2005).

Nos Estados Unidos da América o Centro de Controle de Doenças dos Estados Unidos (CDC-EUA) apresenta uma série de recomendações para as escolas de todo o país, na lógica de que a saúde dos escolares é uma ação que deve ser trabalhada de maneira coordenada para a melhoria da saúde dos escolares e aprendizado nas escolas norte-americanas. Dentre o proposto pelo 
CDC a escola é a primeira instituição responsável pela saúde das crianças e adolescentes, por ter contato com mais de $95 \%$ das crianças e adolescentes em idade escolar e por ter um papel importante nos desfechos de saúde e sociais desse grupo etário, tendo como uma de suas atividades a responsabilidade de garantir um ambiente que propicie o crescimento e desenvolvimento saudável (CDC, 2006; CDC, 2007).

Programas e políticas baseadas no ambiente escolar são uma das maneiras mais eficientes de reduzir os riscos à saúde e proteger a saúde dos escolares (CDC, 2006; CDC, 2007). A iniciativa do CDC é baseada em uma rede para planejamento e execução das ações, que são centradas em sete componentes: educação em saúde; educação física; senviços de saúde; saúde mental e serviço social; serviços de nutrição; ambientes saudáveis e seguros; envolvimento da família e comunidade; bem-estar dos trabalhadores da escola (CDC 2006; CDC, 2007).

Embora o CDC apresente as proposições gerais, os Estados Unidos possuem uma série de políticas voltadas para a saúde e bem-estar, promovidas pela federação, estados e município, cabe aos atores locais organizarem a melhor composição dessas políticas para atuar no ambiente escolar, atuando nas desigualdades, construindo parcerias entre escolas e demais parceiros e atores da comunidade e somando esforços para criação de ambientes protetores e evitando os riscos à saúde. As metas do Programa do CDC são: melhorar o conhecimento, atitudes e habilidades dos estudantes; melhorar os seus comportamentos relacionados à saúde e desfechos; melhorar os resultados na educação e na sociedade (CDC, 2006; CDC, 2007). 
As ações de saúde no ambiente escolar são uma prática, que em alguns países da Europa, remontam do século XVII e que no Brasil foram iniciadas no início do século XX. Inicialmente, estas ações tinham um cunho higienista, mas não se limitavam apenas à saúde individual, com orientações para o ambiente escolar. Apenas em 1971, a Lei no $5.692^{4}$ introduziu formalmente no currículo escolar a temática da saúde, sob a designação genérica de Programas de Saúde, com o objetivo de "levar a criança e o adolescente ao desenvolvimento de hábitos saudáveis quanto à higiene pessoal, alimentação, prática desportiva, ao trabalho e ao lazer, permitindo-Ihes a sua utilização imediata no sentido de preservar a saúde pessoal e a dos outros" (Brasil, 1998). As abordagens mais recentes apresentam propostas que superam este modelo higienista e assistencialista, encarando o escolar como um indivíduo inserido em uma comunidade, dentro de um contexto específico e a sua saúde vista de maneira integral. A escola, por sua vez, compõe este cenário complexo (FIGUEIREDO et al., 2010).

No Brasil há relatos de algumas experiências de Programas voltados à saúde do escolar, desenvolvidos e financiados pela gestão local, tanto estadual como municipal. Os mesmos apontam tanto para ações focadas em uma agenda específica: saúde bucal, saúde auditiva, entre outros, como para ações globais em saúde (PENTEADO et al., 2005; IPPOLITO-SHEPHERD et al., 2005; FIGUEI REDO et al., 2010).

\footnotetext{
${ }^{4}$ A Lei 5.692/71 fixou as diretrizes de implementação e implantação do ensino de 1o e 2 o graus.
} 


\subsection{Programa Saúde na Escola}

O Programa Saúde na Escola (PSE) é um Programa proposto pelo Governo Federal que prevê a articulação entre a Atenção Básica e a rede de educação básica envolvendo os Ministérios da Saúde e da Educação, instituído pelo Decreto Presidencial №. 6.286, de 5 de dezembro de 2007. A versão da PNAB - 2011 reconhece o PSE como uma importante ação intersetorial. O objetivo do Programa é implementar ações de diagnóstico, atenção, prevenção e promoção à saúde dos escolares, nas escolas publicas brasileiras, segundo critérios estabelecidos nas Portarias 1.399, de 14 de novembro de 2008, Portaria № 1.861, de 04 de setembro de 2008, Portaria № 675, de 04 de junho de 2008. No texto de instituição do Programa, no Artigo 4ํㅡ, estabelece-se que "As ações em saúde previstas no âmbito do PSE considerarão a atenção, promoção, prevenção e assistência, e serão desenvolvidas articuladamente com a rede de educação pública básica e em conformidade com os princípios e diretrizes do SUS". O PSE está fundamentado em 5 componentes:

COMPONENTE I - Avaliação clínica e psicossocial: compreende ações de atenção integral a saúde dos escolares. Neste componente estão contempladas as ações de avaliação das condições de saúde de crianças, adolescentes, jovens e adultos cobertos pelo PSE. A avaliação da saúde compreende três ações estratégicas: a avaliação clínica e psicossocial; a avaliação nutricional; e a avaliação da saúde bucal que devem ser desenvolvidas conjuntamente pela equipe de saúde e a equipe escolar.

COMPONENTE II - Ações de promoção da saúde e prevenção das doenças e agravos compreendem as ações de promoção da saúde na escola 
como: Ações de Promoção da Saúde e Prevenção de doenças e agravos; Promoção da Alimentação Saudável; Promoção da atividade física; Educação para a saúde sexual e reprodutiva; Prevenção ao uso do álcool, tabaco e outras drogas.

COMPONENTE III - Educação permanente e capacitação de profissionais da Educação e Saúde e de jovens para o PSE: compreende a educação permanente de Jovens para Promoção da Saúde e Educação permanente e capacitação de profissionais de saúde e educação para atuação conjunta nas atividades que compreendem o Programa.

COMPONENTE IV - Monitoramento e avaliação da saúde dos estudantes: compreende o monitoramento e avaliação da saúde dos estudantes para o levantamento de necessidade da comunidade escolar, planejamento e execução das ações de saúde e educação. O monitoramento deve ser realizado através de ações locais e por pesquisas e inquéritos nacionais e oficiais, como o Censo escolar e a PeNSE.

COMPONENTE V - Monitoramento e avaliação do PSE: compreende o monitoramento e avaliação do programa através da coleta de informações do trabalho realizado pelas equipes por meio de sistemas de informação e formulários eletrônicos. 
Quadro 1: Evolução da adesão municipal do Programa Saúde na Escola no período de 2008 a 2013, número de equipes de Atenção Básica vinculadas ao Programa e número de escolares envolvidos nas ações. Brasil, 2014.

\begin{tabular}{|l|c|c|c|c|}
\hline Ano & 2008 & $2009 / 2010$ & $2011 / 2012$ & $2013 / 2014$ \\
\hline Municípios & 608 & 1253 & 2495 & 4861 \\
\hline Equipes de Atenção Básica & 5130 & 9014 & 1439 & 30045 \\
\hline Escolares & 1.941 .763 & 8.502 .412 & 11.946 .778 & 18.713 .940 \\
\hline
\end{tabular}

Fonte: Coordenação do Programa Saúde na Escola (CGAN/DAB/SAS/Ministério da Saúde).

O PSE, desde a sua criação, teve um processo de adesão municipal organizado de acordo com o Índice de Desenvolvimento da Educação Básica (IDEB) municipal e cobertura populacional da Estratégia de Saúde da Família nos municípios. No 1o ano de adesão ao Programa eram elegíveis apenas "Municípios com IDEB, no ano de 2005, menor ou igual a 2,69 nos anos iniciais do ensino fundamental e que tenham $100 \%$ de cobertura populacional por Equipes Saúde da Família e municípios participantes do Programa Mais Educação ${ }^{5 "}$. Em 2009 o critério para o IDEB no ano de 2007, foi menor ou igual a 3,1 nos anos iniciais do ensino fundamental e $70 \%$ ou mais de cobertura populacional por Equipes Saúde da Família, com base na competência financeira de agosto de 2009. Os critérios foram sendo ampliados até que no ano de 2013 o PSE foi universalizado, podendo ser implementado por qualquer município brasileiro, neste ano 4.681 municípios aderiram, representando 30.045 equipes de $A B, 65.535$ estabelecimentos de ensino e 18.713 .940 escolares, conforme descrito no Quadro 1. Todos os municípios têm que firmar

\footnotetext{
${ }^{5}$ O Programa Mais Educação, instituído pela Portaria Interministerial no 17/2007 e regulamentado pelo Decreto 7.083/10, constitui-se como estratégia do Ministério da Educação para induzir a ampliação da jornada escolar e a organização curricular na perspectiva da Educação Integral. Disponível em: http://portal. mec. gov.br/index.php?option=com_content\&view=article\&id=16690\&l temid=1115 acessado em 8/06/2014.
} 
um termo de compromisso, assinado pelos secretários municipais de saúde e educação, além do comprometimento com ações essenciais e optativas. As ações essenciais são definidas pelo Governo Federal e devem ser desenvolvidas por todos os municípios enquanto as ações optativas podem ser selecionadas pelos municípios de acordo com a realidade e necessidade local ${ }^{6}$.

No ano de 2012 foi instituída a Semana Saúde na Escola ${ }^{7}$ com o objetivo de promover as ações do PSE no início do ano letivo e trabalhar uma temática espećfica. A semana de 2012 ocorreu entre os dias de 5 a 9 de março com o tema "Prevenção da obesidade na infância e na adolescência". Na ocasião, 1.968 municípios aderiram às ações da semana, representando $78,9 \%$ dos municípios vinculados ao PSE naquele ano.

\subsection{Ações de alimentação e nutrição no contexto escolar}

O Caderno de Atenção Básica n 24: Saúde na Escola "busca trazer os principais conceitos e práticas de Avaliação das Condições de Saúde das Crianças, Adolescentes e Jovens que estão na escola pública dentro de uma abordagem contemporânea de promoção da saúde escolar, com ênfase na discussão da efetividade das iniciativas promovidas pelas equipes de Saúde da Família". Dentre as propostas, as ações de alimentação e nutrição, propriamente ditas, estão alocadas em dois componentes: Avaliação das condições de saúde das crianças, adolescentes e jovens que estão na escola,

\footnotetext{
${ }^{6}$ Dados disponíveis nas Portarias do Programa, disponíveis no Anexo A. Números do Programa disponíveis em http://dab. saude. gov.br/portaldab/ acessado em 5/01/2014.

${ }^{7}$ Portaria №. 357, DE 1/03/2012: Institui a Semana Anual de Mobilização Saúde na Escola (Semana Saúde na Escola) e o respectivo incentivo financeiro, e estabelece regras específicas para a execução no ano de 2012. Disponível em:

http://bvsms.saude.gov.br/bvs/saudelegis/gm./2012/prt0357_01_03_2012.html acessado em 9/01/2014.
} 
com a "Monitorização do crescimento" com a avaliação nutricional - Vigilância Alimentar e Nutricional dos escolares e Ações de promoção da alimentação adequada e saudável.

Dentre as ações de Promoção da alimentação adequada e saudável na atenção básica, podem ser desenvolvidas ações como: “Estimular e apoiar professores e diretores na inclusão da Promoção da alimentação adequada e saudável e da prática da atividade física, como parte do projeto políticopedagógico das escolas no território; Promover, incentivar e implantar hortas escolares e comunitárias; Incentivar a realização de oficinas culinárias nas escolas", que reforçam as ações de alimentação e nutrição e que podem ser realizadas com apoio das equipes de $A B$ dentro das escolas (JAIME et al., 2011).

Em termos de legislação federal, destaca-se a Portaria Interministerial MS/MEC no. 1.010 de 2006 publicada em 8 de maio de 2006 e: "Instituiu as diretrizes para a Promoção da alimentação adequada e saudável nas Escolas de educação infantil, fundamental e nível médio das redes públicas e privadas, em âmbito nacional". A Portaria tem como eixos prioritários (i) as ações de educação alimentar e nutricional; (ii) estímulo à produção de hortas escolares para a realização de atividades com os alunos e a utilização dos alimentos produzidos na alimentação ofertada na escola; (iii) estímulo à implantação de boas práticas de manipulação de alimentos nos locais de produção e fornecimento de serviços de alimentação do ambiente escolar; (iv) restrição ao comércio e à promoção comercial no ambiente escolar de alimentos e preparações com altos teores de gordura saturada, gordura trans, açúcar livre e 
sal e incentivo ao consumo de frutas, legumes e verduras; (v) monitoramento da situação nutricional dos escolares (BRASI L, 2006).

\subsection{A importância da avaliação dos Programas em Saúde}

A avaliação de programas e senviços ofertados pela administração pública no Brasil, principalmente no campo das políticas sociais e de saúde, historicamente não são os alvos prioritários de avaliações sistemáticas. Entretanto há evidências dos esforços realizados pelos gestores para mudar este cenário. Os recursos financeiros destinados para os programas sociais costumeiramente são menores do que o necessário, o que torna crucial o aumento da eficiência e da eficácia e a avaliação sistemática e contínua dos programas e políticas públicas é um instrumento importante para o melhor uso dos recursos aplicados (COSTA \& CASTANHAR, 2003).

Há várias definições para o conceito de avaliação voltada as políticas públicas, Segundo DONABEDIAN (1978), avaliar é monitorar continuamente os serviços de saúde oferecidos, para detectar e corrigir precocemente os desvios dos padrões encontrados, permitindo o aperfeiçoamento e desenvolvimento dos serviços avaliados. O UNICEF (1990) define como um "exame sistemático e objetivo de um programa, finalizado ou em curso, que contemple o seu desempenho, implementação e resultados, com vistas à determinação de sua eficiência, efetividade, impacto, sustentabilidade e a relevância de seus objetivos", tendo como principal propósito orientar tomadores de decisão para a continuidade ou não de uma ação e seu aperfeiçoamento (COSTA \& CASTANHAR, 2003). 
No Brasil, além da escassez de recursos públicos, a avaliação se torna necessária pela necessidade de quantificar os resultados alcançados pelas políticas implementadas e o aumento da democracia no país ampliou a agenda de reivindicações (GARCIA, 1997). Segundo SILVA (1999), o interesse pela avaliação no Brasil se dá pela preocupação dos governos com a mensuração dos resultados esperados e não esperados alcançados pela implementação dos programas e entender quais mecanismos são responsáveis pelos êxitos e fracassos das ações, além do empoderamento das instituições na tomada de decisões sobre as ações correntes e na adoção de novas estratégias e ainda a transparência, qualidade e a prestação de contas referente aos recursos implementados. 


\section{J usti fi cativa}

O Brasil apresenta, com o PSE, uma ação institucionalizada e organizada pelo Governo Federal, com finalidade de "contribuir para a formação integral dos estudantes da rede pública de educação básica por meio de ações de prevenção, promoção e atenção à saúde". O PSE é uma resposta às diferentes propostas, desenvolvidas anteriormente no âmbito local, na agenda da saúde do escolar, garantindo, a institucionalidade e financiamento das ações. Estudos de políticas públicas, como o proposto, podem gerar subsídios para a ação local e o planejamento das atividades futuras desenvolvidas.

O público prioritário do PSE, crianças e adolescentes, representam a fase do curso da vida caracterizada por grandes mudanças e vulnerabilidades que devem ser consideradas. A Promoção de modos de vida saudável, nesse período, tende a perdurar ao longo dos anos e repercutir na vida adulta.

É nessa fase que se formam boa parte dos hábitos alimentares que são influenciados pelo comportamento familiar, social, cultural e pelos espaços onde o indivíduo passa a maior parte do seu tempo: o ambiente escolar e a agenda de alimentação e nutrição proposta para o PSE tem se mostrado como uma ação promissora no programa, configurando-se como atividades essenciais a Promoção da Alimentação Adequada e Saudável e Vigilância Alimentar e Nutricional, que gera dados constantes sobre o estado nutricional dos escolares brasileiros. 
Dado este contexto, torna-se oportuno conhecer como o PSE está se desenvolvendo localmente, frente ao proposto pela legislação, e como as ações e alimentação e nutrição estão organizadas a fim de elaborar estratégias que possam responder aos atuais agravos de saúde presente na vida das crianças e jovens brasileiros.

Na literatura acadêmica há poucos registros sobre o PSE o que aponta para a originalidade do trabalho apresentado, além dos resultados do mesmo contribuírem para Componente $\mathrm{V}$ de Monitoramento e avaliação do PSE, previsto no Decreto que o institui. 


\section{Objetivos}

\subsection{Objetivo geral}

Realizar um diagnóstico da gestão local do Programa Saúde na Escola nos municípios brasileiros, com foco nas ações de alimentação e nutrição e avaliar a evolução do estado nutricional de crianças e adolescentes com idades entre 7 e 18 anos, atendidos pela Atenção Básica a fim de verificar momento mais oportuno para a realização de intervenções que objetivem o adequado desenvolvimento do crescimento, e consequentemente, do estado nutricional em crianças e adolescentes.

\subsection{Objetivos específicos}

- Realizar um breve diagnóstico sobre a implantação do Programa Saúde na Escola nos municípios brasileiros participantes do programa;

- Analisar a implantação das ações de alimentação e nutrição nos municípios brasileiros participantes do Programa Saúde na Escola;

- Avaliar a evolução do estado nutricional de crianças e adolescentes com idades entre 7 e 18 anos, atendidos pela Atenção Básica com dados registrados no Sistema de Vigilância Alimentar e Nutricional - SISVAN no período de 2008 a 2012;

- Verificar qual o momento mais oportuno para a realização de intervenções que objetivem o adequado desenvolvimento do crescimento e estado nutricional em crianças e adolescentes como parte das ações do PSE. 


\section{Metodol ogia}

Para atingir com os objetivos específicos propostos, o presente estudo adotou duas estratégias metodológicas diferentes, ambas de abordagem quantitativa. Para alcançar os objetivos de realizar um breve diagnóstico sobre a implantação do PSE nos municípios brasileiros participantes do programa e analisar a implantação das ações de alimentação e nutrição nos municípios participantes do PSE foi realizado um estudo transversal com os gestores municipais da área da saúde do Programa Saúde na Escola. O objetivo relacionado à avaliação da evolução do estado nutricional de crianças e adolescentes com idades entre 7 e 18 anos, atendidos pela Atenção Básica com dados registrados no Sistema de Vigilância Alimentar e Nutricional SISVAN no período de 2008 a 2012 foi desenvolvido mediante a análise de uma série histórica de cinco anos consecutivos de dados do estado nutricional, de crianças e adolescentes, registrados no SISVAN. Com base nos achados anteriores: análise da implantação do PSE e avaliação da evolução do estado nutricional de crianças e adolescentes em idade escolar, foi possível realizar reflexões sobre o momento mais oportuno para a realização de intervenções focadas no adequado desenvolvimento do crescimento e estado nutricional em crianças e adolescentes como parte das ações do PSE. 


\subsection{Análise da implantação municipal do Programa Saúde}

\section{na Escola}

\subsubsection{Modelo teórico}

Os resultados foram organizados de acordo com o modelo proposto por HARTZ (2005), que é baseado nos componentes da ação avaliada, nos serviços relacionados e nas práticas requeridas para execução dos seus componentes e os resultados esperados e produtos para o grupo atendido e na organização dos senviços.

Segundo HARTZ (2005): “A análise da implantação visa, sobretudo, identificar os procedimentos implicados na produção dos efeitos de uma intervenção". A avaliação de programas deve ser embasada no entendimento de como os componentes do programa se relacionam e o produto gerado aos seus beneficiários, e não apenas no processo pelo qual as ações se desenvolvem. Baseia-se em três componentes conceituais:

Figura 6: Componentes conceituais na avaliação de programas.

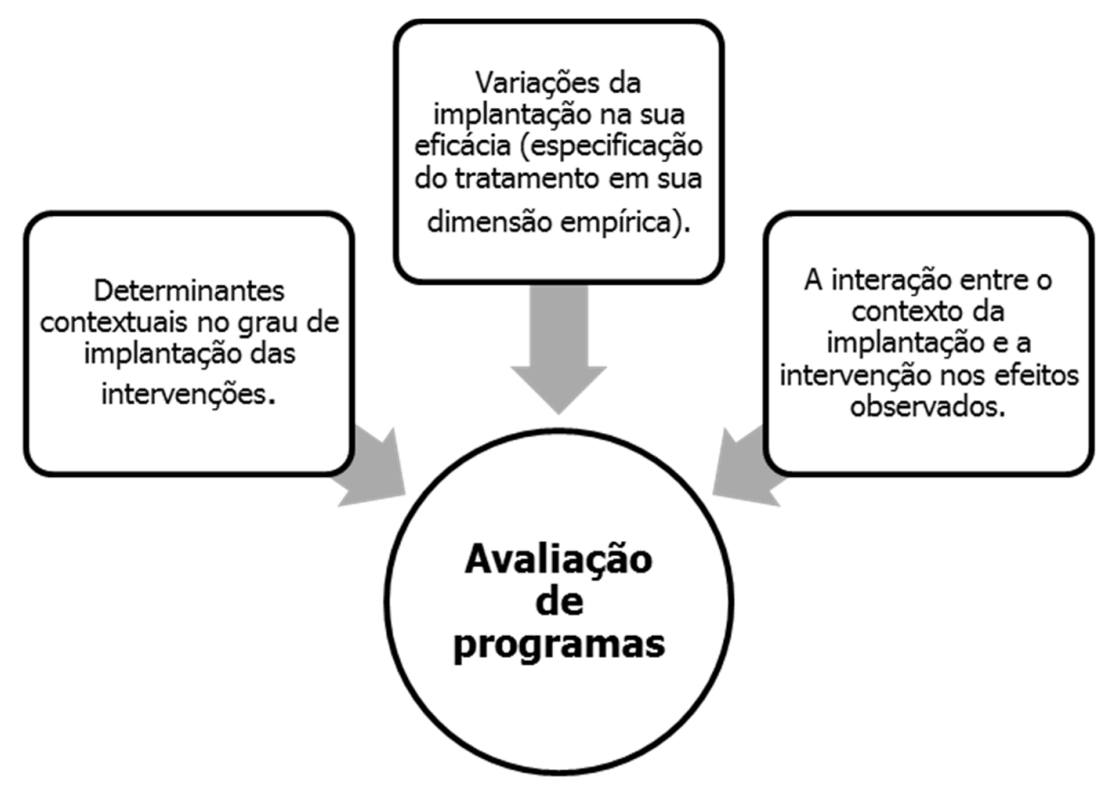

Adaptado de Hart, 1997. 
A referência proposta amplia o foco da avaliação na tentativa de superar o modelo de causa e consequência, entendendo a interferência e interação de outros fatores, que na avaliação de programas, resultam no estudo do processo. Entende-se que a implantação adequada da operacionalização de um programa pode ser mensurada por meio do desenvolvimento das ações com base em suas normativas. Para se analisar a implantação das ações de alimentação e nutrição do PSE seguiram-se os passos propostos:

- Especificar a priori os componentes da intervenção;

- Identificar as práticas requeridas para a implantação da intervenção;

- Descrever as práticas correntes com base nos pressupostos teóricos da intervenção organizada de acordo com o nível das áreas envolvidas;

- Analisar a variação na implantação em virtude da variação das características contextuais.

Na proposta apresentada, o grau de implantação individual de cada município não foi avaliado e sim o conjunto dos municípios segundo o porte populacional, que é um dos definidores da rede de saúde instalada no território. Para tanto foi analisada a integridade das ações e as adequações em relação às normas propostas para o PSE. Aqui estão denominadas como normas do Programa o conjunto de portarias e o decreto de criação do Programa, descritas no Anexo A.

Segundo o Decreto № 6.286/2007 a finalidade do PSE é “contribuir para a formação integral dos estudantes da rede pública de educação básica por meio de ações de prevenção, promoção e atenção à saúde". Com base nesta finalidade, os efeitos do Programa poderão ser observados a longo prazo com a 
melhoria dos indicadores de educação como o IDEB, que avalia o desempenho dos escolares em provas de disciplinas básicas (língua portuguesa e matemática) nas séries iniciais e nas séries finais do ensino fundamental. Ressalta-se que para avaliar a formação de maneira integral, outras estratégias e indicadores devem ser propostos, além de uma avaliação que leve em conta aspectos tanto quantitativos como qualitativos, uma vez que a formação integral não é resultado apenas da educação formal e pode ser potencializada por uma série de políticas sociais que vão além das políticas de educação e saúde.

Para a operacionalização da avaliação, os itens levantados foram organizados de acordo com o modelo proposto pelo Grupo de Pesquisa Interdisciplinar em Saúde da Universidade de Montreal - Gris (1992) ${ }^{8}$ :

Apreciação da Estrutura: Em qual medida os recursos são empregados para que os objetivos do programa sejam alcançados.

Apreciação do Processo: Qual a adequação dos serviços para o alcance dos resultados esperados. Pode ser avaliado a partir dos achados no programa em comparação com as normas predeterminadas. O processo pode ser subdividido em dimensões, a saber:

- A dimensão técnica dos serviços: adequação dos serviços às necessidades;

- A dimensão das relações interpessoais: interação entre os cuidadores e os cuidados, satisfação pelo serviço feito e/ou recebido;

\footnotetext{
${ }^{8}$ GRIS: Grupo de Pesquisa Interdisciplinar em Saúde da Universidade de Montreal, Canadá - referido por Hartz (1997).
} 
- A dimensão organizacional: acessibilidade aos serviços, cobertura dos serviços oferecidos, caráter multiprofissional e interorganizacional dos cuidados, tempo e continuidade da ação.

A Apreciação dos Resultados: comparação entre resultados observados e resultados esperados. Comparação dos índices dos resultados obtidos com critérios e com normas de resultados esperados.

DONABEDI AN (1980) define estes elementos como:

Estrutura - recursos físicos, humanos, materiais e financeiros necessários para a assistência médica. Inclui financiamento e disponibilidade de mão-de-obra qualificada.

Processo - atividades envolvendo profissionais de saúde e pacientes, com base em padrões aceitos. A análise pode ser sob o ponto de vista técnico e/ou administrativo.

Resultado - produto final da assistência prestada, considerando saúde, satisfação de padrões e de expectativas. 
Figura 7: Modelo de avaliação normativa proposto pelo GRIS (1992).

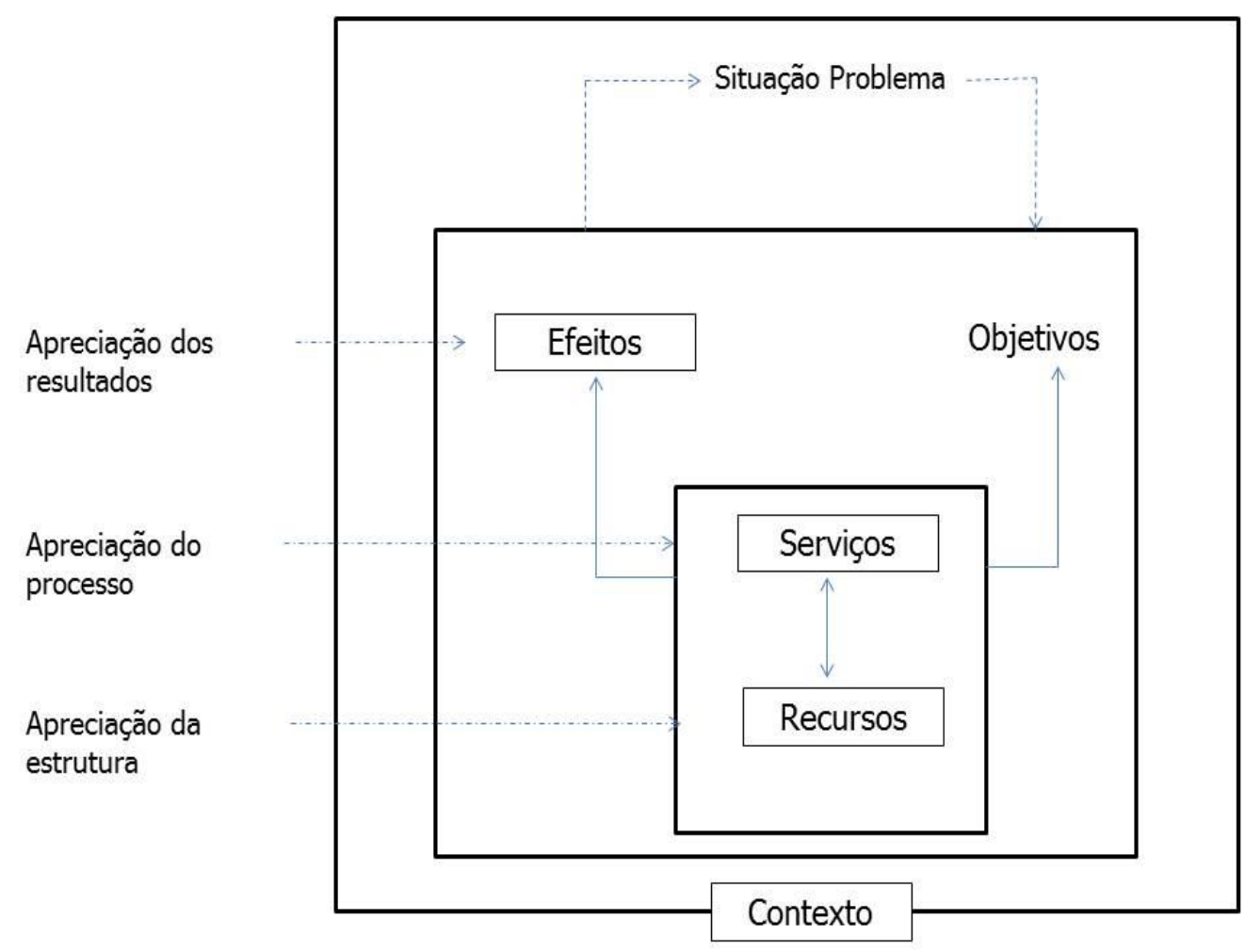


Figura 8: Adaptação do Modelo de avaliação normativa proposto pelo GRIS (1992) para avaliação do Programa Saúde na Escola.

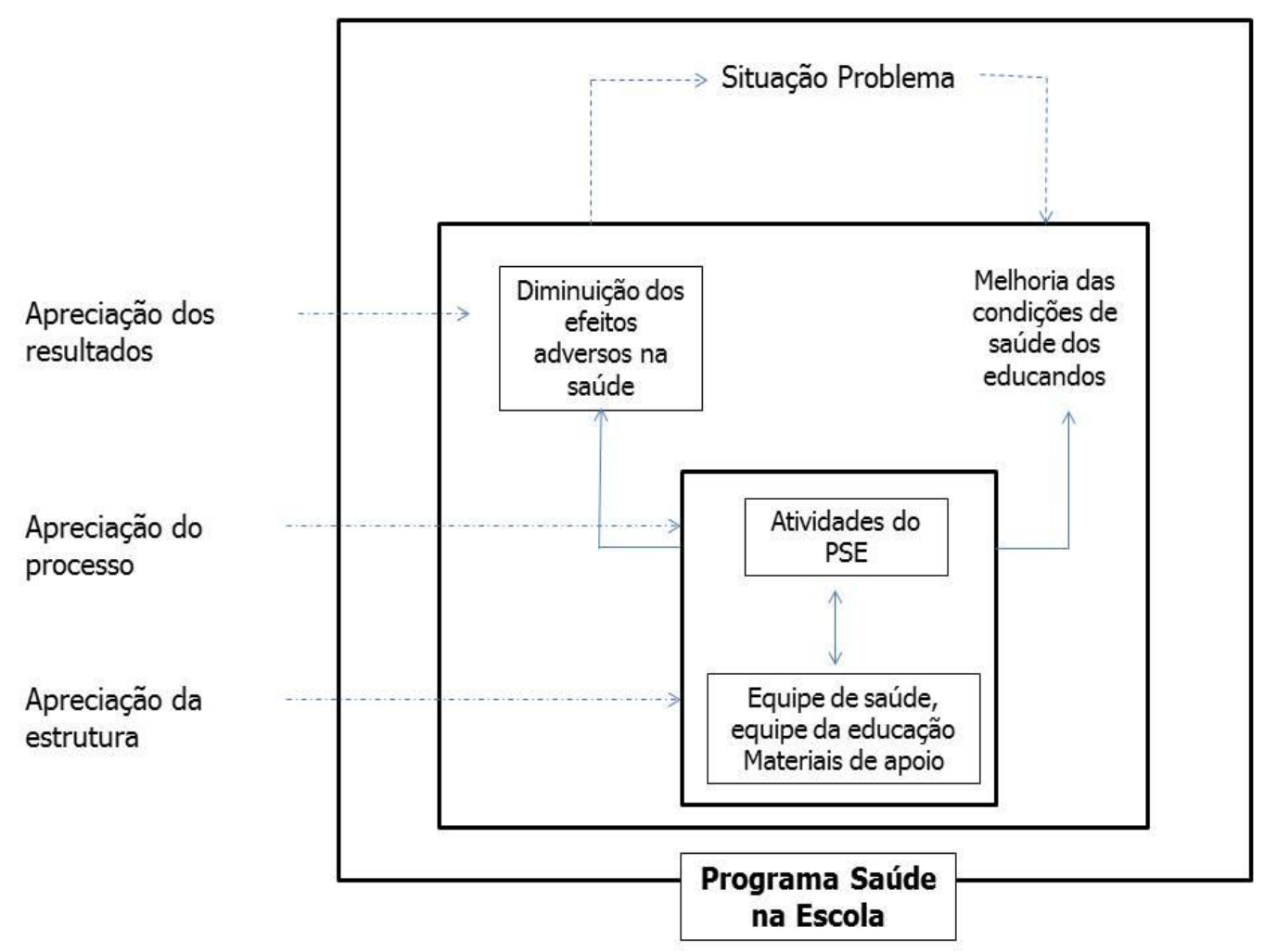

Com base no proposto o modelo teórico, a implantação do Programa foi em:

Estrutura: atividades relacionadas à gestão do Programa, como o município se organiza para a execução das ações no nível local, organização do Grupo de trabalho intersetorial para a gestão do programa, interlocução com diferentes setores dentro e fora da Secretaria de Saúde, governança do programa, tecnologias de cuidado e suporte disponível no território para ampliar o escopo de atuação da atenção básica. 
Processo: Atividades de planejamento - ações relacionadas à fase de adesão ao e pactuações iniciais para organização das atividades do PSE no município. Neste item também foram incorporadas as ações referentes à avaliação prévia da oferta de serviços para início das ações do programa, bem como o monitoramento;

Resultado: Como se dá a implantação das ações do PSE no cotidiano das equipes de saúde e de educação.

\subsubsection{Levantamento dos dados}

Para a coleta de informações municipais foi realizada uma pesquisa por meio de questionário eletrônico, disponibilizado para todos os coordenadores municipais do PSE, da área da saúde, por meio da plataforma eletrônica FormSUS, disponível no endereço (www.formsus.datasus.gov.br).

Foram enviadas mensagens por meio de correio eletrônico para todos os gestores, que aderiram ao Programa no ano de 2013. A lista com os endereços eletrônicos de todos os coordenadores do PSE foi solicitada para a coordenação do Programa Saúde na Escola, no Ministério da Saúde. A mensagem continha o texto, conforme descrito no Anexo C, solicitando que o formulário (Anexo D) fosse preenchido por gestores de municípios. O formulário ficou disponível por 60 dias, entre os meses de agosto de setembro de 2013 . Foi realizada uma tentativa de contato com o endereço eletrônico disponibilizado e cerca de $10 \%$ dos endereços eletrônicos apresentaram erro e voltaram das caixas de correio eletrônico dos respectivos destinatários. Ao acessar o sistema do FormSUS, por meio do endereço eletrônico disponibilizado para este fim, o respondente 
acessava o Termo de Consentimento Livre e Esclarecido para participar do estudo e a 1a questão do formulário era sobre a concordância em participar do estudo. Esta era a única pergunta que deveria ser obrigatoriamente respondida pelo respondente.

O questionário foi divido em seções na qual os diferentes temas foram agrupados, conforme descrito a seguir:

1. Aceite em participar da pesquisa:

2. Dados Institucionais

3. Caracterização da Atenção Básica no Município

4. Planejamento das ações

5. Atuação do nutricionista no município

6. Materiais de apoio para as ações

7. Ações de alimentação e nutrição

8. Componente I - avaliação das condições de saúde

9. Componente II - Promoção da Saúde

10. Semana Saúde na Escola 2012

O questionário foi composto de 60 perguntas fechadas classificadas como múltiplas ou dicotômicas, de acordo com a natureza das perguntas e as possibilidades de resposta.

A estratégia utilizada foi realizar um levantamento preliminar de dados com base em um questionário construído baseado na estrutura legal do PSE, conhecida pelos gestores locais. Esse questionário permitiu elencar as informações que posteriormente foram classificadas dentro dos três eixos: estrutura, processo e resultado, dentre o modelo de avaliação proposto neste 
trabalho. Aos dados respondidos no questionário foram agregados dados de número de habitantes de acordo com o Censo populacional de 2010 (IBGE, 2011), cobertura de Estratégia de Saúde da Família no ano de $2012^{9}$, IDEB (Índice de Desenvolvimento da Educação Básica) do ano de 2011 para a 4a e 8a série ${ }^{10}$.

A diagramação do modelo lógico segue o proposto por BEZERRA et al. (2010). As dimensões de avaliação são subdivididas em componentes baseados em parâmetros organizador em produtos por sua vez geram os resultados esperados para as ações que compõem o programa.

O Quadro 2 apresenta o modelo teórico, composto pelos seguintes componentes, definidos a seguir:

Dimensão: fator mais distal de classificação, definido de acordo com o referencial teórico de avaliação adotado, divido em 3 grupo - estrutura, processo e resultado;

Componente: segundo nível de organização da proposta de avaliação. Organizado de acordo com as atividades realizadas no programa em questão articulação intra e intersetorial (Governança do PSE na SMS; Grupo de Trabalho Intersetoria; Articulação intersetorial), instrumentos de planejamento (Pactuação intersetorial para adesão - termo de adesão; Plano municipal de trabalho; Plano municipal de Saúde; Demanda local); Atuação das equipes de saúde para execução da ação (Suporte de equipe multi-profissional da AB para o PSE; Suporte de profissional nutricionista no município; Materiais de apoio

\footnotetext{
${ }^{9}$ Dados disponíveis em http://dab. saude.gov.br/portaldab/historico cobertura sf.php acessado a última vez em 16 de novembro de 2013.

${ }^{10}$ Dados disponíveis em http://ideb.inep.gov.br/ acessado a última vez em 16 de novembro de 2013.
} 
para realização da ação; Ações de Alimentação e Nutrição; Equipe de AB e equipe da escola), Avaliação e monitoramento (Monitoramento e avaliação do PSE; Sistema de informação);

Parâmetro: questão que será avaliada para a definição do item proposto nos produtos;

Produtos: descrição das atividades esperadas para cada um dos parâmetros de referência propostos quando o programa é desenvolvido dentro do esperado para aquela atividade;

Resultados: desfecho esperado para o parâmetro de referência quando o programa é desenvolvido dentro do esperado para cada atividade.

Localização no questionário: localização do item de acordo com o instrumento de levantamento de dados utilizado. 
Quadro 2: Componentes do modelo teórico adotado para avaliar a implantação das ações do Programa Saúde na Escola nos municípios brasileiros.

\begin{tabular}{|c|c|c|c|c|c|}
\hline Dimensão & Componente & Parâmetro & Produtos & Resultados & Localização no questionário \\
\hline ESTRUTURA & Demanda local & $\begin{array}{l}\text { Número de escolas } \\
\text { públicas no município }\end{array}$ & $\begin{array}{l}\text { Número de escolas com atividades } \\
\text { da ESF no município }\end{array}$ & $\begin{array}{l}\text { Percentual municipal de } \\
\text { escolas que participam da } \\
\text { ação }\end{array}$ & Dados Institucionais \\
\hline ESTRUTURA & $\begin{array}{l}\text { Suporte de equipe } \\
\text { multi-profissional da } \\
\text { AB para o PSE }\end{array}$ & $\begin{array}{l}\text { NASF no município que } \\
\text { atua junto ao PSE }\end{array}$ & $\begin{array}{l}\text { Apoio matricial e técnico para as } \\
\text { ações das equipes de } A B\end{array}$ & $\begin{array}{l}\text { Aumento da resolutividade } \\
\text { das ações em saúde na } \\
\text { escola }\end{array}$ & $\begin{array}{l}\text { Caracterização da Atenção } \\
\text { Básica no Município }\end{array}$ \\
\hline ESTRUTURA & $\begin{array}{l}\text { Grupo de Trabalho } \\
\text { Intersetorial }\end{array}$ & $\begin{array}{c}\text { Conformação inicial do } \\
\text { GTI }\end{array}$ & $\begin{array}{l}\text { Presença dos gestores da saúde e } \\
\text { da educação responsáveis pelo } \\
\text { programa para garantia da } \\
\text { intersetorialidade }\end{array}$ & $\begin{array}{l}\text { Cumprimento dos } \\
\text { parâmetros propostos na } \\
\text { legislação do programa }\end{array}$ & Planejamento das ações \\
\hline
\end{tabular}




\begin{tabular}{|c|c|c|c|c|c|}
\hline Dimensão & Componente & Parâmetro & Produtos & Resultados & Localização no questionário \\
\hline ESTRUTURA & $\begin{array}{l}\text { Suporte de } \\
\text { profissional } \\
\text { nutricionista no } \\
\text { município }\end{array}$ & $\begin{array}{l}\text { Número de nutricionistas } \\
\text { atuantes nos municípios } \\
\text { e funções (saúde, } \\
\text { educação, gestão, NASF) } \\
\text { atua junto ao PSE }\end{array}$ & $\begin{array}{l}\text { Apoio matricial e técnico para as } \\
\text { ações de alimentação e nutrição no } \\
\text { município - aumento do escopo das } \\
\text { ações de alimentação e nutrição na } \\
\text { escola (p.ex:melhoria das ações da } \\
\text { alimentação escolar por conta de } \\
\text { um nutricionista no PNAE). }\end{array}$ & $\begin{array}{c}\text { Qualificação técnica para } \\
\text { as ações de alimentação e } \\
\text { nutrição na escola }\end{array}$ & $\begin{array}{l}\text { Atuação do nutricionista no } \\
\text { município }\end{array}$ \\
\hline ESTRUTURA & $\begin{array}{l}\text { Materiais de apoio } \\
\text { para realização da } \\
\text { ação }\end{array}$ & $\begin{array}{l}\text { Utilização de materiais } \\
\text { de apoio para as ações } \\
\text { de avaliação das } \\
\text { condições de saúde }\end{array}$ & $\begin{array}{c}\text { Desenvolvimento e uso de fichas e } \\
\text { outros materiais para apoiar as } \\
\text { ações do PSE in loco }\end{array}$ & $\begin{array}{l}\text { Padronização das ações } \\
\text { básicas nos municípios e } \\
\text { apoio técnico aos } \\
\text { profissionais que } \\
\text { desenvolvem as ações. }\end{array}$ & $\begin{array}{l}\text { Materiais de apoio para as } \\
\text { ações }\end{array}$ \\
\hline PROCESSO & $\begin{array}{c}\text { Pactuação } \\
\text { intersetorial para } \\
\text { adesão - termo de } \\
\text { adesão }\end{array}$ & $\begin{array}{l}\text { Termo de adesão do } \\
\text { município }\end{array}$ & $\begin{array}{c}\text { Adesão do município com o termo - } \\
\text { definição de escolas, unidades e } \\
\text { equipes de saúde, } \\
\text { responsabilidades e metas. }\end{array}$ & $\begin{array}{l}\text { Acordo técnico-politico } \\
\text { entre saúde e educação }\end{array}$ & $\begin{array}{c}\text { Atividade obrigatória para todos } \\
\text { os municípios que aderem ao } \\
\text { programa }\end{array}$ \\
\hline PROCESSO & $\begin{array}{l}\text { Plano municipal de } \\
\text { trabalho }\end{array}$ & $\begin{array}{l}\text { Levantamento da } \\
\text { demanda e da oferta } \\
\text { para as ações do PSE }\end{array}$ & Número de escolas município & $\begin{array}{l}\text { Levantamento das } \\
\text { necessidades para } \\
\text { planejamento das ações de } \\
\text { saúde para a população }\end{array}$ & Dados Institucionais \\
\hline PROCESSO & $\begin{array}{l}\text { Plano municipal de } \\
\text { Saúde }\end{array}$ & $\begin{array}{l}\text { Diagnóstico da demanda } \\
\text { e da capacidade } \\
\text { operativa no município } \\
\text { para desenvolvimento } \\
\text { das ações e }\end{array}$ & $\begin{array}{l}\text { Inserção do PSE no Planejamento } \\
\text { das açoes de saude do município }\end{array}$ & $\begin{array}{l}\text { Institucionalização das } \\
\text { ações do PSE nas açoes de } \\
\text { saúde do município }\end{array}$ & Planejamento das ações \\
\hline
\end{tabular}




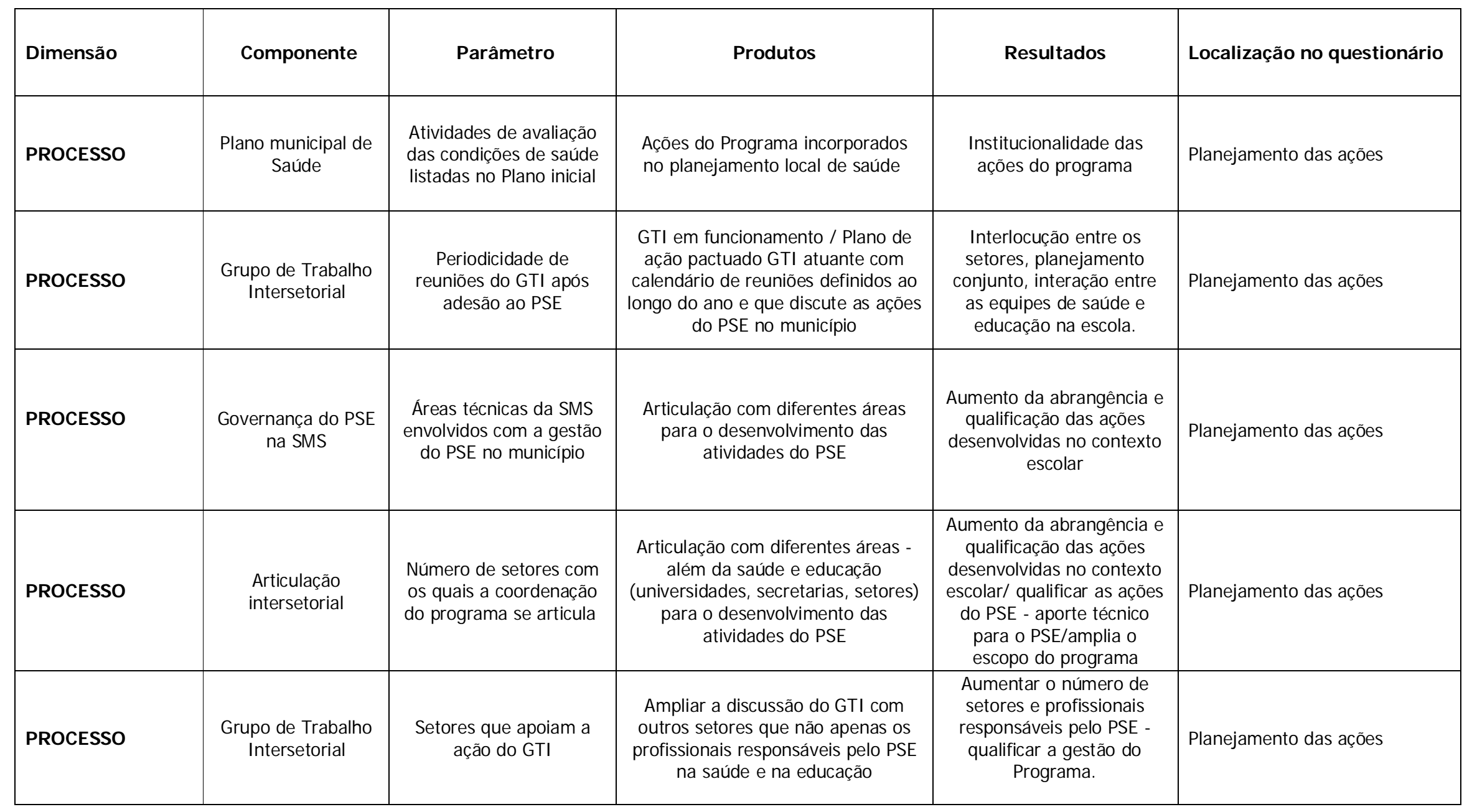




\begin{tabular}{|c|c|c|c|c|c|}
\hline Dimensão & Componente & Parâmetro & Produtos & Resultados & Localização no questionário \\
\hline PROCESSO & $\begin{array}{l}\text { Monitoramento e } \\
\text { avaliação do PSE }\end{array}$ & $\begin{array}{l}\text { Programação da } \\
\text { periodicidade da ação de } \\
\text { monitoramento da saúde } \\
\text { dos escolares }\end{array}$ & $\begin{array}{c}\text { Acompanhamento contínuo das } \\
\text { ações em saúde e condições dos } \\
\text { escolares acompanhados pelo } \\
\text { programa }\end{array}$ & $\begin{array}{c}\text { Elementos para avaliar e } \\
\text { planejar as ações do } \\
\text { Programa -repactuar metas } \\
\text { e ações }\end{array}$ & $\begin{array}{l}\text { Ações de alimentação e } \\
\text { nutrição; } \\
\text { Componente I - avaliação das } \\
\text { condições de saúde; } \\
\text { Componente II - Promoção da } \\
\text { Saúde }\end{array}$ \\
\hline PROCESSO & $\begin{array}{l}\text { Ações de } \\
\text { Alimentação e } \\
\text { Nutrição }\end{array}$ & $\begin{array}{l}\text { Planejamento das } \\
\text { atividades de } A \& N \text { no } \\
\text { plano de trabalho }\end{array}$ & $\begin{array}{l}\text { Periodicidade de realização de } \\
\text { diagnóstico ou acompanhamento da } \\
\text { saúde e estado nutricional dos } \\
\text { estudantes cobertos pelo PSE }\end{array}$ & $\begin{array}{l}\text { Ação acontecendo nos } \\
\text { municípios }\end{array}$ & $\begin{array}{l}\text { Componente I - avaliação das } \\
\text { condições de saúde }\end{array}$ \\
\hline RESULTADO & $\begin{array}{l}\text { Equipe de } \mathrm{AB} \text { e } \\
\text { equipe da escola }\end{array}$ & $\begin{array}{l}\text { Interação entre equipe } \\
\text { de saúde e equipe } \\
\text { responsável pela } \\
\text { alimentação escolar no } \\
\text { município } \\
\end{array}$ & $\begin{array}{l}\text { Discussão sobre a qualidade e } \\
\text { possibilidades da alimentação } \\
\text { escolar no território. }\end{array}$ & $\begin{array}{l}\text { Melhorias do cardápio } \\
\text { oferecido pela alimentação } \\
\text { escolar e ambiente } \\
\text { alimentar }\end{array}$ & Planejamento das ações \\
\hline RESULTADO & $\begin{array}{l}\text { Equipe de } \mathrm{AB} \text { e } \\
\text { equipe da escola }\end{array}$ & $\begin{array}{l}\text { Avaliação geral das } \\
\text { condições de saúde } \\
\text { (clínica e psicossocial) }\end{array}$ & $\begin{array}{l}\text { Mapeamento da situação de saúde } \\
\text { da população da escola }\end{array}$ & $\begin{array}{l}\text { Planejamento e execução } \\
\text { das ações com base na } \\
\text { demanda encontrada }\end{array}$ & $\begin{array}{l}\text { Componente I - avaliação das } \\
\text { condições de saúde }\end{array}$ \\
\hline RESULTADO & $\begin{array}{l}\text { Equipe de } A B \text { e } \\
\text { equipe da escola }\end{array}$ & $\begin{array}{c}\text { Fluxo de } \\
\text { encaminhamentos para } \\
\text { as unidades de saúde } \\
\text { após triagem baseada } \\
\text { nas ações do PSE nas } \\
\text { escolas }\end{array}$ & $\begin{array}{c}\text { Aumento da captação de indivíduos } \\
\text { na idade escolar para as ações na } \\
\text { RAS }\end{array}$ & $\begin{array}{l}\text { Prevenção de agravos } \\
\text { futuros, atualização de } \\
\text { calendário vacinal e } \\
\text { condutas de saúde com } \\
\text { foco na faixa etária do } \\
\text { Programa. }\end{array}$ & $\begin{array}{l}\text { Componente I - avaliação das } \\
\text { condições de saúde }\end{array}$ \\
\hline
\end{tabular}




\begin{tabular}{|c|c|c|c|c|c|}
\hline Dimensão & Componente & Parâmetro & Produtos & Resultados & Localização no questionário \\
\hline RESULTADO & $\begin{array}{l}\text { Equipe de } A B \text { e } \\
\text { equipe da escola }\end{array}$ & $\begin{array}{l}\text { Monitoramento do peso } \\
\text { e altura dentro das ações } \\
\text { de monitoramento da } \\
\text { saúde dos escolares }\end{array}$ & $\begin{array}{l}\text { Monitoramento frequente do estado } \\
\text { nutricional dos escolares }\end{array}$ & $\begin{array}{l}\text { Diagnóstico e atuação em } \\
\text { cima da situação de saúde } \\
\text { apresentada/ Avaliação do } \\
\text { estado nutricional }\end{array}$ & $\begin{array}{l}\text { Componente I - avaliação das } \\
\text { condições de saúde }\end{array}$ \\
\hline RESULTADO & $\begin{array}{l}\text { Equipe de } \mathrm{AB} \text { e } \\
\text { equipe da escola }\end{array}$ & $\begin{array}{l}\text { Ações de promoção da } \\
\text { saúde e prevenção das } \\
\text { doenças e agravos. }\end{array}$ & $\begin{array}{l}\text { Desenvolvimento de ações } \\
\text { planejadas entre a equipe de saúde } \\
\text { e educação, com base nas } \\
\text { necessidades locais, de acordo com } \\
\text { a realidade e necessidades }\end{array}$ & $\begin{array}{l}\text { Realização das atividades } \\
\text { de Promoção da saúde } \\
\text { entre os escolares. }\end{array}$ & $\begin{array}{l}\text { Componente II - Promoção da } \\
\text { Saúde }\end{array}$ \\
\hline RESULTADO & $\begin{array}{l}\text { Equipe de } \mathrm{AB} \text { e } \\
\text { equipe da escola }\end{array}$ & $\begin{array}{l}\text { Atividades de Promoção } \\
\text { da alimentação } \\
\text { adequada e saudável }\end{array}$ & $\begin{array}{l}\text { Desenvolvimento de ações } \\
\text { planejadas entre a equipe de saúde } \\
\text { e educação, com base nas } \\
\text { necessidades locais, de acordo com } \\
\text { a realidade e necessidades }\end{array}$ & $\begin{array}{l}\text { Realização das atividades } \\
\text { de Promoção da saúde } \\
\text { entre os escolares. }\end{array}$ & $\begin{array}{l}\text { Componente II - Promoção da } \\
\text { Saúde }\end{array}$ \\
\hline RESULTADO & $\begin{array}{l}\text { Equipe de } A B \text { e } \\
\text { equipe da escola }\end{array}$ & $\begin{array}{l}\text { Educação permanente e } \\
\text { capacitação de } \\
\text { profissionais da } \\
\text { Educação e Saúde e de } \\
\text { jovens para o PSE }\end{array}$ & $\begin{array}{l}\text { Atualização permanente das } \\
\text { equipes de saúde e educação para } \\
\text { desenvolvimento das ações do PSE }\end{array}$ & $\begin{array}{l}\text { Qualificação das ações a } \\
\text { aumento da resolutividade } \\
\text { e efetividade do trabalho } \\
\text { das equipes com os } \\
\text { escolares }\end{array}$ & $\begin{array}{l}\text { Ações de alimentação e } \\
\text { nutrição; } \\
\text { Componente I - avaliação das } \\
\text { condições de saúde; } \\
\text { Componente II - Promoção da } \\
\text { Saúde. }\end{array}$ \\
\hline RESULTADO & $\begin{array}{l}\text { Sistema de } \\
\text { informação }\end{array}$ & $\begin{array}{l}\text { Inserção dos dados nos } \\
\text { sistemas de informação }\end{array}$ & $\begin{array}{c}\text { Alimentar os sistemas de } \\
\text { informação de maneira organizada } \\
\text { e periódica }\end{array}$ & $\begin{array}{c}\text { Uso contínuo da } \\
\text { informação para prestar } \\
\text { contas e planejar as ações } \\
\text { de saúde no Programa. }\end{array}$ & $\begin{array}{c}\text { Componente I - avaliação das } \\
\text { condições de saúde }\end{array}$ \\
\hline
\end{tabular}




\subsubsection{Análise dos dados}

Para a análise das características gerais, os municípios foram primeiramente divididos de acordo com o seu número de habitantes, resultando esta divisão em 4 grupos, para fins de comparação. As demais informações foram analisadas apenas para o conjunto total dos municípios.

As variáveis foram analisadas de acordo com a sua origem. Para variáveis contínuas foram realizadas médias e para variáveis categóricas foram feitas porcentagem e teste de $\chi^{2}$ e análise de valor de $p$. Foram consideradas diferenças significativas quando o valor de $p$ apresentado foi menor do que 0,05 .

\subsection{Análise longitudinal do estado nutricional de crianças e adolescentes com dados registrados no SI SVAN}

A caracterização do estado nutricional dos escolares foi feita a partir da análise de dados oriundos do SISVAN de todos os registros do sistema, de indivíduos com idades entre 7 e 18 anos, com dados registrados entre os anos de 2008 e 2012, referentes aos registros de acompanhamentos da $A B$ excluindo-se os registros referentes ao acompanhamento das condicionalidades do Programa Bolsa Família.

\subsubsection{O Sistema de Vigilância Alimentar e Nutricional - SI SVAN}

O SISVAN, atualmente alimentado por praticamente todos os municípios brasileiros e contempla os dados de estado nutricional e consumo alimentar da população acompanha pelas equipes de atenção básica à saúde.

O SISVAN possui um formulário padrão para registro dos dados que leva em consideração dados do estabelecimento de saúde, dados cadastrais do 
indivíduo, informações nutricionais, doenças, deficiências/intercorrências e tipo de acompanhamento ${ }^{11}$. Para fins de análise foram utilizadas as seguintes informações: data de nascimento; sexo; data do acompanhamento; idade; peso e altura.

\subsubsection{Obtenção dos dados e variáveis estudadas}

A obtenção dos dados do sistema foi feita através de solicitação para a Coordenaação-Geral de Alimentação e Nutrição - CGAN, por meio de ofício, com base na Lei $12.527 / 2011^{12}$. Foram solicitados dados de peso, altura, sexo, data de nascimento, data de avaliação, código do município (IBGE), idade em anos e o tipo de acompanhamento . Não foram fornecidos dados de identificação como nome e número de documentos, garantindo o sigilo do usuário ao qual a informação pertence. Os dados disponibilizados foram usados para a análise dos resultados que compõem esta tese e serão utilizados apenas para fins acadêmicos.

\subsubsection{Classificação do estado nutricional}

O estado nutricional de crianças e adolescentes foram analisados com base em índices antropométricos que, ao serem comparados com uma população de referência, permitem a avaliação do estado nutricional. Os índices são calculados a partir das seguintes informações: data de nascimento, data de realização do exame antropométrico, peso e altura. Para a comparação com os

\footnotetext{
${ }^{11}$ Dados disponíveis em http://189.28.128.100/dab/docs/portaldab/documentos/passo_passo_sisvanweb.pdf acessado a última vez em 21 de novembro de 2013.

12 Lei no 12.527, de 18 de Novembro de 2011 - Regula o acesso a informações previsto no inciso XXXIII do art. 5o, no inciso II do § 3o do art. 37 e no § 20 do art. 216 da Constituição Federal; altera a Lei o 8.112, de 11 de dezembro de 1990; revoga a Lei № 11.111, de 5 de maio de 2005, e dispositivos da Lei no 8.159, de 8 de janeiro de 1991; e dá outras providências.
} 
valores de referência, também é necessária a informação referente ao sexo, uma vez que meninos e meninas possuem perfis de crescimento diferenciados. Para a classificação do estado nutricional foram adotadas as referências disponibilizadas pela Organização Mundial de Saúde (OMS 2007).

Além da presença das medidas, é importante que haja plausibilidade entre a medida apresentada e a idade/sexo do examinado. Para as análises seguintes, a variação aceita para a massa corporal foi de 3,0 a $200 \mathrm{~kg}$ e para altura foi de 45 a $200 \mathrm{~cm}$, estes valores foram definidos a partir de dois critérios: 1ํ - a maioria dos equipamentos disponíveis nas UBS tem capacidade de mensuração dentro dos intervalos propostos e; 2 ㅇ - de acordo com a plausibilidade biológica - no que se refere aos limites inferiores, não é possível que um indivíduo com idade de 7 anos ou mais apresente preso corporal menor que $3,0 \mathrm{~kg}$ e altura menor que $40 \mathrm{~cm}$. Valores fora desse intervalo foram considerados implausíveis e foram descartados.

Na construção dos índices, foram observados valores de flags, valores esses também considerados implausíveis mesmo depois de retirados valores de peso e altura considerados fora do padrão.

Quadro 3: Relação dos Índices antropométricos utilizados e valores limites em escores Z.

\begin{tabular}{|l|c|c|}
\hline Índice & Limite inferior & Limite superior \\
\hline Altura-para-idade & -6 & +5 \\
\hline Peso-para-idade & -6 & +6 \\
\hline Peso-para-altura & -5 & +5 \\
\hline IMC para idade & -5 & +5 \\
\hline
\end{tabular}

Fonte: Organização Mundial da Saúde ${ }^{13}$.

${ }^{13}$ Disponível em http://www.who.int/growthref/tools/en/ último acesso em 6/01/2014. 


\subsubsection{1 Í ndices antropométricos}

A avaliação antropométrica de crianças é realizada a partir de índices que avaliam tanto o peso como a altura e os comparam com uma população de referência- crianças de que tem um ótimo padrão de alimentação e nutrição, que podem atingir o seu melhor potencial de crescimento e assim atingir padrões de normalidade. Os índices antropométricos aqui utilizados serão expressos em escores z comparando-se o peso da criança com a mediana de peso esperada para sua altura e sexo.

Escore-z é um termo estatístico que quantifica a distância do valor observado em relação à mediana dessa medida ou ao valor que é considerado normal na população. Corresponde à diferença padronizada entre o valor aferido e a mediana dessa medida da população de referência e é calculado pela seguinte fórmula:

\section{Escore-z $=$ (valor observado) - (valor da mediana de referência) Desvio-padrão da população de referência}

- IMC: Índice de Massa Corporal - é um índice simples, que faz a relação entre o peso e altura de um indivíduo, comumente utilizado para adultos, e que pode ser calculado a partir da seguinte equação: peso (kg) / [altura $(\mathrm{m})]^{2}$;

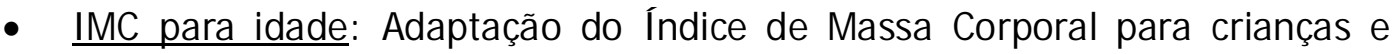
adolescentes, com classificação e pontos de corte diferenciados de acordo com a idade e o sexo. Utilizado comumente para crianças maiores de 5 anos em substituição ao índice peso-para-altura, que indica o equilíbrio entre a massa corporal da criança, e seu crescimento linear. Desvios 
negativos indicam depleção do tecido adiposo (casos agudos de desnutrição) e desvios positivos apontam para o acúmulo excessivo e risco para obesidade.

Recomendações da Organização Mundial da Saúde (OMS) indicam que valores de escores $z$ abaixo de -2 para os três indicadores determinam casos de déficits ponderais e valores de peso-para-altura maiores a +2 escores $z$ apontam para excesso de peso e obesidade. A população de referência para o cálculo e comparação dos índices antropométricos utilizadas neste documento seguem o proposto pela OMS, publicado no ano de 2007 (WHO, 2007).

Valores inferiores a -2 escores $z$ índices altura-para-idade, peso-paraidade e peso-para-altura definem, respectivamente, os casos de déficits de altura, de peso e de peso-para-altura. O risco de desnutrição na população será virtualmente nulo quando déficits de altura, de peso e de peso-para-altura forem encontrados com frequência semelhante à encontrada na distribuição de referência, ou seja, em cerca de $2-3 \%$ das crianças, aumentando progressivamente à medida que a frequência daqueles déficits ultrapassar e se distanciar do limiar de 2-3\%. Valores do índice peso-para-altura superiores a +2 escores $z$ definem os casos de excesso de peso-para-altura, que podem ser tomados, na falta de uma medida direta da adiposidade da criança, como indicativos da obesidade infantil. Novamente neste caso, frequências em torno de $2-3 \%$ de casos de excesso de peso-para-altura são esperadas mesmo em populações bem nutridas, indicando virtual ausência do risco de obesidade na população. 
Para fins de confrontação das informaç̧ões de peso e altura das crianças e adolescentes acompanhadas pelo SISVAN com um inquérito nacional e com uma referência populacional, foi realizada a comparação das medianas, de acordo com a idade e o sexo dos indivíduos, com as medianas de altura e idade resultantes da Pesquisa Nacional de Orçamentos Familiares - POF 2008-9 (IBGE, 2010) e com as medianas dos indivíduos que compõem a referência de crescimento proposta pela OMS (WHO, 2007).

Após a comparação das medianas, calculou-se o estado nutricional de cada indivíduo que foi dassificado de acordo com o Escore-Z para o sexo e idade, e a partir destas informações, foi possível fazer as análises tanto de evolução do estado nutricional bem como de aumento do ganho ponderal, por idade e por unidade de Escore-Z, por idade, objetivando analisar o momento mais oportuno para a realização de intervenções com foco no adequado desenvolvimento do crescimento e estado nutricional em crianças e adolescentes como parte das ações do PSE. Todas as análises de dados foram feitas no software Stata ${ }^{\circledR}$ versão 10. 


\section{Aspectos éti cos}

O estudo seguiu as normas e diretrizes regulamentadoras de pesquisas de acordo com a Resolução do Conselho Nacional de Saúde № 466, de $12 / 12 / 2012$

O presente projeto foi apresentado para o Comitê de Ética e Pesquisa da Faculdade de Saúde Pública da Universidade de São Paulo e aprovado de acordo com o Ofício COEP/371/11 (Anexo B).

A coleta de informações feita via internet não teve a identificação do respondente e os gestores e profissionais só puderam responder o questionário depois da leitura e do acordo com os objetivos do estudo.

Com relação aos dados relativos ao estado nutricional, originários do SISVAN, todos os registros foram fornecidos sem identificação do indivíduo ao qual aqueles dados pertenciam, sendo identificado apenas idade e sexo.

O protocolo aqui proposto não apresentou riscos aos participantes e seus benefícios suplantam os eventuais desconfortos que possam ocorrer. Ao final da pesquisa será enviado a todos os colaboradores um resumo com os principais achados, bem como a disponibilização do endereço eletrônico de divulgação desta Tese, além da divulgação por meio de publicações científicas. 


\section{Resultados}

\section{1 Análise da implantação do Programa Saúde na Escola nos municípios brasileiros.}

Foram respondidos 387 questionários, destes 3 (0,78\%) não concordaram em participar do estudo, 4 apresentavam dados duplicados e 380 questionários foram analisados. No questionário aplicado, apenas a pergunta referente ao Termo de Consentimento Livre e Esclarecido era obrigatória para todos os participantes, bem como o aceite (ou não) em participar do estudo. Por conta disso o número de respondentes para cada questão pode sofrer uma variação, por conta da não obrigatoriedade das respostas.

\subsubsection{Estrutura}

As Tabelas 1, 2 e 3 apresentam os resultados que caracterizam a estrutura dos municípios para o desenvolvimento das ações do Programa Saúde na Escola.

A partir dos dados coletados foi feita uma distribuição em quartis, divididos igualmente, gerando 4 quartis (93 municípios em cada grupo), com base no porte populacional dos municípios participantes do estudo e também na proporção do número de habitantes de todos os municípios brasileiros, a fim de verificar se o porte populacional interferia nos resultados. A divisão proposta só foi utilizada para os resultados descritos na Tabela 1, nas demais Tabelas estão descritos apenas os resultados do conjunto do total de todos os 
municípios, pois os mesmos não tiveram diferenças significativas quando a análise foi realizada por grupos (dados não apresentados).

O 1o quartil tem média populacional de 3.680,50 habitantes (mín: 1.030 e máx: 5.916); oo quartil: 9.268,13 habitantes (mín: 5.978 e máx: 13.468); 3o quartil: 20.490,82 habitantes (mín: 13.491 e máx: 31.951); 4o quartil: 253.275,4 habitantes (mín: 32.060 e máx: 6.355.949). A Tabela 1 apresenta a descrição dos municípios segundo os quartos. A maioria dos municípios respondentes está situada na Região Nordeste, seguida da Região Sudeste do Brasil. Quando comparados entre os municípios da mesma Região, pode-se observar que nas Regiões Sul, Sudeste e Centro-Oeste, mais da metade dos municípios estão no $1^{\circ}$ e $2^{\circ}$ quartil, enquanto na Região Norte, a distribuição dos municípios nos quartis apresenta menor variação com menor concentração de municípios no segundo quartil.

Com relação ao ano de adesão ao programa, pode-se observar que no ano de 2008, metade dos municípios são pertencentes ao 4ํ quartil, nos anos de 2009 e 2010 os municípios do segundo quartil apresentaram maior número de adesões, enquanto nos anos de 2011 e 2012 as maiores proporções estão nos municípios do 3o quartil e no ano de 2013 os municípios do 1o quartil são os mais frequentes (Tabela 1 ).

A caracterização da educação no município foi realizada com base no seu número de escolas e pelo indicador IDEB, apresentados na Tabela 1 . O número médio de escolas no município aumenta de acordo com porte populacional. Com relação ao IDEB nota-se que a sua média apresenta queda com o 
aumento do porte populacional dos municípios, tanto nas séries iniciais $\left(4^{\mathrm{a}}\right.$ série) como nas séries finais ( $8^{\mathrm{a}}$ série) do ensino fundamental.

A Saúde nos municípios está apresentada a partir dos dados da Atenção Básica. O número médio de equipes de Estratégia de Saúde da Família aumenta de acordo com o porte populacional do município, porém a cobertura média populacional da Estratégia Saúde da Família é decrescente, sendo maior nos menores municípios. Cerca de $45 \%$ dos municípios tem equipes de NASF, apresentando diferenças de acordo com o porte populacional, sendo mais frequente nos maiores municípios. A Tabela 1 também descreve como ocorre o apoio do NASF ao PSE: a maioria das equipes tem atuação direta nas escolas, cerca da metade atuam apoiando as ações das equipes de $A B$ (matriciamento) em questões referentes ao Programa e apenas um quinto apoia nas ações de planejamento. 
Tabela 1 - Distribuição dos municípios segundo características demográficas, educacionais e de estruturação da Atenção Básica. Brasil, 2014.

\begin{tabular}{|c|c|c|c|c|c|c|c|}
\hline & $\mathrm{n}$ & $\begin{array}{c}\text { Porte } \\
\text { populacional } \\
\text { até } 5.916 \text { hab. }\end{array}$ & $\begin{array}{c}\text { Porte } \\
\text { populacional } \\
\text { entre } 5.978 \text { e } \\
13.468 \text { hab } \\
\end{array}$ & $\begin{array}{c}\text { Porte } \\
\text { populacional } \\
\text { entre } 13.491 \\
\text { e } 31.951 \text { hab }\end{array}$ & $\begin{array}{c}\text { Porte } \\
\text { populacional } \\
\text { acima de } \\
32.060 \text { hab }\end{array}$ & Geral & $p$ \\
\hline Região & & $(\%)$ & $(\%)$ & $(\%)$ & $(\%)$ & $(\%)$ & \\
\hline Norte & 31 & 25,81 & 16,13 & 29,03 & 29,03 & 8,33 & 0,001 \\
\hline Nordeste & 122 & 14,75 & 20,49 & 38,52 & 26,23 & 32,80 & \\
\hline Sudeste & 103 & 27,18 & 31,07 & 14,56 & 27,18 & 27,69 & \\
\hline Sul & 72 & 34,72 & 30,56 & 13,89 & 20,83 & 19,35 & \\
\hline Centro-Oeste & 44 & 31,82 & 20,45 & 27,27 & 20,45 & 11,83 & \\
\hline Média populacional & 372 & $3.680,50$ & $9.268,10$ & $20.490,80$ & $253.275,40$ & $71.678,70$ & \\
\hline Ano de adesão ao PSE & & $(\%)$ & $(\%)$ & $(\%)$ & (\%) & $(\%)$ & \\
\hline 2008 & 24 & 25,00 & 8,33 & 16,67 & 50,00 & 100 & 0,00 \\
\hline 2009 & 15 & 13,33 & 40,00 & 26,67 & 20,00 & 100,00 & \\
\hline 2010 & 30 & 3,33 & 36,67 & 26,67 & 33,33 & 100,00 & \\
\hline 2011 & 73 & 27,40 & 20,55 & 30,14 & 21,92 & 100,00 & \\
\hline 2012 & 66 & 21,21 & 25,76 & 37,88 & 15,15 & 100,00 & \\
\hline 2013 & 159 & 30,19 & 25,79 & 18,24 & 25,79 & 100,00 & \\
\hline Caracterização da educação & & $(\%)$ & $(\%)$ & $(\%)$ & $(\%)$ & $(\%)$ & \\
\hline Número médio de escolas por município & 351 & 5,37 & 12,10 & 64,00 & 114,40 & 45,90 & \\
\hline IDEB médio na 4a série (2011) & 359 & 5,05 & 5,01 & 4,47 & 4,76 & 4,82 & \\
\hline IDEB médio na 8a série (2011) & 361 & 4,12 & 3,90 & 3,68 & 3,82 & 3,87 & \\
\hline \multicolumn{8}{|l|}{ Caracterização da Atenção Básica no Município } \\
\hline Número médio de equipes de Estratégia Saúde da Família & 371 & 1,50 & 3,10 & 6,30 & 35,70 & 11,30 & \\
\hline Número médio de equipes de ESF no PSE & 371 & 1,41 & 3,15 & 6,39 & 20,80 & 7,84 & \\
\hline Cobertura média de Estratégia Saúde da Família (2012) (\%) & 372 & 93,84 & 90,28 & 86,54 & 62,27 & 83,23 & \\
\hline Presença de equipe de NASF no município & 364 & 23,91 & 38,71 & 54,02 & 66,30 & 45,60 & 0,00 \\
\hline Equipes de NASF apoiam as para as ações do PSE (\% ) & 146 & 100,00 & 96,67 & 100,00 & 98,25 & 98,65 & 0,617 \\
\hline Modalidade de apoio das equipes de NASF & & $(\%)$ & $(\%)$ & $(\%)$ & $(\%)$ & $(\%)$ & \\
\hline Atuação direta nas escolas & 137 & 80,00 & 82,14 & 80,49 & 69,81 & 76,64 & 0,515 \\
\hline Atendimento dos jovens com alguma demanda específica de saúde & 137 & 53,33 & 71,43 & 63,41 & 56,60 & 61,31 & 0,535 \\
\hline Matriciamento das ações & 137 & 46,67 & 50,00 & 43,90 & 56,60 & 50,36 & 0,661 \\
\hline Auxílio no planejamento das ações das equipes nas escolas & 137 & 33,33 & 25,00 & 19,51 & 13,21 & 19,71 & 0,299 \\
\hline Não sei informar & 137 & 0,00 & 0,00 & 0,00 & 1,89 & 0,73 & 0,66 \\
\hline
\end{tabular}


Tabela 2 - Distribuição da força de trabalho e atuação do nutricionista nos municípios do Programa Saúde na Escola. Brasil, 2014.

\begin{tabular}{|c|c|c|c|}
\hline \multirow{3}{*}{$\begin{array}{l}\text { Respondente da pesquisa é o gestor responsável pelo Programa Saúde } \\
\text { na Escola no Município }\end{array}$} & \multirow{3}{*}{$\frac{n}{384}$} & \multicolumn{2}{|c|}{$\%$} \\
\hline & & $\operatorname{sim}(\%)$ & não (\%) \\
\hline & & 79,11 & 20,89 \\
\hline Profissão do respondente da pesquisa & 384 & \multicolumn{2}{|c|}{$\%$} \\
\hline Enfermeiro & & \multicolumn{2}{|c|}{53,60} \\
\hline Outro profissional & & \multicolumn{2}{|c|}{26,50} \\
\hline Outros profissionais da saúde & & \multicolumn{2}{|c|}{14,80} \\
\hline Nutricionista & & \multicolumn{2}{|c|}{5,20} \\
\hline Setor da Secretaria Municipal de Saúde no qual o PSE está alocado & 379 & \multicolumn{2}{|c|}{$\%$} \\
\hline Atenção Básica & & \multicolumn{2}{|c|}{48,66} \\
\hline Outros setores & & \multicolumn{2}{|c|}{43,82} \\
\hline Coordenação PSE & & \multicolumn{2}{|c|}{7,53} \\
\hline Profissionais da educação que atuam no PSE & 281 & $\operatorname{sim}(\%)$ & não (\%) \\
\hline Professores & & 91,21 & 8,79 \\
\hline outros & & 50,92 & 49,08 \\
\hline Professor de educação física & & 32,97 & 67,03 \\
\hline Agente de educação & & 21,98 & 78,02 \\
\hline Psicólogo & & 18,32 & 81,68 \\
\hline Profissionais da saúde que atuam no PSE & & $\operatorname{sim}(\%)$ & não (\%) \\
\hline Equipe de Saúde da família & 368 & 90,22 & 9,78 \\
\hline NASF & 368 & 38,86 & 61,14 \\
\hline Equipe de Atenção Básica tradicional & 368 & 34,24 & 65,76 \\
\hline outros & 368 & 21,74 & 78,26 \\
\hline \multirow[t]{2}{*}{ Equipe volante } & 368 & 3,54 & 96,46 \\
\hline & $\mathrm{n}$ & $\operatorname{sim}(\%)$ & não (\%) \\
\hline Presença do profissional nutricionista atuando no município & 269 & 93,31 & 6,69 \\
\hline Número de nutricionistas atuam no município & 237 & \multicolumn{2}{|c|}{$\%$} \\
\hline um & & \multicolumn{2}{|c|}{43,46} \\
\hline dois a cinco & & \multicolumn{2}{|c|}{46,84} \\
\hline seis a dez & & \multicolumn{2}{|c|}{6,75} \\
\hline onze a vinte & & \multicolumn{2}{|c|}{2,11} \\
\hline Mais que vinte & & \multicolumn{2}{|c|}{0,84} \\
\hline Local de atuação do nutricionista no município & 242 & $\operatorname{sim}(\%)$ & não (\%) \\
\hline Alimentação escolar & & 71,07 & 28,93 \\
\hline Atenção saúde & & 63,22 & 36,78 \\
\hline Educação - gestão & & 45,87 & 54,13 \\
\hline Saúde - gestão & & 44,63 & 55,37 \\
\hline Assistência Social & & 3,31 & 96,69 \\
\hline Outros & & 3,31 & 96,69 \\
\hline Presença do nutricionista nas equipes do NASF & & \multicolumn{2}{|c|}{$\%$} \\
\hline Sim, em todas & 150 & \multicolumn{2}{|c|}{72,67} \\
\hline Sim, em parte delas & & \multicolumn{2}{|c|}{11,33} \\
\hline Não, em nenhuma & & \multicolumn{2}{|c|}{16,00} \\
\hline
\end{tabular}


Segundo a Tabela 2 , dos respondentes da pesquisa, $79,11 \%$ são os gestores do Programa do município. Com relação à profissão do gestor do PSE no município, pouco mais da metade é de enfermeiros, seguidos de outros profissionais da saúde (Médico, Odontólogo, Fisioterapeuta, Terapeuta Ocupacional, Psicólogo, Fonoaudiólogo, Assistente social), 5,2\% dos gestores do Programa são nutricionistas e $26,5 \%$ gestores são oriundos de outras profissões. Quanto ao setor de lotação na Secretaria de Saúde, metade dos respondentes está lotado na $A B$, mais de $40 \%$ em outros setores e apenas 7,5\% estão lotados em coordenação específica para o Programa.

Ao se analisar os profissionais da educação que atuam no Programa, cerca de $90 \%$ das escolas contam com os professores, além da equipe de $A B$, para desenvolver nas ações localmente. Cerca de um terço conta com a atuação do professor de educação física nas ações do PSE. Os profissionais da saúde que mais atuam no Programa são aqueles pertencentes às Equipes da Estratégia Saúde da Família, seguidos dos profissionais que atuam nos NASF. Cerca de um quinto dos municípios, o setor saúde, também adotam outras estratégias para a realização das ações com os escolares, como no caso das equipes volantes dedicadas ao PSE (Tabela 2).

Mais de $90 \%$ dos municípios tem nutricionista trabalhando em algum setor e o número de profissionais, na quase totalidade dos municípios, não passa de cinco, estando a maioria $(71,07 \%)$ lotada nas atividades do Programa Nacional de Alimentação Escolar - PNAE, seguida do setor saúde 
(gestão ou atenção). Cerca de $70 \%$ das equipes tem este profissional em todas as equipes e aproximadamente $10 \%$ o tem em ao menos parte das equipes e $16 \%$ declararam não ter nutricionista no seu quadro de profissionais do NASF (Tabela 2).

Tabela 3 - Distribuição da conformação dos Grupos de trabalho e materiais de apoio para desenvolvimento das ações do PSE. Brasil, 2014.

\begin{tabular}{llcc}
\hline & $n$ & sim (\%) & não (\%) \\
\hline Conformação inicial do GTI & 268 & 97,76 & 2,24 \\
Saúde & 268 & 87,31 & 12,69 \\
Educação & 268 & 12,69 & 87,31 \\
Assistência social & 268 & 20,90 & 79,10 \\
Segurança alimentar e nutricional & 268 & 14,93 & 85,07 \\
Outros & 255 & 9,80 & 90,20 \\
Imunização & 255 & 7,45 & 92,55 \\
DST/Aids & 255 & 5,49 & 94,51 \\
Outras áreas & $n$ & sim (\%) & não (\%) \\
\hline Materiais recebidos pelo município os enviados pelo Ministério da & $n$ & \\
Educação para apoiar as ações de promoção da alimentação adequada e & & 34,36 & 65,64 \\
saudável & 260 & 23,17 & 76,83 \\
Álbum seriado "o que é vida saudável" & 260 & 15,39 & 84,61 \\
Manual Operacional para Promoção da alimentação saudável nas Escolas & 260 & 62,31 & 37,69 \\
Revista Ciência hoje & 260 & 56,39 & 43,61 \\
Não foi recebido nenhum material & 266 & & \\
Desenvolvimento pelo município de ficha padrão para avaliação das \\
condições de saúde dos educandos
\end{tabular}

Os dados da Tabela 3 apresentam a composição inicial dos Grupos de Trabalho Intersetorial (GTI) que são responsáveis pela gestão do Programa no município. No início das atividades locais do PSE, praticamente todos os GTI contavam com a representação do setor saúde, $87 \%$ contavam com representante da educação, um quinto dos grupos contavam com um representante do setor de segurança alimentar e nutricional, cerca de $12 \%$ com a assistência social e 15\% contavam com outros setores. Com relação 
aos materiais de apoio para o desenvolvimento das ações, cerca de dois terços dos respondentes não receberam materiais educativos de apoio para a realização das ações, pouco mais da metade dos municípios $(56,4 \%)$ desenvolveram alguma ficha padronizada pra avaliar as condições de saúde dos educandos.

\subsubsection{Processo}

As questões referentes ao componente do Processo estão descritas na Tabela 4. Ao se analisar o conjunto dos municípios, $62,8 \%$ destes pactuaram as ações do PSE no Plano Municipal de Saúde e dentre os que pactuaram a ação, cerca de três quartos afirmam que a ação é repactuada anualmente, rediscutindo as ações do Programa neste fórum. Dos respondentes, 59,54\% afirmaram que o GTI realizou um diagnóstico prévio (levantamento da demanda e da oferta instalada em cada território das Equipes de Saúde da Família) antes do início das ações do Programa.

A Tabela 4 também apresenta a articulação intrassetorial com as diferentes áreas da Secretaria Municipal de Saúde, a área mais citada foi a de saúde bucal, seguida da alimentação e nutrição, saúde da criança e saúde do adolescente. A área da vigilância em saúde foi citada por menos de um quinto dos respondentes. A articulação intersetorial está presente em mais de $60 \%$ dos municípios, com destaque para a articulação com outras secretarias de governo e Secretarias Estaduais de Saúde e Educação. 
Tabela 4 - Caracterização do processo de trabalho do Grupo de Trabalho Intersetorial para realização das atividades do Programa Saúde na Escola. Brasil, 2014.

\begin{tabular}{|c|c|c|c|}
\hline & $\mathrm{n}$ & $\%$ & \\
\hline & & $\operatorname{sim}(\%)$ & não (\%) \\
\hline Pactuação das ações do PSE no conselho municipal de saúde & 269 & 62,83 & 37,17 \\
\hline Repactuação anual & 148 & \multicolumn{2}{|c|}{$\%$} \\
\hline Sim & & \multicolumn{2}{|c|}{74,32} \\
\hline Não & & \multicolumn{2}{|c|}{9,46} \\
\hline Não sei informar & & \multicolumn{2}{|c|}{16,22} \\
\hline Realização de diagnóstico inicial, pelo GTI, para a implementação do PSE & 262 & \multicolumn{2}{|c|}{$\%$} \\
\hline Sim & & \multicolumn{2}{|c|}{59,54} \\
\hline Não & & \multicolumn{2}{|c|}{30,53} \\
\hline Não sei informar & & \multicolumn{2}{|c|}{9,92} \\
\hline $\begin{array}{l}\text { Articulação intrasetorial do GTI para a execução das ações do PSE } \\
\text { (áreas da Secretaria Municipal de Saúde) }\end{array}$ & & $\operatorname{sim}(\%)$ & não (\%) \\
\hline Saúde bucal & 255 & 89,02 & 10,98 \\
\hline Alimentação e Nutrição & 255 & 79,22 & 20,78 \\
\hline Saúde da criança & 255 & 72,94 & 27,06 \\
\hline Saúde do adolescente & 255 & 71,76 & 28,24 \\
\hline Saúde mental & 255 & 53,94 & 46,06 \\
\hline Promoção da saúde & 255 & 27,84 & 72,16 \\
\hline Vigilância em saúde & 255 & 18,82 & 81,18 \\
\hline Imunização & 255 & 9,80 & 90,20 \\
\hline $\begin{array}{l}\text { Articulação intersetorial do GTI para a execução das ações do PSE } \\
\text { (outros setores) }\end{array}$ & 257 & 66,93 & 33,07 \\
\hline Setores & & $\operatorname{sim}(\%)$ & não (\%) \\
\hline $\begin{array}{l}\text { Outras secretarias municipais (agricultura, cultura, meio ambiente, } \\
\text { assistência social, etc) }\end{array}$ & 154 & 68,18 & 31,82 \\
\hline Secretaria Estadual de Saúde & 154 & 35,06 & 64,94 \\
\hline Secretaria Estadual de Educação & 154 & 32,47 & 67,53 \\
\hline Universidades & 154 & 16,88 & 83,12 \\
\hline Organizações não governamentais & 154 & 16,23 & 83,77 \\
\hline Entidades religiosas & 154 & 3,90 & 96,10 \\
\hline Associações comunitárias & 154 & 1,95 & 98,05 \\
\hline Extensão rural & 154 & 1,30 & 98,70 \\
\hline outros & 154 & 5,19 & 94,81 \\
\hline Frequência de reuniões do GTI & 259 & & \\
\hline Semanal/quinz/mensal & & & \\
\hline Bimestral/trimestral & & & \\
\hline Semestral/anual & & & \\
\hline O GTI não se reuniu no último ano & & & \\
\hline \multirow[t]{2}{*}{ Não sabe informar } & & \multicolumn{2}{|c|}{6,19} \\
\hline & & $\operatorname{sim}(\%)$ & não (\%) \\
\hline $\begin{array}{l}\text { Realização de reuniões entre o GT e a equipe da alimentação escolar do } \\
\text { município para discussão do cardápio oferecido pela alimentação escolar }\end{array}$ & 263 & 37,26 & 62,74 \\
\hline
\end{tabular}


No que se refere à frequência das atividades do Grupo de Trabalho Intersetorial, por volta de $45 \%$ realizam reuniões com frequência igual ou inferior a de encontros mensais, cerca de um terço realizam reuniões com periodicidades que variam de bimestrais a anuais e pouco mais de $10 \%$ dos entrevistados afirmaram que o GTI não havia realizado reuniões no último ano. Ao ser questionado sobre a atuação do GTI com a equipe da alimentação escolar, para discussão da alimentação oferecida para os escolares apenas 37,3\% dos respondentes afirmaram realizar esta ação, embora esta não seja uma ação obrigatória do GTI (Tabela 4).

\subsubsection{Resultado}

O componente do Resultado está descrito nas Tabelas de 5 a 7. As ações de alimentação e nutrição relacionadas ao componente I do Programa estão descritas na Tabela 5. As atividades de avaliação do estado nutricional dos escolares, antes da implantação do PSE, eram realizadas por pouco menos da metade dos respondentes, sendo as ações desenvolvidas, em grande parte, pelas equipes de saúde.

Praticamente todos os respondentes afirmaram que as ações do PSE acontecem prioritariamente no ambiente da escola e cerca de $40 \%$ também desenvolvem ações na UBS. Aproximadamente um quinto dos respondentes afirmou utilizar outro espaço da comunidade para a realização das ações do Programa. No que se refere à atuação no território (Tabela 5) $66 \%$ dos gestores afirmaram, que as ações são desenvolvidas pelas equipes da ESF, 
nas escolas do seu território e pouco menos de metade atua também em escolas fora da sua área de cobertura.

Atualmente $85,4 \%$ dos respondentes afirmaram realizar a avaliação do estado nutricional, que é uma das ações previstas no Programa, sendo que na maioria dos casos a ação é desenvolvida na escola, pela equipe de saúde e em aproximadamente em metade dos municípios, os professores também desempenham esta tarefa. Ao serem questionados quanto à periodicidade da avaliação do estado nutricional, 34,1\% dos respondentes afirmaram que a mesma é realizada anualmente, 26,4\% semestralmente, $12,5 \%$ trimestralmente, $8,5 \%$ a cada dois meses e $18,4 \%$ afirmaram que a ação é realizada mensalmente. Verifica-se que 85,9\% dos entrevistados afirmaram realizar a classificação do estado nutricional. Quase totalidade dos respondentes $(96,1 \%)$ afirmou que, quando casos de extremos nutricionais (desnutrição ou obesidade) são encontrados, estes são encaminhados para algum serviço de saúde.

Quando questionados sobre o local de encaminhamento dos escolares, quando necessário, 64,1\% encaminham os escolares para a Atenção Básica e 26,6\% encaminham não apenas para Atenção Básica, mas também para outros pontos da rede de atenção a saúde. Cerca de $70 \%$ dos respondentes confirmaram a presença de um fluxo de encaminhamento para a UBS de educandos diagnosticados com baixo peso ou excesso de peso e cerca de 73,9\% afirmam fazer o registro de dados de saúde dos escolares. O sistema de informação mais citado foi o SISVAN, seguido do SIMEC - Sistema 
Integrado de Monitoramento Execução e Controle do Ministério da Educação ${ }^{14}$ (Tabela 5).

Tabela 5 - Distribuição das ações de alimentação e nutrição do Componente I Avaliação do estado nutricional dos escolares do PSE, e atuação das equipes no território. Brasil, 2014.

\begin{tabular}{|c|c|c|c|}
\hline & $\mathrm{n}$ & \multicolumn{2}{|c|}{$\%$} \\
\hline \multicolumn{4}{|l|}{ Componente I - Avaliação das condições de Saúde } \\
\hline $\begin{array}{l}\text { Realização de ações de avaliação do estado nutricional dos escolares } \\
\text { como atividade de rotina antes do PSE ser implementado }\end{array}$ & 271 & $\%$ & \\
\hline Sim & & 42,44 & \\
\hline Não & & 40,22 & \\
\hline Não sei informar & & 17,34 & \\
\hline Quem desenvolvia as ações & & $\operatorname{sim}(\%)$ & Não (\%) \\
\hline Saúde & 104 & 79,81 & 20,19 \\
\hline Educação & 104 & 53,85 & 46,15 \\
\hline Outros setores & 104 & 4,81 & 95,19 \\
\hline Local onde as ações são realizadas & & $\operatorname{sim}(\%)$ & não (\%) \\
\hline Escola & 268 & 98,51 & 1,49 \\
\hline UBS & 268 & 39,93 & 60,07 \\
\hline Hospital & 268 & 1,87 & 98,13 \\
\hline Centro de especialidade & 268 & 2,61 & 97,39 \\
\hline Outro espaço da comunidade & 268 & 19,03 & 80,97 \\
\hline Organização do município para a ação & & $\operatorname{sim}(\%)$ & não (\%) \\
\hline Equipe de Saúde da Família cuida das escolas do território & 273 & 66,04 & 33,96 \\
\hline Equipe volante & 273 & 3,40 & 96,60 \\
\hline Equipe de saúde específica para as ações do PSE & 273 & 11,70 & 88,30 \\
\hline $\begin{array}{l}\text { Equipe Atenção Básica/Saúde da Família cobre escolas dentro e fora do } \\
\text { seu território }\end{array}$ & 273 & 41,89 & 58,11 \\
\hline $\begin{array}{l}\text { Avaliação do estado nutricional dos escolares desenvolvida com a ESF } \\
\text { em parceria com a equipe da escola }\end{array}$ & 260 & & \\
\hline Sim & & & \\
\hline Não & & & \\
\hline Profissionais desenvolvem a ação & & $\operatorname{sim}(\%)$ & não (\%) \\
\hline Equipe $A B / E S F$ & 221 & 81,82 & 18,18 \\
\hline Professores & 221 & 50,23 & 49,77 \\
\hline NASF & 221 & 31,22 & 68,78 \\
\hline Nutricionista Alimentação escolar & 221 & 31,22 & 68,78 \\
\hline Funcionários da escola & 221 & 25,34 & 74,66 \\
\hline Alunos & 221 & 19,00 & 81,00 \\
\hline
\end{tabular}

${ }^{14}$ O SIMEC é um sistema operacional desenvolvido pelo Ministério da Educação e que possui um espaço específico para registro das ações do Programa Saúde na Escola. Disponível em http://simec.mec. gov.br/ 


\begin{tabular}{|c|c|c|c|}
\hline Gestores municipais do PSE & 221 & 9,95 & 90,05 \\
\hline GTI & 221 & 5,43 & 94,57 \\
\hline Outros & 221 & 3,62 & 96,38 \\
\hline Familiares & 221 & 0,91 & 99,09 \\
\hline Frequência de avaliação do estado nutricional dos escolares & 223 & \multicolumn{2}{|c|}{$\%$} \\
\hline Anual & & \multicolumn{2}{|c|}{34,08} \\
\hline Semestral & & \multicolumn{2}{|c|}{26,46} \\
\hline Trimestral & & \multicolumn{2}{|c|}{12,56} \\
\hline Bimestral & & \multicolumn{2}{|c|}{8,52} \\
\hline Mensal & & \multicolumn{2}{|c|}{18,39} \\
\hline Realização da classificação do estado nutricional pela equipe de saúde & 256 & 85,94 & 14,06 \\
\hline $\begin{array}{l}\text { Encaminhamento dos casos de desnutrição e excesso de peso são para } \\
\text { o serviço de saúde }\end{array}$ & 258 & 96,12 & 3,88 \\
\hline Local de encaminhamento & 248 & \multicolumn{2}{|c|}{$\%$} \\
\hline Atenção Básica & & \multicolumn{2}{|c|}{64,11} \\
\hline Ambulatório de especialidade & & \multicolumn{2}{|c|}{6,85} \\
\hline Hospital & & \multicolumn{2}{|c|}{0,81} \\
\hline$A B$ e outros pontos & & \multicolumn{2}{|c|}{26,61} \\
\hline Outros pontos da Rede de Saúde & & \multicolumn{2}{|c|}{1,61} \\
\hline & & $\operatorname{Sim}(\%)$ & não (\%) \\
\hline $\begin{array}{l}\text { Presença de fluxo de encaminhamento para a UBS de educandos } \\
\text { diagnosticados com baixo peso ou excesso de peso }\end{array}$ & 256 & 71,88 & 28,12 \\
\hline Registro dos dados em sistema de informação & 257 & 73,93 & 26,07 \\
\hline \multicolumn{4}{|l|}{ Sistema } \\
\hline SISVAN & & 65,36 & 34,64 \\
\hline SIMEC & & 42,60 & 57,40 \\
\hline Sistema Próprio do M unicípio & & 16,76 & 83,24 \\
\hline Outro & & 27,93 & 72,07 \\
\hline
\end{tabular}

As ações do componente II estão descritas na Tabela 6. Dentre os eixos listados neste componente do Programa, a temática mais citada foi a de Promoção da alimentação adequada saudável, seguidas pelas temáticas de Educação para a saúde sexual e reprodutiva; Prevenção ao uso do álcool, tabaco e outras drogas e Promoção da atividade física. Segundo os entrevistados, 92,1\% das ações de promoção são realizadas em parceria das equipes de saúde. Ao se questionar quais atividades de Promoção da alimentação adequada e saudável eram desenvolvidas, as mais citadas foram 
palestras, ações coletivas em saúde/grupos e dia ou semana da alimentação saudável; as ações menos citadas foram visitas externas, atividades culturais e gincanas e jogos. A maioria das ações tem frequência semestral, $21,3 \%$ realizam as ações anualmente enquanto 16,3\% mensalmente.

Tabela 6 - Distribuição das ações de alimentação e nutrição do Componente II - Ações de promoção da saúde e prevenção das doenças e agravos. Brasil, 2014.

\begin{tabular}{|c|c|c|c|}
\hline \multirow{2}{*}{\multicolumn{2}{|c|}{$\begin{array}{cc}\text { Componente II - Ações de promoção da saúde e prevenção das doenças e agravos } \\
\text { Con }\end{array}$}} & \multicolumn{2}{|c|}{$\%$} \\
\hline & & & \\
\hline \multicolumn{2}{|c|}{ Ações de promoção da saúde: } & $\operatorname{sim}(\%)$ & não (\%) \\
\hline Promoção da alimentação adequada e saudável & 248 & 95,16 & 4,84 \\
\hline Educação para a saúde sexual e reprodutiva & 243 & 93,00 & 7,00 \\
\hline Prevenção ao uso do álcool, tabaco e outras drogas. & 244 & 92,62 & 7,38 \\
\hline Promoção da atividade física & 236 & 83,90 & 16,10 \\
\hline $\begin{array}{l}\text { Realização de atividades de Promoção da alimentação adequada e } \\
\text { saudável pela equipe de saúde, em parceria com a equipe da escola }\end{array}$ & 255 & 92,16 & 7,84 \\
\hline \multicolumn{4}{|l|}{ Ações desenvolvidas } \\
\hline Palestra & 258 & 89,53 & 10,47 \\
\hline Ações coletivas em saúde/grupos & 258 & 60,08 & 39,92 \\
\hline Dia ou semana da alimentação saudável & 258 & 47,67 & 52,33 \\
\hline Outras atividades & 258 & 15,50 & 84,50 \\
\hline Horta escolar & 255 & 13,33 & 86,67 \\
\hline Oficinas culinárias & 258 & 13,18 & 86,82 \\
\hline Gincanas/jogos & 258 & 9,69 & 90,31 \\
\hline Ação cultural (Exposição/música) & 258 & 3,88 & 96,12 \\
\hline Visitas externas & 258 & 1,55 & 98,45 \\
\hline Periodicidade das ações de promoção da alimentação saudável & 239 & \multicolumn{2}{|c|}{$\%$} \\
\hline Mensal & & \multicolumn{2}{|c|}{16,32} \\
\hline Bimestral & & \multicolumn{2}{|c|}{12,97} \\
\hline Trimestral & & \multicolumn{2}{|c|}{20,08} \\
\hline Semestral & & \multicolumn{2}{|c|}{29,29} \\
\hline Anual & & \multicolumn{2}{|c|}{21,34} \\
\hline
\end{tabular}

A Tabela 7 apresenta os dados referentes à Semana Saúde na Escola no ano de 2012. Dos municípios entrevistados $62,4 \%$ realizaram a ação no ano de 2012. Dentre as atividades propostas para a semana, "Atividades 
educativas de Promoção da alimentação adequada e saudável e modos de vida saudáveis" foram realizadas por cerca de três quartos dos entrevistados, seguidas das atividades sobre a temática da saúde sexual, saúde reprodutiva, prevenção DST/Aids. Ao serem questionados a respeito da sua opinião relativa à realização da Semana, dois terços afirmaram ser uma boa estratégia de mobilização. Apenas $2,4 \%$ afirmaram que a ação tem baixa adesão entre as escolas e os jovens e 1,2\% afirmaram que a semana atrapalha as atividades da equipe de saúde.

Tabela 7 - Distribuição das atividades realizadas na Semana Saúde na Escola no ano de 2012. Brasil, 2014.

\begin{tabular}{|c|c|c|c|}
\hline & $\mathrm{n}$ & $\operatorname{sim}(\%)$ & não (\%) \\
\hline Realização da semana Saúde na escola no ano de 2012 & 250 & 62,40 & 37,60 \\
\hline \multicolumn{4}{|l|}{ Atividades foram realizadas na Semana Saúde na Escola 2012} \\
\hline $\begin{array}{l}\text { Atividades educativas de Promoção da alimentação adequada e saudável } \\
\text { e modos de vida saudáveis }\end{array}$ & 205 & 71,22 & 28,78 \\
\hline $\begin{array}{l}\text { Atividades educativas sobre a temática da saúde sexual, saúde } \\
\text { reprodutiva, prevenção DST/Aids }\end{array}$ & 196 & 59,18 & 40,82 \\
\hline $\begin{array}{l}\text { Atividades educativas sobre a temática dos riscos do uso de álcool, tabaco, } \\
\text { crack e outras drogas }\end{array}$ & 191 & 57,59 & 42,41 \\
\hline $\begin{array}{l}\text { Atividades educativas sobre diversidade sexual, bullying, homofobia, } \\
\text { discriminação e preconceito }\end{array}$ & 187 & 45,99 & 54,01 \\
\hline \multicolumn{4}{|l|}{ Opinião sobre a realização da Semana Saúde na Escola } \\
\hline $\begin{array}{l}\text { É uma boa estratégia de mobilização e auxilia o trabalho de temáticas } \\
\text { específicas }\end{array}$ & 257 & 63,05 & 36,95 \\
\hline Atrapalha as atividades da equipe de saúde por conta da mobilização & 257 & 1,20 & 98,80 \\
\hline Tem baixa adesão das escolas e jovens & 257 & 2,41 & 97,59 \\
\hline Auxilia na divulgação do PSE e de suas ações & 257 & 24,90 & 75,10 \\
\hline
\end{tabular}




\subsection{Avaliação da evolução do estado nutricional de crianças e adolescentes com idades entre 7 e 18 anos}

A Tabela 8 apresenta o total de dados analisados para cada um dos anos, de acordo com o sexo. Foram excluídos todos os valores de peso e altura considerados fora do padrão, conforme descrito na metodologia. Ao se calcular os índices antropométricos também foram excluídos os valores considerados implausíveis.

Tabela 8 - Distribuição de número de registros avaliados do SISVAN-Web, segundo sexo e ano. Brasil, 2014.

\begin{tabular}{cccccc}
\hline \multirow{2}{*}{ Ano } & \multicolumn{2}{c}{ Masculino } & \multicolumn{2}{c}{ Feminino } & \multirow{2}{*}{ Total } \\
& $\mathbf{n}$ & $\%$ & $\mathbf{n}$ & $\%$ & \\
\hline 2008 & 31.086 & 26,24 & 87.364 & 73,76 & 11845 \\
2009 & 60.509 & 33,59 & 119.616 & 66,41 & 180125 \\
2010 & 51.818 & 38,21 & 83.807 & 61,79 & 135625 \\
2011 & 64.903 & 38,72 & 102.706 & 61,28 & 167609 \\
2012 & 89.147 & 41,79 & 124.170 & 58,21 & 213317 \\
\hline
\end{tabular}

Para a validação dos valores encontrados para o peso e altura, as medianas dos valores foram comparados com dois valores de referência, os valores da Pesquisa de Orçamentos Familiares - POF, 2008/9 (IBGE, 2010a) e da referência proposta pela Organização Mundial da Saúde (DE ONIS, 2007). A Figura 9 apresenta a mediana da altura, dos indivíduos do sexo masculino, acompanhados pelo SISVAN nos anos de 2008 a 2012 e os valores da POF e da OMS para o mesmo grupo etário. Os dados da mediana, para cada idade e sexo estão descritos no Anexo E. 
Figura 9 - Mediana da altura, de indivíduos do sexo masculino, com idades entre 7 e 18 anos com dados registrados no SISVAN-Web, comparado com POF 2008/9 e com OMS 2007. Brasil, 2014.

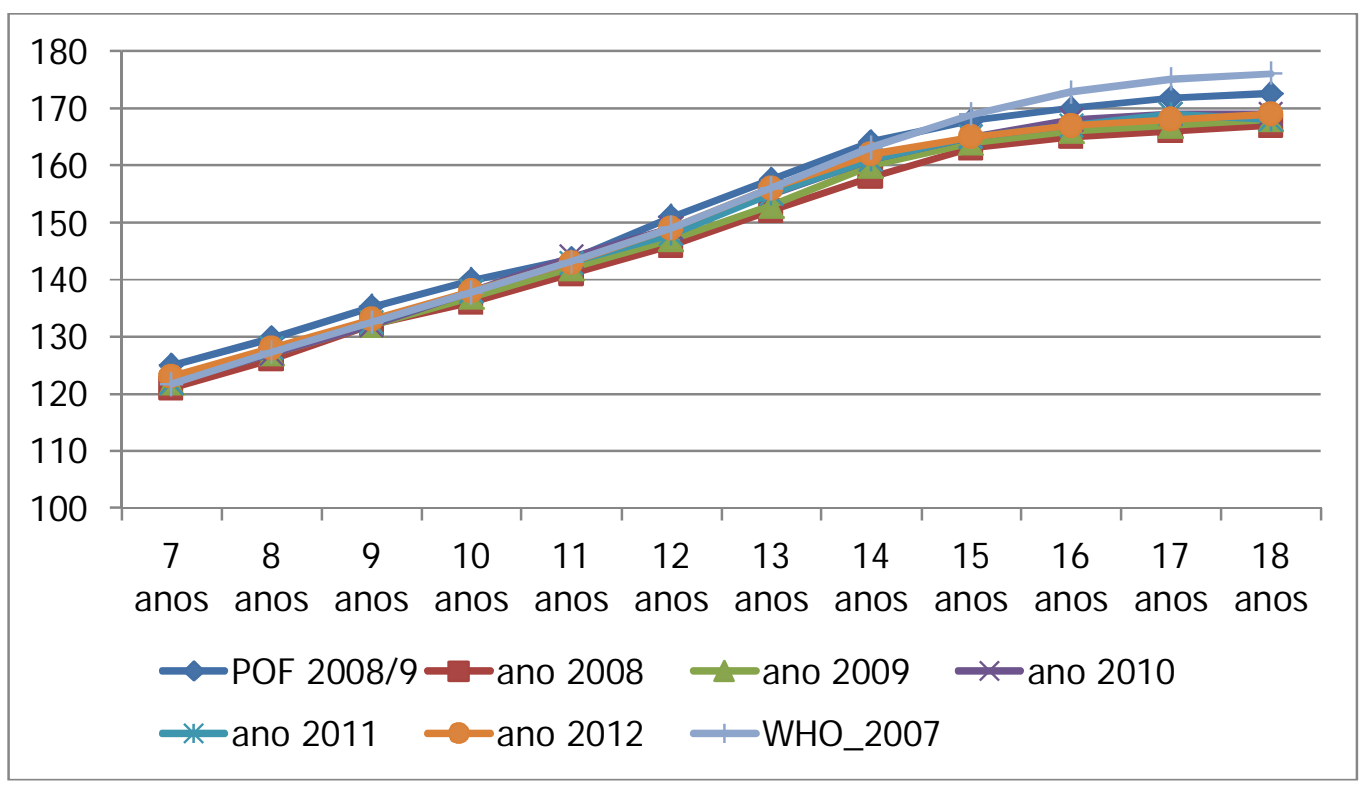

Figura 10 - Mediana da altura, de indivíduos do sexo feminino, com idades entre 7 e 18 anos com dados registrados no SISVAN-Web, comparado com POF 2008/9 e com OMS 2007. Brasil, 2014.

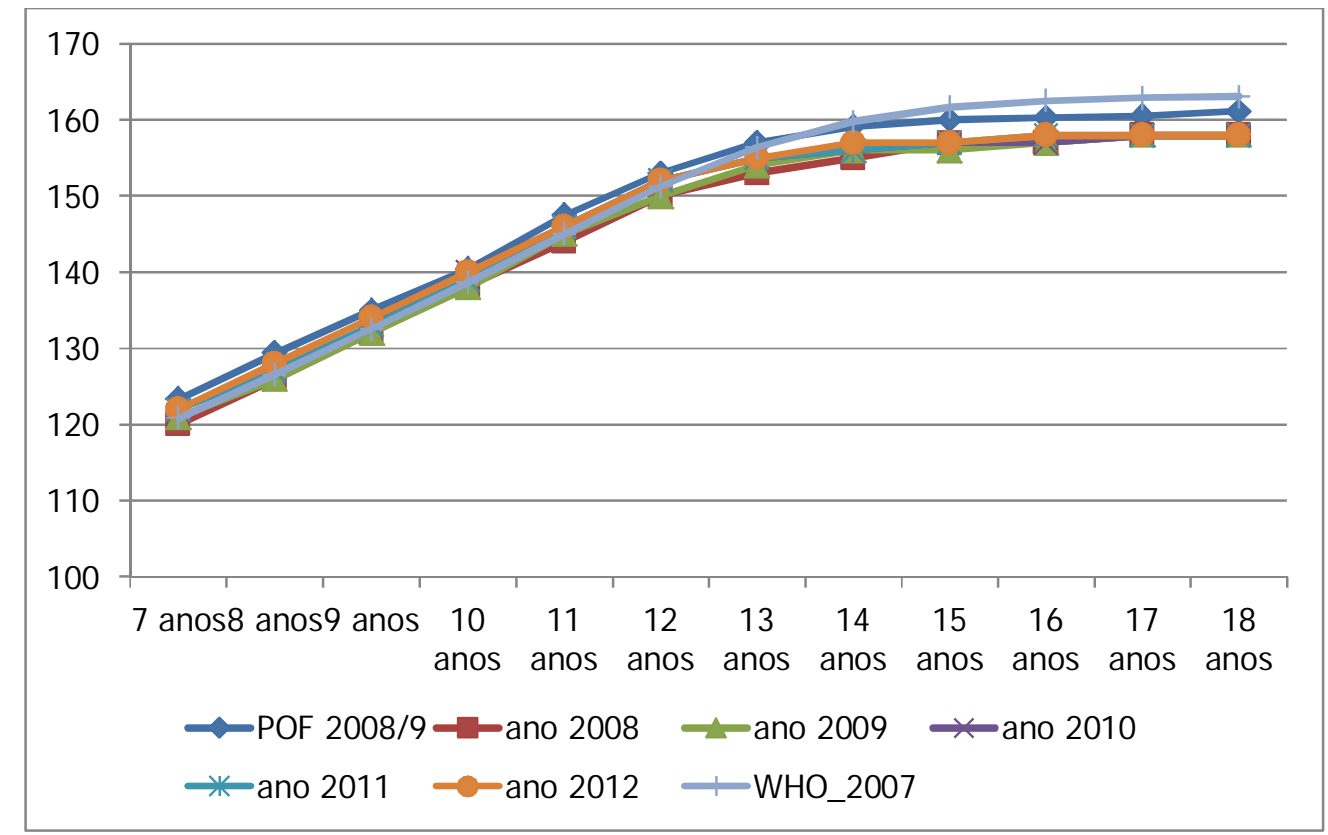


A mesma comparação foi realizada para as medianas da altura, dos indivíduos do sexo feminino, acompanhadas pelo SISVAN no período de 2008 a 2012 (Figura 10). Para ambos os sexos, a mediana da idade é praticamente igual no período entre 7 e 13 anos de idade e sendo inferior aos dados referentes ao inquérito e à referência da OMS nas idades acima de 15 anos para os meninos e acima dos 13 anos para as meninas.

As medianas do peso estão apresentadas nas Figuras 11 e 12 . Ao se comparar os dados do sexo masculino, observa-se que os dados da mediana de peso, oriundos da POF 2008-9, sempre foram superiores aos valores registrados tanto no SISVAN-Web e ao serem comparados com os valores da OMS, esta tendência se inverte ao 15 anos de idade (Figura 11). No sexo feminino esta tendência observada é semelhante com inversão dos valores acima dos 12 anos. 
Figura 11 - Mediana do peso, de indivíduos do sexo masculino, com idades entre 7 e 18 anos com dados registrados no SISVAN-Web, comparado com POF 2008/9 e com OMS 2007. Brasil, 2014.

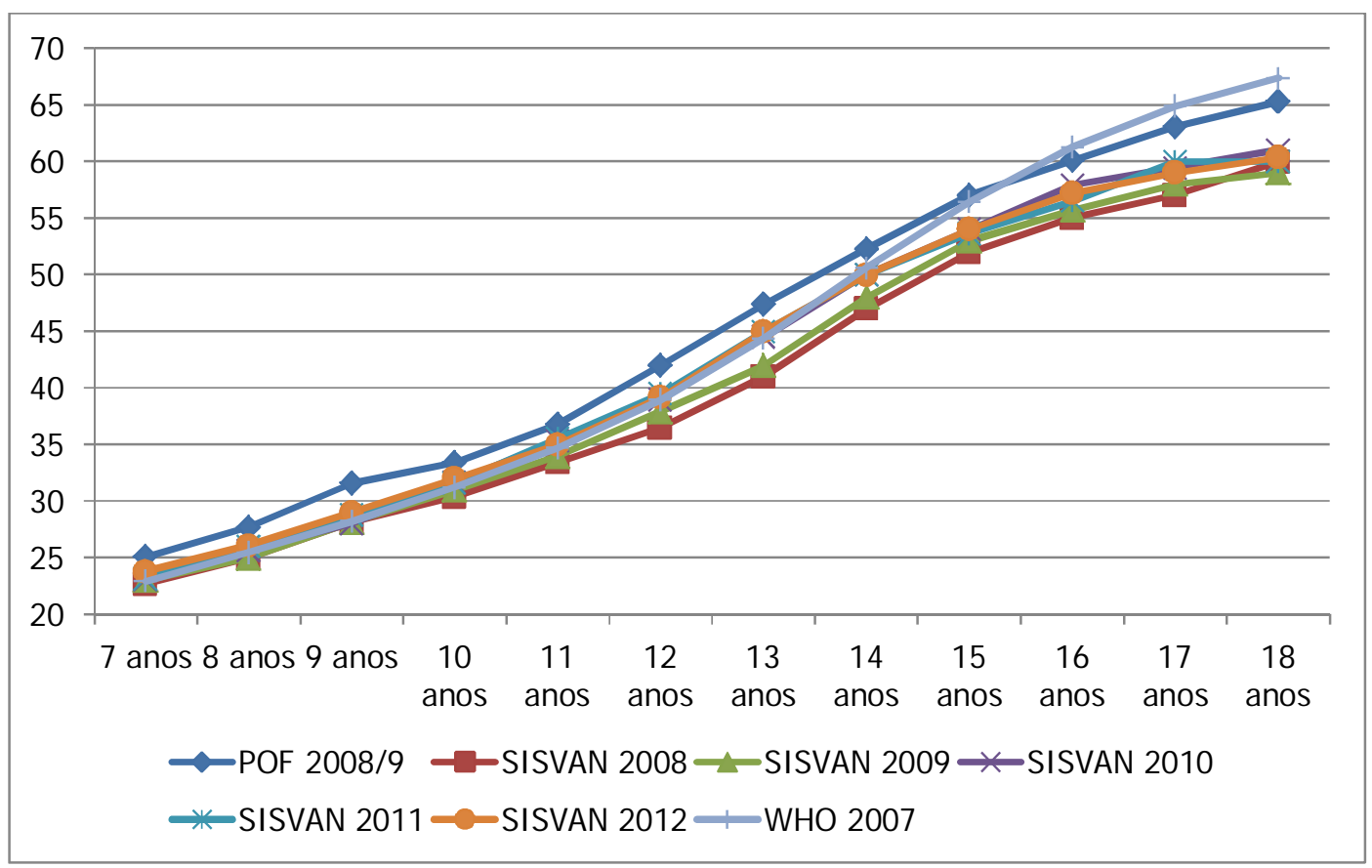

Figura 12 - Mediana do peso, de indivíduos do sexo feminino, com idades entre 7 e 18 anos com dados registrados no SISVAN-Web, comparado com POF 2008/9 e com OMS 2007. Brasil, 2014.

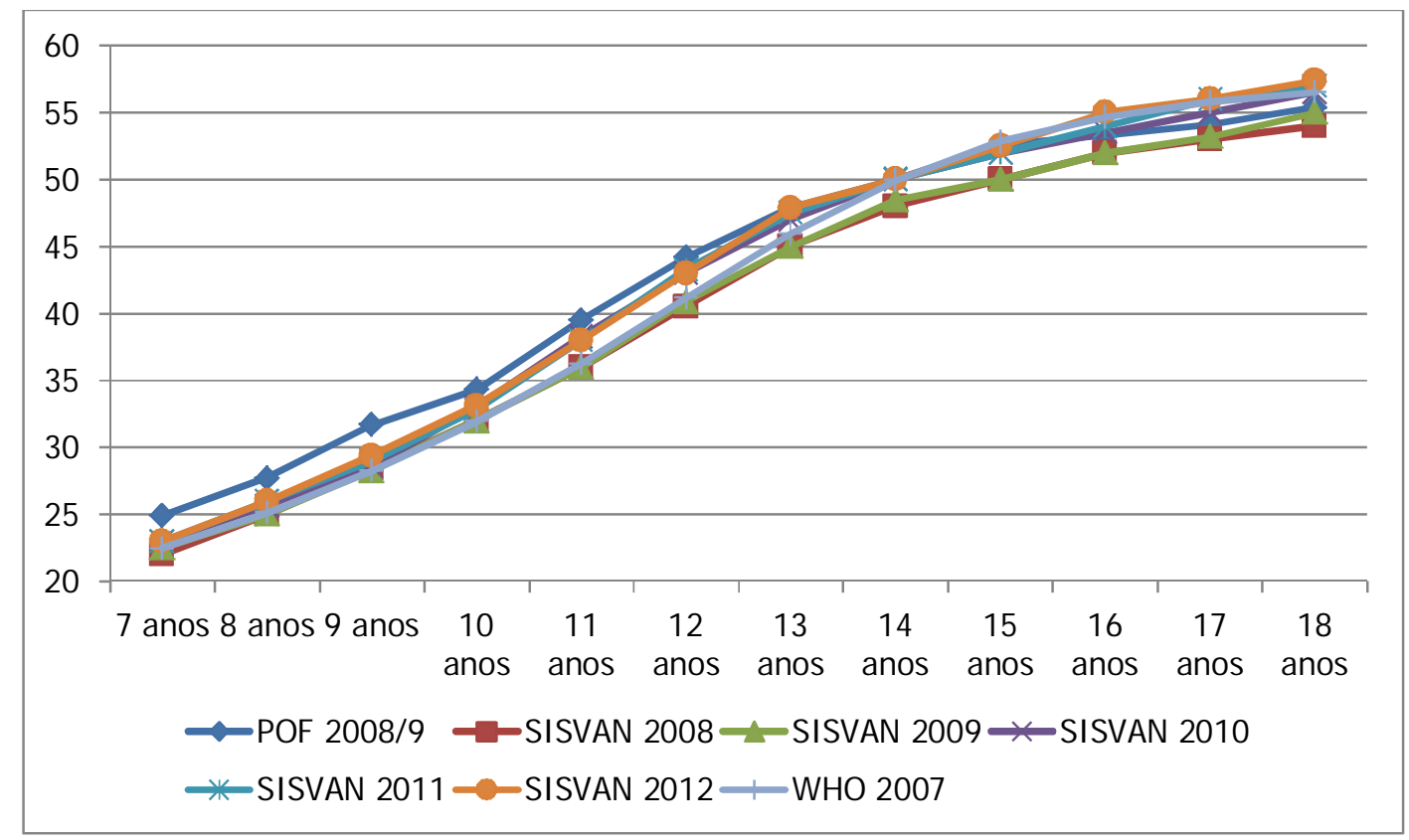


Figura 13 - Variação dos valores médios de escore-Z do Índice de Massa Corporal para a Idade, de indivíduos de ambos os sexos, com idades entre 7 e 18 anos, acompanhados pelo SISVAN, no período de 2008 a 2012. Brasil, 2014.

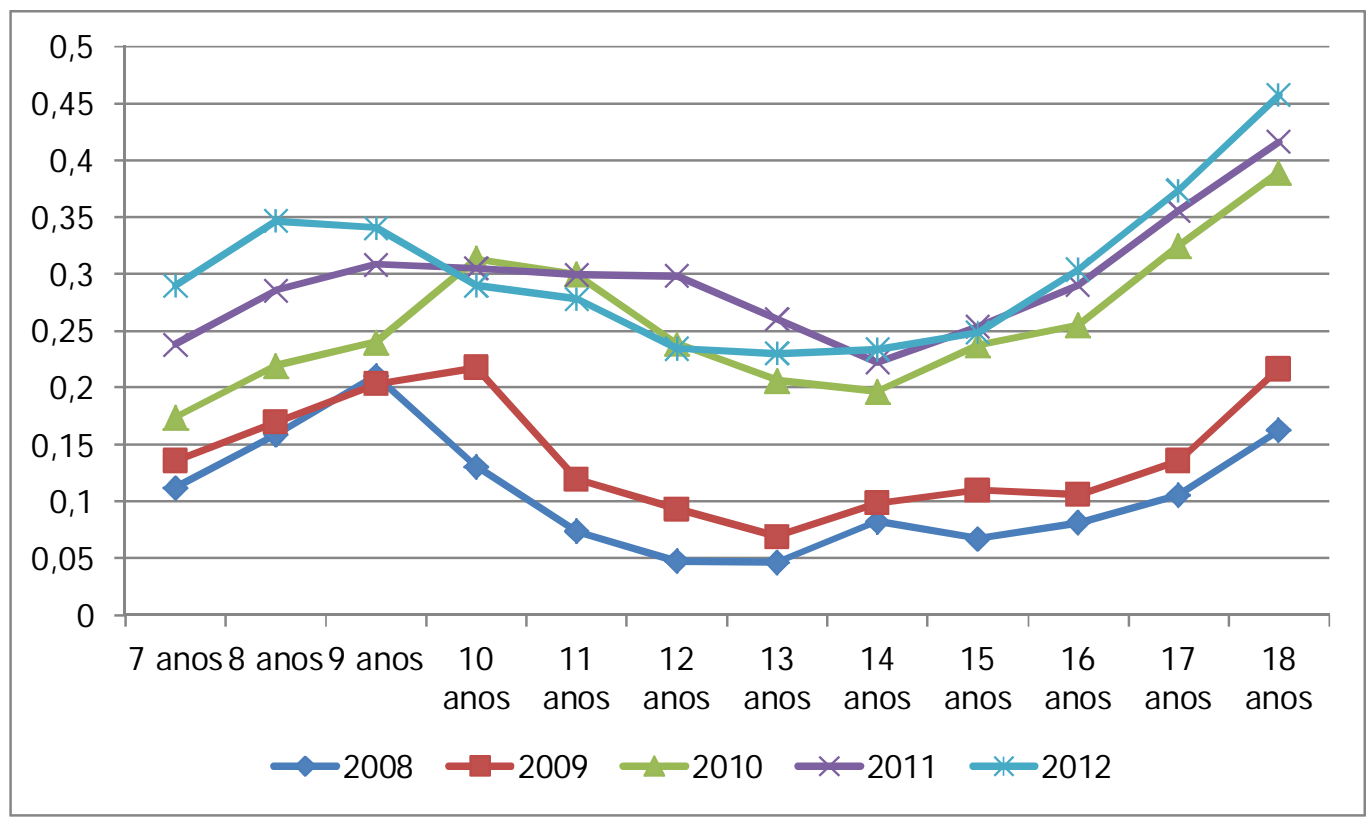

A variação do estado nutricional dos escolares foi feita a partir da evolução da média do escore-Z do IMC para a idade. O compilado geral da variação, de ambos os sexos está descrito na Figura 13. Nota-se que anualmente o valor médio do escore-Z do IMC para a idade sofre um pequeno aumento, variando de 0,1 na idade 7 anos a 0,45 na idade 18 . Na comparação geral observou-se que os valores mais altos estão alocados nas idades extremas do Figura (7 e 18 anos). Pode-se perceber que a flutuação tem um padrão que segue praticamente igual ao longo dos anos observados e que a curva apresenta 2 importantes pontos de declive, situados nas idade de 10 e 14 anos. No período correspondente dos 7 aos 10 anos há um 
incremento no valor médio do escore-Z de IMC para a idade. No período entre 10 e 14 anos a curva apresenta uma inflexão, com redução dos valores e aos 14 anos a curva retoma o seu crescimento.

As Figuras 14 e 15 apresentam os dados organizados por sexo, masculino e feminino, respectivamente. A evolução do estado nutricional ocorre de maneira completamente diferente entre os sexos. Aos 7 anos de idade as médias de escore-Z de IMC para a idade são superiores no sexo masculino, que apresenta uma queda ao longo do período escolar. A maior oscilação ocorre entre os 10 e 14 anos de idade e as menores médias foram encontradas aos 18 anos (Figura 14).

Figura 14 - Variação dos valores médios de escore-Z do Índice de Massa Corporal para a Idade, de indivíduos do sexo masculino, com idades entre 7 e 18 anos, acompanhados pelo SISVAN, no período de 2008 a 2012. Brasil, 2014.

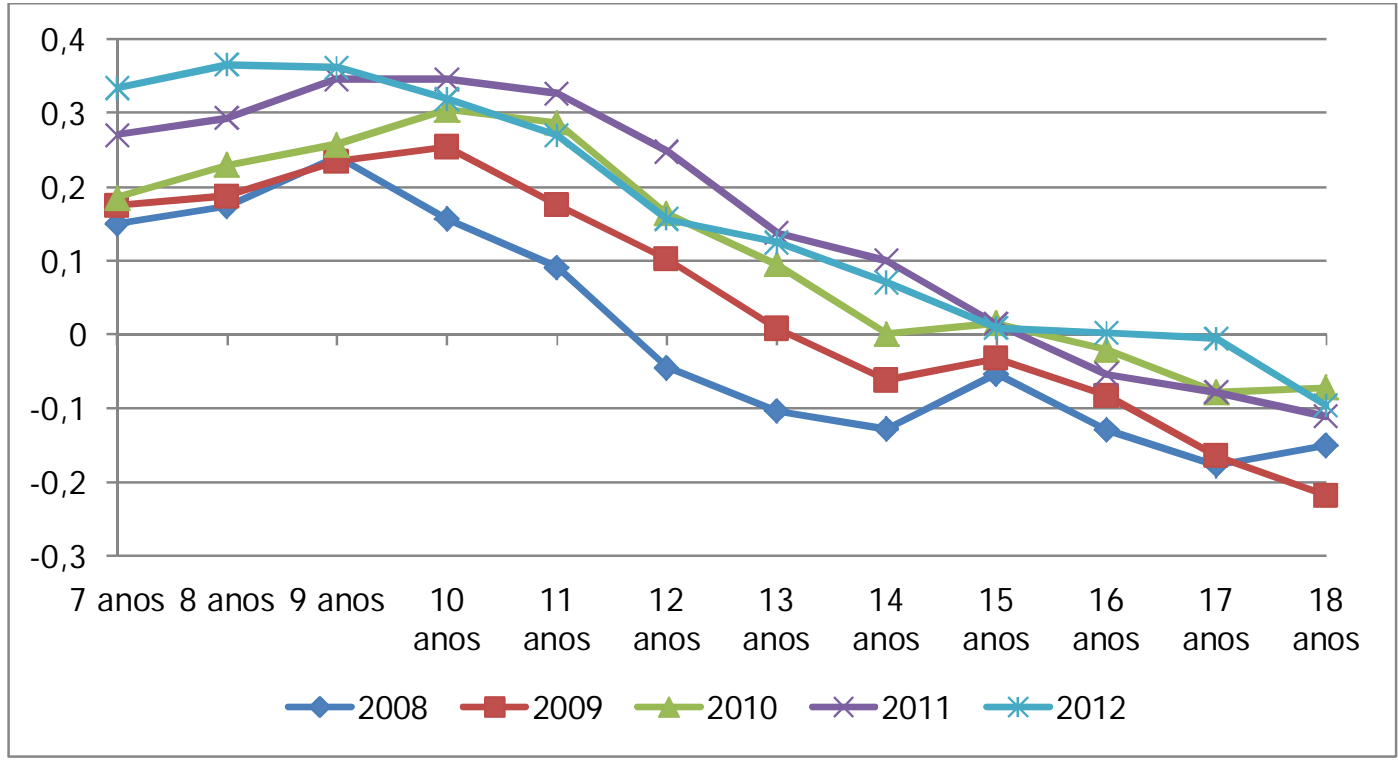


Figura 15 - Variação dos valores médios de escore-Z do Índice de Massa Corporal para a Idade, de indivíduos do sexo feminino, com idades entre 7 e 18 anos, acompanhados pelo SISVAN, no período de 2008 a 2012. Brasil, 2014.

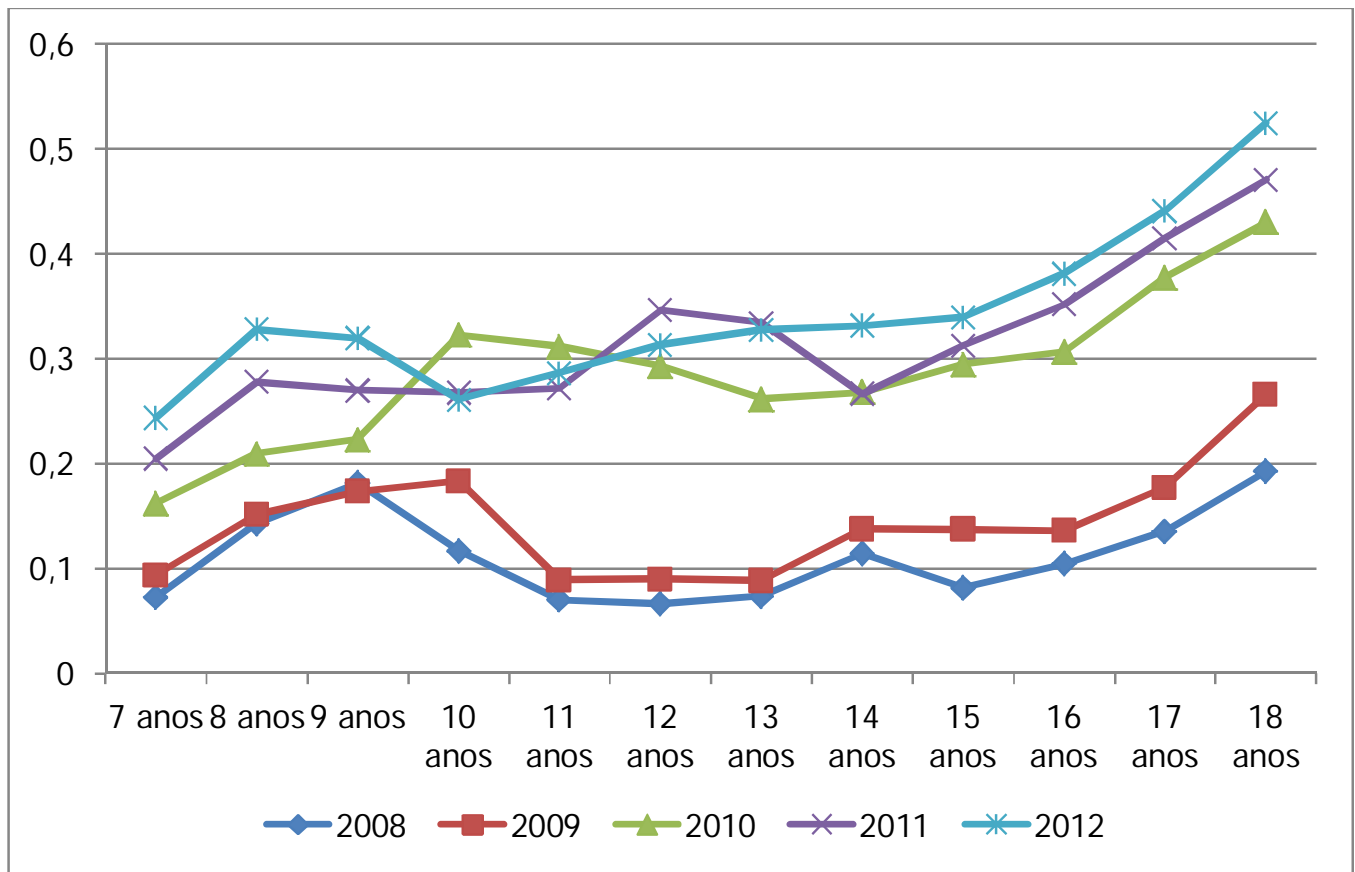

O sexo feminino apresenta um comportamento diferente do masculino (Figura 15). Entre o período de 7 a 14 anos há uma pequena oscilação nas médias e a curva se torna ascendente a partir dos 14 anos, com elevação em todos os períodos analisados. Embora apresente diferenças entre os sexos, ambos apresentam um incremento positivo do escore- $Z$ ao longo dos anos.

Os valores referentes as prevalências do estado nutricional dos indivíduos analisados, por sexo, idade e ano de acompanhamento estão descritos no Anexo F: Distribuição de desvios nutricionais (baixo peso, sobrepeso e obesidade) segundo idade e sexo, de indivíduos acompanhados SISVAN no anos de 2008 a 2012. 


\section{Di scu ssão}

Nas últimas décadas houve um aumento do investimento em políticas públicas e programas governamentais e com isso movimentos internacionais de apoio à avaliação destas ações vêm sendo estimulados. A avaliação tem como uma de suas funções, conhecer os resultados e redirecionar os rumos das ações, quando necessário. No Brasil, os investimentos na avaliação dessas políticas e programas ainda é prática incipiente, e requer esforços tanto do setor público como do acadêmico para que o poder público possa avaliar suas iniciativas e investimentos de maneira sistêmica e como parte do processo de gestão de suas ações (HENRI QUE et al., 2007).

A escola é um espaço importante para a realização de intervenções que podem mudar a tendência atual de aumento da obesidade em escolares. Estudos apontam que medidas relacionadas à alimentação e ao bem estar, tanto dos professores como dos escolares, tendem a ser mais bem sucedidos e com maior durabilidade (BEAM et al., 2012a). Os resultados tendem a ser melhores quando há um investimento no treinamento da equipe que executa o programa e ajuda a fazer a interlocução entre a equipe escolar e a comunidade na qual a escola está inserida. A soma das estratégias: mudança do perfil de alimentos oferecidos, estímulo à prática de atividade física, aliado à ações de capacitação dos professores e articulação comunitária, tendem a ter mais êxito (BEAM et al., 2012b). 
BROWN et al. (2007), em uma revisão sobre intervenções para prevenção da obesidade em escolares afirma que não há evidências convincentes para intervenções que objetivem mudanças no peso corporal, mas que há evidência que programas multi-componentes, que atuam no ambiente escolar, atividade física e alimentação escolar podem ter um efeito positivo na mudanças de hábitos e que a prática regular de atividade física tem efeito positivo na manutenção do peso dos escolares. Intervenções que atuam na mudança do consumo alimentar de crianças podem ser efetivas, principalmente entre aquelas que tem hábitos alimentares não saudáveis. JAIME e LOCK (2009) em outra revisão, que avaliou o efeito das políticas dirigidas às ações de alimentação e nutrição no ambiente escolar sobre o avanço da obesidade em escolares, o autor afirmam que intervenções com mais de um componente tendem a ter melhores resultados, embora haja pouco impacto sobre o IMC como desfecho. As políticas atuais se mostram exitosas no que se refere ao consumo alimentar e ambiente escolar e as escolas tem sido apontadas como um dos principais ambientes para combater a obesidade infantil, sendo de grande importância a avaliação destas politicas, principalmente para a mensuração dos seus efeitos no enfrentamento da obesidade.

Para a análise da implantação do PSE levamos em consideração os atos normativos que regulam o Programa, entendendo que a implantação ocorre quando estas ações ocorrem de maneira rotineira e organizada dentro do território. Segundo LIMA (2012) os resultados da implantação de um 
programa, dependem em parte dos gestores locais, que colocam as diretrizes em prática.

A estrutura está baseada nas ações e na oferta de serviços para que o PSE possa ser desempenhado com qualidade e dentro do esperado pela legislação proposta pelo Governo Federal, discutidas e pactuadas de maneira tripartite (Gestores federais, estaduais e municipais), para que as ações sejam executadas. O primeiro indicador apresentado é referente ao desempenho da educação nos municípios. Percebe-se que os municípios menores apresentam indicadores de desempenho melhor do que os municípios maiores, sendo esta relação inversamente proporcional. A Atenção Básica também está melhor estruturada em municípios maiores que tem maiores coberturas da Estratégia de Saúde da Família, que segundo a PNAB (2011) é a estratégia preferencial de expansão da Atenção Básica dos municípios. O contrário é encontrado quando se analisa a presença de NASF, que é maior nos municípios maiores.

As ações de alimentação e nutrição tendem a ter maior qualificação quando há a presença do profissional nutricionista atuando no território, mas não deve ser ele o único estimulador destas ações. Os achados apontam para pouco menos de metade dos municípios com equipes de NASF e destas, quase três quartos, contam com o nutricionista na equipe, que executam ações nas escolas, matriciando ${ }^{15}$ as equipes de $A B$, mas há pouca interação

15 Segundo o Caderno de Atenção Básica 27 - DI RETRIZES DO NASF: “O apoio matricial será formado por um conjunto de profissionais que não têm, necessariamente, relação direta e cotidiana com o usuário, mas cujas tarefas serão de prestar apoio às equipes de referência (equipes de SF). Assim, se a equipe de referência é composta por um conjunto de profissionais considerados essenciais na 
destas equipes e destes profissionais no planejamento das ações que serão executadas na escola. Foi informado que mais de $90 \%$ dos municípios tem nutricionista trabalhando em algum setor (saúde, educação, assistência social, etc), mas o número de profissionais é baixo. A maioria está lotada nas atividades do PNAE, que pode ser explicado por conta da necessidade de um Responsável Técnico para desenvolver as ações do Programa (Brasil, 2013x, seguido do setor saúde - gestão ou atenção.

A gestão das ações no município é feita, em sua maioria, por enfermeiros, refletindo a inserção deste profissional na gestão das ações em saúde, principalmente na AB. O PSE é um programa que faz parte do escopo de ação da $A B$, mas a sua gestão pode estar em diferentes setores, de acordo com a organização local das Secretarias de Saúde: cerca de metade está alocado na $A B$ e a outra metade em outros setores. Outra questão importante é que pouco mais da metade dos municípios tem um ficha padrão, desenvolvida localmente, para avaliar as condições de saúde dos educandos, o que reflete uma baixa organização central, dentro dos municípios, para a execução das ações locais.

O Programa foi pensado para ser uma ação intersetorial e deveria congregar esforços de atuação tanto dos profissionais da saúde como da educação, mas a realidade mostra que cerca de $10 \%$ dos entrevistados não apontam os professores como responsáveis pela execução das ações do

condução de problemas de saúde dos clientes, eles deverão acionar uma rede assistencial necessária a cada caso ... de forma a assegurar, de modo dinâmico e interativo, a retaguarda especializada nas equipes de referência ... O apoio matricial apresenta as funções de suporte: assistencial e técnicopedagógico".

Disponível em http://189.28.128.100/dab/docs/publicacoes/cadernos_ab/abcad27.pdf 
Programa, que provavelmente é executado localmente, apenas pelas equipes de saúde. No setor saúde, as equipes da ESF são os grandes executores da ação local, podendo estas responder por escolas que estão fora da área de cobertura. Isso pode ser explicado pelo fato de que, no início das atividades, o PSE era vinculado única e exclusivamente as Equipes de SF, tendo esta lógica mudado com o tempo, resultando em outras estratégias possíveis, como as equipes volantes, que fazem apenas as ações do PSE.

Um dos preceitos da $A B$ é a questão do território entendendo que equipamentos sociais que lá estão alocados são de sua responsabilidade e que necessitam de intervenções em saúde (BRASI L, 2012a). A relação das equipes de $A B$ com as escolas, proposta no PSE, são baseadas nesta lógica e deveriam estar, automaticamente, listadas no escopo de atividades e na responsabilidade sanitária das equipes. Por sua vez, a equipe escolar tem o dever de acompanhar e intervir nas ações em saúde voltadas aos escolares. Segundo os Parâmetros Curriculares Nacionais (PCN) os conteúdos de saúde devem ser tratados dentro do currículo escolar de forma transversal e interdisciplinar, integrando as ações cotidianas e contribuindo com o processo de aprendizagem (BRASIL, 1998). Autores afirmam que esse processo ainda é fragmentado e pontual, uma vez que as equipes de saúde comparecem as escolas apenas em momentos pontuais, para a realização de campanhas e na lógica do controle de doenças (FIGUEI REDO et al., 2010).

Por ser um programa alinhado com os princípios e diretrizes do SUS, o PSE deveria ser implementado com a participação efetiva das equipes de 
saúde e educação. Essa interação tende a fornecer aos escolares "uma tutoria de resiliência que Ihes confira proteção contra a dependência química, o risco de câncer, acidentes e violência, doenças sexualmente transmissíveis/aids, gravidez e doenças crônicas" (FIGUEI REDO et al., 2010).

Outra questão importante relacionada a intersetorialidade do Programa é a questão dos Grupos de Trabalho Intersetorial (GTI) que são responsáveis pela gestão do Programa no município. AERTS et al. (2004) afirma que a intersetorialidade pode ser definida como "a articulação de saberes e experiências na identificação participativa de problemas coletivos, nas decisões integradas sobre políticas e investimentos, com o objetivo de obter retornos sociais na perspectiva da inclusão social". As normativas do PSE define que estes grupos devem ter, ao menos, a presença de representantes do setor saúde e da educação para a gestão e planejamento das ações do PSE. Pouco menos de $3 \%$ dos GTI não contavam com a presença de um representante da saúde e cerca de 13\% não contavam com um representante da educação. Em contrapartida, um quinto contavam com representante da Segurança Alimentar e Nutricional - SAN e 15\% com representante de outros setores, ampliando as discussões sobre a gestão local do Programa.

A abordagem intersetorial deve extrapolar a ação apenas do governo, bem como a promoção da saúde deve ser composta por diferentes setores, uma vez que apenas o trabalho desenvolvido, setorialmente ou não, pelos governos não tem se mostrado eficaz para solucionar os problemas e os 
determinantes de saúde (AERTS et al., 2004). Segundo MENDES e AKERMAN (2007), a intersetorialidade deve ser fruto de um processo, organizado e sistemático, com a participação efetiva dos diferentes setores, com um objetivo em comum e implica na equalização dos poderes e horizontalidade das relações.

A estrutura para a execução das ações do Programa pode ser questionada, uma vez que metade dos gestores do Programa não está alocada na $A B$ e nem todos os GTI contavam com saúde e educação na sua composição. A presença de nutricionistas é pequena e a concentração dos profissionais é mais alta na alimentação escolar, que dentre suas atribuições estão previstas ações de avaliação do estado nutricional e de promoção da alimentação adequada e saudável ${ }^{16}$, o que pode ajudar nas ações do Programa, com a melhoria dos cardápios, por exemplo, mas que não garante que esses profissionais atuem diretamente com os escolares ou no apoio ao planejamento das ações. A presença de NASF ainda é baixa, o que poderia potencializar e qualificar as ações de alimentação e nutrição no PSE.

A avaliação do componente do processo foi feita com base nas atividades de pactuação e articulação para a garantia da realização das ações. Uma das "tarefas" na gestão do PSE é a descrição e pactuação das ações no Programa no Plano Municipal de Saúde, o que foi sinalizado por $62,8 \%$ dos respondentes. No processo de discussão municipal três quartos

\footnotetext{
${ }^{16}$ De acordo com o proposto pela Resolução CFN no 465 de 23/08/2010: Dispõe sobre as atribuições do Nutricionista, estabelece parâmetros numéricos mínimos de referência no âmbito do Programa de Alimentação Escolar (PAE) e dá outras providências. Disponível em: http://www.cfn.org. br/novosite/arquivos/Resol-CFN-465-atribuicao-nutricionista-PAE.pdf acessado em 9/03/2014
} 
afirmam que a ação é repactuada anualmente. Ao se tratar do planejamento para iniciar as ações do Programa, apenas 59,5\% afirmaram que o GTI realizou um diagnóstico prévio antes do início das ações do Programa. Pouco menos de $70 \%$ dos GTI se encontram com regularidade (frequências inferiores a reuniões trimestrais), indicando que cerca de um terço dos grupos são pouco atuantes e com baixa periodicidade de atividades. Isto pode refletir numa fraca articulação entre os setores (saúde e educação).

Embora a gestão das ações do PSE deva estar, prioritariamente, na $A B$, é de extrema importância a articulação dos gestores do Programa com as diferentes áreas programáticas da Secretaria de Saúde, a fim de qualificar e reforçar a ação, como a Saúde Bucal, seguida da Alimentação e Nutrição, Saúde da Criança E Saúde do Adolescente. A área da vigilância em saúde foi citada por menos de um quinto dos respondentes. A articulação intersetorial está presente em mais de $60 \%$ dos municípios, com destaque para a articulação com outras Secretarias de governo e Secretarias Estaduais de Saúde e Educação. A articulação com setores fora do governo é pequena, sendo que a Universidade é o órgão que mais aparece na citação dos respondentes. Embora a maioria dos nutricionistas estejam alocados na alimentação escolar, apenas $37 \%$ dos respondentes afirmaram haver reuniões para discussão entre a equipe que cuida do PSE e os profissionais envolvidos na alimentação escolar, cujo Programa tem como um de seus objetivos realizar a educação alimentar e nutricional dos escolares 
beneficiários da ação (BRASIL, 2009) e a interlocução com o PSE poderia ampliar e potencializar esta ação.

O resultado esperado está relacionado à realização das ações previstas nos componentes I (Avaliação Clínica e Psicossocial) e II do Programa. Quem desenvolve as ações, por parte do setor saúde, são as equipes de Saúde da Família, organizadas em diferentes arranjos, de acordo com a organização local. A escola é o lócus central das ações, que também são realizadas nas UBS, conforme afirmado por $40 \%$ dos entrevistados. Ao se avaliar as atividades de avaliação do estado nutricional, cerca de metade dos respondentes informou que a ação era realizada na escola antes do Programa ser executado nos municípios, apontando para uma relação das ações de saúde no contexto escolar que tem um histórico prévio no país. As ações de pesar e medir os escolares são realizadas por quase a totalidade dos respondentes, mas nem todos realizam a avalição do estado nutricional, não dando seguimento para a ação em si, uma vez que as medidas coletadas não são interpretadas, de acordo a com a idade e o sexo, e por sua vez não avaliam corretamente o estado nutricional dos estudantes.

Dentre aqueles que classificam o estado nutricional, praticamente todos afirmaram que os casos extremos (desnutrição ou obesidade) são encaminhados para algum serviço de saúde, mas que nem sempre este serviço é a Atenção Básica. Os respondentes afirmam que os dados dos escolares são registrados em algum sistema de informação, sendo o SISVAN o mais referido. Dados provenientes do SISVAN contestam esta informação, 
uma vez que em 2012 o SISVAN Web apresentou cerca de 900.000 registros de indivíduos entre 7 e 18 anos (excluindo aqueles acompanhados pelo Programa Bolsa Família) valor bem abaixo do total de escolares participantes do PSE no mesmo ano, que segundo dados descritos no Quadro 1, em 2008 o PSE contemplava 1,9 milhão de escolares e no ano de 2012 esta cifra chegou a 11,9 milhões. Esta disparidade entre o acompanhamento e o registro de dados apontam para a necessidade de ações que reforcem com os trabalhadores locais a importância do registro dos dados.

As ações do componente II (Promoção da Saúde e de atividades de Prevenção) estão presentes nas atividades escolares e as ações de promoção da alimentação adequada e saudável foi a mais citada entre as possibilidades apresentadas. As ações de promoção da saúde ainda estão centradas em um modelo de transmissão de conhecimento com a realização de palestras, ações coletivas em saúde/grupos e dia ou semana da alimentação saudável. As atividades mais lúdicas como visitas externas, atividades culturais e gincanas e jogos são pouco praticadas para o desenvolvimento das ações de promoção na escola. Embora aconteçam, a frequência é baixa e aparentemente não estão inseridas de forma concreta nas atividades do currículo escolar, sendo pontuais e sazonais.

As ações de promoção da saúde, desenvolvidas no contexto escolar, devem objetivar o fortalecimento das capacidades dos escolares para atuar no cuidado da própria saúde, correlacionando-as com o conteúdo programático lecionado em sala de aula, sendo este um dos principais 
desafios: aliar a teoria oferecida pela escola na educação formal com a aplicação na vida prática (MOURA et al., 2007). O modelo apresentado de promoção da saúde com predominância de palestras e atividades pouco práticas tende a não concretizar esta vocação da promoção da saúde. A escola, segundo MOURA et al. (2007), pode ser um espaço de humanização e de práticas que gerem promoção da saúde e promovam estilos de vida saudáveis.

Ao serem questionados sobre as atividades da Semana Saúde na Escola do ano de 2012, mais de metade dos entrevistados afirmaram ter realizado a ação e a maioria desenvolveu "Atividades educativas de Promoção da alimentação adequada e saudável e modos de vida saudáveis". De acordo com os entrevistados, a semana tem boa aceitação e ajuda a divulgar e a iniciar as ações do PSE, demonstrando a boa adesão das equipes a uma ação de mobilização específica proposta pelo Governo Federal.

Os resultados apresentados não apontam para uma diferença na implantação do PSE quando se avalia a questão do porte populacional, de acordo com os achados o Programa apresenta desempenho semelhante, independente do porte do município. A adesão ao PSE, durante esse período foi feita de maneira ordenada, de acordo com critérios determinados: No primeiro ano de implantação só eram elegíveis municípios que tivessem 100\% de cobertura da Estratégia Saúde da Família e com IDEB no ano de 2005, menor ou igual a 2,69 nos anos iniciais do ensino fundamental e que 
tivessem $100 \%$ de cobertura populacional por Equipes Saúde da Família e municípios participantes do Programa Mais Educação. Isso fez com que neste ano, tivessem municípios de grande porte e pequenos municípios. Ao longo dos anos (2009 a 2011) a maior cobertura de Estratégia Saúde da Família diminui a sua importância na estratégia de elegibilidade ao programa, permitindo que municípios com $70 \%$ de cobertura populacional pudessem aderir ao Programa, aliado a valores mais altos de IDEB. Apenas no ano de 2013 que o PSE foi universalizado, permitindo que qualquer município pudesse aderir ao programa.

Os achados da gestão local apontam as ações de alimentação e nutrição (Vigilância Alimentar e Nutricional e Promoção da Alimentação Adequada e Saudável) são presentes e frequentes no escopo das atividades desenvolvidas localmente pelo PSE. Foi observado que $85 \%$ dos entrevistados afirmaram que realizam a avaliação e estado nutricional dos escolares e mais da metade afirma que adota o SISVAN para registrar estes dados. A alimentação dos sistemas realizada localmente permite que nacionalmente se possam analisar as tendências do estado nutricional desta população.

Para a avaliação do estado nutricional de escolares, principalmente com foco na avaliação da obesidade em crianças e adolescentes, atualmente são propostos uma série de indicadores. Desde o ano de 1995, a OMS recomenda que para a avaliação do estado nutricional de crianças maiores de 5 anos de idade e adolescentes, o IMC para a idade é o indicador mais 
adequado e pode ser utilizado combinado com outras medidas antropométricas (OMS, 1995). Para avaliar o estado nutricional, tanto COLE et al. (2005) como CÁNDIDO et al. (2012) reiteram o IMC como um importante e prático indicador, não invasivo e de baixo custo, que tem alta sensibilidade e especificidade para avaliar a gordura corporal e por sua vez, o estado nutricional de crianças e jovens. GOMES et al. (2010) em um estudo que comparou diferentes métodos de avaliação corporal de adolescentes, levando em consideração o sexo e o estado de maturação sexual dos jovens, afirma que para inquéritos populacionais, a avaliação do estado nutricional por meio da avaliação do IMC para a idade tem se mostrado a medida mais prática e efetiva. Os resultados encontrados foram avaliados de acordo com o IMC para a idade e comparados com a população de referência proposta pela OMS no ano de 2007 (DE ONIS et al., 2007).

A equipe de Atenção Básica deve estar treinada e equipada para a realização das ações de nutrição na $A B$. O trabalho da equipe deve ser apoiado em três ações: investigação da história clínica, exame físico e mensuração e avalição das medidas antropométricas. A avaliação do estado nutricional por meio da mensuração do peso e da altura permitem um rápido diagnóstico dos desvios nutricionais e o acompanhamento do crescimento e desenvolvimento das crianças e adolescentes. As ações podem ser qualificadas com a investigação dos hábitos alimentares e com a observância do território em questão (ALVAREZ et al., 2011). JAIME et al (2011) descrevem como ações da atenção básica, no campo da promoção da 
alimentação saudável: “Estimular e apoiar professores e diretores na inclusão da Promoção da alimentação adequada e saudável e da prática da atividade física como parte do projeto político pedagógico das escolas no território"; "Promover, incentivar e implantar hortas escolares e comunitárias"; "Incentivar a realização de oficinas culinárias nas escolas".

Optou-se por avaliar a evolução do estado nutricional por meio da variação do escore-Z do IMC-para-a-idade, de acordo com o sexo dos escolares. Segundo COLE et al. (2005) os valores de escore-Z são muito usados para avaliar a adiposidade em crianças e adolescentes transversalmente e a identificação das mudanças nos valores de z-escore é uma escolha lógica para avaliar a obesidade ao longo do tempo, da mesma maneira que a variação do escore-Z para a altura permite avaliar a velocidade de crescimento. Diversos estudos avaliaram o estado nutricional de crianças e escolares brasileiros, mas a maioria dos trabalhos encontrados apresentam resultados pontuais ou de um grupo etário específico (ARAÚJ O et al., 2010a; ARAÚJO et al., 2010b; GOMES et al., 2009; SILVA et al., 2009; FERREIRA e LUCIANO, 2010).

O SISVAN Web é o sistema de informação que compõem o Sistema de Vigilância Alimentar e Nutricional e armazena e sistematiza as informações de estado nutricional dos usuários da Atenção Básica do SUS. A vigilância pode ser realizada no nível individual quando cada indivíduo é acompanhado de maneira sistemática na Atenção Básica e tem a evolução do estado nutricional acompanhada por um profissional de saúde e no nível coletivo, 
como a análise do estado nutricional de escolares de uma determinada área. Ações individuais resultam em respostas imediatas quando da necessidade de resolução de desvios nutricionais. No caso das coletividades, os dados devem ser compilados, analisados e usados como referência para as ações voltadas aos grupos em questão. Os dados gerados pelo sistema devem ser de domínio dos gestores e das equipes de saúde para que, a partir da realidade local, possam planejar e executar as ações (COUTINHO et al., 2009).

Foram avaliados cerca de 700 mil registros individuais de peso e altura de crianças e adolescentes com idades entre 7 e 18 anos entre os anos de 2008 e 2012. Os valores encontrados foram comparados com as medianas de peso e altura de uma população de referência, proposta pela OMS, e de um inquérito populacional brasileiro, realizado nos anos de 2008 e 2009 - a Pesquisa de Orçamentos Familiares - POF. A análise do estado nutricional, com base nos valores médios do escore-Z, do IMC para a idade, aponta para um claro aumento anual no peso médio dos escolares, além daquele esperado em função do crescimento, em ambos os sexos. A avaliação do grupo revela um perfil de peso que varia ao longo do período observado, com um aumento da média nos períodos entre 7 e 10 anos e 14 e 18 anos e uma queda nos valores no período entre 10 e 14 anos de idade. Os sexos se comportam de maneira diferente, sendo que aos 7 anos de idade os meninos possuem médias maiores de IMC para a idade, quando comparados as meninas, e aos 18 anos, esta tendência se inverte. 
Estudo realizado com escolares chineses, entre os anos de 1995-2010 também revelou um aumento no peso dos escolares chineses durante o período. As disparidades entre os sexos também foram observadas, os meninos apresentam percentuais mais altos de obesidade quando comparados as meninas (SONG et al., 2013). Outro estudo realizado com escolares chineses com idades entre 5 e 18 anos encontrou diferentes padrões de mudança na composição corporal ao se comparar diferentes grupos etários, um de 5 a 11 anos e outro de 12 a 18 anos, com diferença de sexo não-significativa (XIONG et al., 2012). Na Suécia foram acompanhadas duas coortes com nascidos nos anos de 1974 e 1990, acompanhados no período do ensino médio, e a comparação do ganho de peso entre os grupos demonstrou um aumento de peso entre o grupo que foi seguindo no segundo período. Os meninos apresentaram uma tendência mais preocupante quando comparado com as meninas, que ganharam peso, mas este ganho não impactou no IMC (LISSNER et al., 2013). Escolares sicilianos, com idades entre 11 e 13 anos, foram acompanhados em 19992001 e 2009-2010, e foi observado aumento do escore Z do IMC para a idade e das prevalências de obesidade neste período, sendo o aumento maior entre os meninos (PARRINO et al., 2012).

J AGO et al. (2013) analisou a variação do IMC, de escolares norteamericanos, entre o 6o e o $8^{\circ}$ ano escolar e seu impacto no risco de desenvolver doenças cardiovasculares, foram analisados os seguintes parâmetros: triglicérides em jejum, pressão arterial, HDL-C, glicose e um 
escore para risco metabólico e verificou-se que aumentos escore-Z do IMC para a idade estão relacionados a aumento do risco cardiovascular, para ambos os sexos. No estudo HELENA, realizado com escolares com idades entre 12 e 17 anos de diferentes países europeus, as meninas eram, em média, oito centímetros mais baixas e 7 kg mais leves, que os meninos, além de terem índices menores de pressão arterial, mas por outro lado, elas apresentavam estágios de maturação sexual mais avançados, maiores taxas e excesso de peso e menores prevalências de obesidade, quando comparadas aos meninos (BÉGHIN et al., 2012).

A variação do IMC no período entre a adolescência e o ingresso na idade adulta (12 a 26 anos de idade) foi analisado por LEE et al. (2011), com dados de inquéritos norte-americanos, realizados num período de 4 décadas (1959-2002). Um aumento acelerado da obesidade foi observado depois dos anos 1990, tanto entre adolescentes como entre os adultos, sendo maior entre as mulheres. Segundo o autor, o ganho de peso tende a aumentar nesta fase de transição, podendo refletir numa tendência para toda a idade adulta.

Diversos estudos investigam a associação entre o excesso de peso dos escolares e fatores socioeconômicos e culturais. Revisão feita por CARDOSO et al. (2009) com mais de 50 estudos que relacionavam Excesso de peso e diferentes fatores com adolescentes entre 10 e 19 anos encontrou como fatores comportamentais diretamente associados ao excesso de peso: ter feito dieta ou regime de restrição calórica, consumo de laxantes e remédios, 
consumo frequente de refrigerante (mais de três vezes na semana) e comprar lanche na cantina escolar. Fatores associados inversamente foram: o hábito de realizar a refeição do café da manha, o consumo de cereais no café da manhã, o consumo frequente de frutas, verduras e legumes, o total de energia consumida, não omitir refeições. Alguns estudos apontaram que o hábito de jantar com a família tem efeito protetor com relação ao excesso de peso em adolescentes. A mesma relação foi encontrada com as horas de sono e a prática de atividade física, quanto maior a frequência, menor a chance de ter excesso de peso. O tempo de horas de tela (televisão e computador) tem associação positiva com o excesso de peso em adolescentes. O autor recomenda que sejam realizadas intervenções tanto individuais como coletivas e que estas levem em consideração o nível socioeconômico da família, comportamento alimentar individual e estilo de vida dos jovens (CARDOSO et al., 2009).

As diferenças de comportamento do estado nutricional entre os sexos aqui encontradas, podem ser explicadas por uma série de fatores, tanto biológicos como sociais. O desenvolvimento e a maturação sexual entre meninos e meninas ocorrem em idades diferenciadas e o estirão de crescimento também. O início da puberdade é um destes fatores que pode iniciasr entre os 7e 13 anos em meninas e 9,5 e 13,5 anos entre os meninos (PEDEN \& KENISTON, 1998).

WANG (2002) alerta para a relação entre a obesidade e a maturação sexual precoce, em seu estudo com indivíduos com idades entre 8 a 14 anos 
de ambos os sexos, observou-se que a maturação sexual precoce estava positivamente associada ao sobrepeso e a obesidade entre as meninas e o inverso foi observado entre os meninos mas a índices elevados de gordura localizada e IMC também foi relacionado a maturação precoce em ambos os sexos. Garotos com maturação precoce tendiam a ser mais magros e enquanto que as garotas nesta condição eram mais gordas que a média do grupo.

O consumo de alimentos e os hábitos alimentares, determinantes do peso corporal, também apresentam padrões diferenciados entre os adolescentes do sexo masculino e feminino. O início do aparecimento dessas diferenças é na fase da adolescência. Homens costumam comer em maior quantidade enquanto as mulheres comem com mais frequência, menores quantidades de alimentos, as mulheres começam a controlar o peso e aderem à dietas com restrições alimentares antes do ingresso na vida adulta. As adolescentes são estimuladas a comer de um modo feminino e costumam ter mais insatisfação com a imagem corporal quando comparadas com os adolescentes do sexo masculino (ROLS et al., 1991).

Diferenças de comportamento, entre os sexos, também são encontradas quando analisa-se a prática de atividade física, fator relacionado com a regulação do peso corporal. Adolescentes do sexo masculino tendem a praticar atividades físicas com mais frequência e mais vigorosas quando comparados com as adolescentes do sexo feminino (FURNHAN et al. 2002). 
No estudo que comparou a correlação entre a prevalência de lazer sedentário e consumo de alimentos não saudáveis, entre os escolares da PeNSE, 65\% dos entrevistados, sendo maior entre as meninas e a frequência de consumo de guloseimas foi diretamente proporcional ao tempo de lazer sedentário, apontando para a necessidade de intervenções que aliem recomendações de modos de vida saudáveis que aliem alimentação e atividade física (CAMELO et al, 2012)

A diferença, entre os sexos, da evolução do estado nutricional encontradas podem ser explicadas por fatores sociais como a evasão escolar e início no mercado de trabalho. Dados da PNAD - 2009 revelaram que $84,1 \%$, dos adolescentes com idades entre 15 a 17 anos estavam matriculados na escola e a taxa líquida (nível compatível com a idade), ou seja, a frequência ao ensino médio neste grupo etário era de apenas 50,6\% (IBGE, 2009b). Os dados de trabalho e emprego da PNAD 2011 apontam que, no ano de $2011,8,8 \%$ meninos e $4,3 \%$ das meninas de 10 a 14 anos eram classificados como economicamente ativos e entre os adolescentes de 15 e 17 anos, esse índice subiu para 37,8\% meninos e $24,5 \%$ das meninas (IBGE, 2012). Esses dados revelam que entre crianças e adolescentes, há maiores frequências de meninos ingressando precocemente no mercado de trabalho, o que pode ser uma das variáveis que explica as diferenças na evolução do estado nutricional. Analisando-se as idades mais velhas, jovens entre 18 e 19 anos, as tendências se mantêm: No ano de 2008, entre as 
mulheres desta faixa etária: $29,6 \%$ só estudavam, $16,8 \%$ trabalhavam e estudavam, $25,3 \%$ só trabalhavam; $25,5 \%$ cuidavam dos afazeres domésticos e 2,7\% afirmaram não realizar nenhuma atividade. Entre os jovens do sexo masculino: $21,6 \%$ só estudavam, $24,1 \%$ trabalhavam e estudavam, 40,0 \% só trabalhavam; 5,5\% cuidavam dos afazeres domésticos e 8,8 \% afirmaram não realizar nenhuma atividade (IBGE, 2009a).

Os achados para os escolares brasileiros apontam para uma tendência similar à encontrada entre os adultos nas avaliações anuais realizadas pelo VIGITEL (Inquérito de Vigilância de Fatores de Risco e Proteção para Doenças Crônicas por Inquérito Telefônico) realizado anualmente desde o ano de 2006. Verifica-se um aumento anual nas prevalências populacionais de excesso de peso de 1,16\%, em média, e de 0,72\% para a obesidade, em média, entre os adultos brasileiros (BRASI L, 2013).

A variação da evolução do peso em crianças e adolescentes não apresentam o mesmo comportamento nos diferentes países, mas os estudos encontrados confirmaram o aumento de excesso de peso nesta faixa etária. As diferenças entre os sexos podem ser explicadas por conta de mudanças fisiológicas e hormonais, questões socioeconômicas, práticas alimentares e modos de vida.

Socialmente a escola é um espaço reconhecido de educação e de formação, além de ser o local em que crianças e adolescentes passam a maior parte do seu tempo, por muitos anos, durante uma etapa importante 
da vida, onde hábitos são formados e valores afirmados. A colaboração da escola para a inserção da agenda de saúde na rotina de crianças e jovens é de extrema importância. A escola deve ser um ambiente protetor, propiciando discussões e práticas acerca dos condicionantes e determinantes da saúde. Todas as escolas deveriam trabalhar na perspectiva de promover saúde, independente de estar alocada ou não dentro de um programa governamental.

Os dados apresentados nos resultados, relacionados à implantação do PSE, apontam para uma limitação das ações do programa para dar uma resposta eficaz para intenir eficazmente na mudança do estado nutricional dos escolares. Apesar de realizar a vigilância alimentar e nutricional, o fato dos dados não serem interpretados faz com que a ação não seja conclusa. Por outro lado, as ações de promoção da alimentação adequada e saudável claramente não estão incorporadas as atividades do currículo escolar, sendo apresentadas e discutidas de maneira pontual, com baixa frequência e com abordagens pouco ativas, como no caso das palestras.

A estrutura das escolas pode ser outro fator limitante para a realização das ações ao se planejar iniciativas que podem ajudar nas ações de promoção da saúde e principalmente, promoção da alimentação saudável. A PeNSE (2012) avaliou a estrutura das escolas, sendo que as da rede privada sempre apresentaram melhores condições quando comparadas às escolas públicas, o que pode ser observado quando perguntado sobre a presença de biblioteca: $89,9 \%$ das privadas contra $86 \%$ das públicas, sala de 
informática: $85,3 \%$ das privadas e $88,9 \%$ das públicas, acesso à computadores na sala de aula: $39,4 \%$ privada e $17,6 \%$ nas públicas, acesso à internet: $91,6 \%$ versus $82,7 \%$ e sala com recursos de mídia: $86,6 \%$ versus 53,9\%. Com relação aos espaços para a prática de atividade física, a quadra para prática de esportes está presente em $93,4 \%$ das privadas e $76,4 \%$ das públicas. Apenas $1 \%$ das escolas possui pista para atletismo e 0,7\% possuem piscinas. Metade das instituições oferecem prática de atividade física com instrutor e as atividades esportivas gratuitas fora do horário regular de aula são oferecidas em $61,5 \%$ das escolas públicas e 38,3\% das escolas privadas (IBGE, 2013).

O entendimento de que as ações de prevenção e promoção da saúde podem contribuir para a formação de cidadãos é um avanço, mas a garantia deste processo, de maneira democrática e participativa requer grandes esforços tanto da Gestão federal como das gestões estaduais e principalmente da municipal.

Com relação ao aumento do sobrepeso e da obesidade em escolares, os dados apresentados apontam para um aumento anual na prevalência deste agravo, tendência observada em ambos os sexos. O monitoramento do estado nutricional por si só não garante mudanças de comportamento, principalmente em crianças e adolescentes, mas permite que as mudanças temporais sejam avaliadas com clareza. Os achados apontam para comportamentos distintos entre os sexos, sendo que entre as meninas há uma tendência ao aumento do peso corporal em todas as idades. Entre os 
meninos o ganho de peso tende a diminuir com a idade, mas mesmo assim, entre os anos analisados, sempre houve incremento do peso corporal, ao decorrer dos anos, independente da idade.

Há evidências que fatores socioeconômicos, psicológicos e biológicos interferem nos hábitos alimentares, na percepção da autoimagem corporal e no ganho excessivo de peso e estes fatores exercem efeitos diferentes entre os sexos, apontando para abordagens específicas de acordo com o gênero (ROLLS et al., 1991). Numa abordagem orientada pelo gênero, meninas devem ser orientadas a não terem aumento no I MC para a idade durante a fase escolar enquanto os meninos devem preservar o padrão atual, mas com observância ao ganho de peso. As ações de Promoção da alimentação adequada e saudável e prevenção da obesidade devem ser iniciadas antes da idade que compreende o ensino fundamental e continuadas ao logo de toda a idade escolar.

Programas voltados para atenção da saúde dos escolares como o PSE tem um grande potencial de ajudar no combate ao aumento do excesso de peso de crianças e adolescentes, mas não podem ser vistos como a única resposta para esta problemática, uma vez que a obesidade é um agravo de origem multifatorial que tem a sua origem não apenas em hábtos individuais mas também na urbanização, aumento da oferta e propaganda de alimentos, redução da atividades física, entre outros fatores (GRUNDY, 1998) e da maneira como o PSE está implementado hoje, com seus recursos e ferramentas de trabalho, há muitas mudanças que podem ser feitas para que 
o mesmo possa contribuir com toda a sua potencialidade nas ações de atenção e promoção da saúde dos escolares.

Em suma, os resultados da tese apresentam questões referentes à gestão local de um programa baseado fortemente numa ação intersetorial, impulsionado por uma agenda de promoção da saúde e com um forte componente de alimentação e nutrição, que vai desde a avaliação do estado nutricional, perpassando pela Promoção da alimentação adequada e saudável e culminando na educação permanente das equipes de saúde e educação. A avaliação da evolução do estado nutricional baseado na evolução do escoreZ desta população nos permite planejar com maior eficácia em qual idade deve ser desenvolvida cada intenvenção nutricional, com o objetivo de prevenir desvios nutricionais como o baixo peso e a obesidade.

O presente estudo apresenta algumas limitações que precisam ser consideradas:

Os municípios possuíam diferentes tempos de adesão ao programa mas todos os anos estão contemplados na análise, permitindo traçar um panorama com entre os diferentes tempos de implantação do programa. O PSE é um Programa que está em fase de implantação e pela sua dinâmica de adesão, escalonada pelos anos, desde o ano de 2008 ainda não permite que todos os municípios envolvidos na ação tenham tempo necessário pra que os resultados das ações possam ser claramente observados.

A análise da gestão local do PSE foi feita por uma amostra de conveniência, os questionários foram enviados para o responsável pela 
adesão ao programa no setor saúde. Foi realizada uma análise quantitativa da gestão local, para algumas questões há necessidade de uma avaliação qualitativa para o melhor entendimento de algumas questões da gestão local. Os resultados refletem o ponto de vista do gestor alocado no setor saúde, uma avaliação com os gestores da educação poderiam trazer outras respostas.

Os dados referentes ao SISVAN eram de avaliações transversais - não é possível afirmar se o mesmo foi avaliado mais de uma vez ou em todas as vezes, se houvesse um identificador único para cada indivíduos, seria possível a realização de outras análises. 


\section{Concl usão}

O Programa Saúde na Escola possui ferramentas e está cunhado em preceitos que Ihe conferem ampla capacidade de enfrentar os desafios em saúde que estão colocados para a população de crianças e adolescentes brasileiros, frequentadores da rede pública de ensino. As ações devem ser planejadas e discutidas de maneira a propiciar um ambiente de práticas e hábitos saudáveis. Os governos devem apoiar as ações e qualificar os profissionais tanto da saúde como da educação.

Estado Nutricional apresenta uma tendência de aumento anual do IMC médio dos escolares, reforçando os diferentes estudos que mostram o aumento do excesso de peso em todas as fases do curso da vida e trazendo mais um alerta sobre este público em específico.

Melhor momento para a intervenção entre crianças e adolescentes é o intervalo entre os 10 e 14 anos, onde há uma tendência de declive na curva de IMC para a idade. Ao se fazer uma avaliação na perspectiva dos gêneros, a intervenção deve ser mais cedo entre as meninas e mais tardia entre os meninos, mas o atual modelo de educação, adotado pelo Brasil, dificulta a abordagem de gênero, uma vez que as escolas são formadas de turmas mistas. O ideal é que as ações de prevenção do ganho e promoção da saúde sejam praticadas desde a pré-escola e continuadas nos outros níveis de ensino, abordando tanto meninas como meninos. 


\section{R eferênci as Bi bli ográfi cas}

AERTS, D. et al. Promoção de saúde: a convergência entre as propostas da vigilância da saúde e da escola cidadã Health promotion: convergence between the principles of health surveillance. Cad. Saúde Pública, v. 20, n. 4, p. 1020-1028, 2004.

ALVAREZ, M H. et al. Valoración nutricional en Atención Primaria, $i$ es posible?. Pediatría Atención Primaria, v. 13, n. 50, p. 255-269, 2011.

ARAÚJ O, C. L. et al. Nutritional status of adolescents: the 11-year follow-up of the 1993 Pelotas (Brazil) birth cohort study. Cadernos de Saúde Pública, v. 26, n. 10, p. 1895-1903, 2010a.

ARAÚJ O, C. L. et al. Estado nutricional dos adolescentes e sua relação com variáveis sociodemográficas: Pesquisa Nacional de Saúde do Escolar (PeNSE), 2009. Ciência \& Saúde Coletiva, v. 15, n. Supl 2, p. 3077-3084, 2010b.

ARREAZA, A. L. V; MORAES, J. C. Vigilância da saúde: fundamentos, interfaces e tendências. Ciênc. saúde coletiva, Rio de Janeiro, v. 15, n. 4, July 2010.

BARKER, D.J. Fetal origins of coronary heart disease. BMJ : British Medical Journal, v. 311, n. 6998, p. 171, 1995.

BATISTA FILHO, Malaquias; RISSIN, Anete. A transição nutricional no Brasil: tendências regionais e temporais. Cad saúde pública, v. 19, n. Supl 1, p. 181-91, 2003.

BEAM, M. et al. Evaluation of the Healthy Schools Program: Part I. Interim Progress. Preventing chronic disease, v. 9, 2012a. 
BEAM, M.et al. Evaluation of the Healthy Schools Program: Part II. The Role of Technical Assistance . Preventing chronic disease, v. 9, 2012a.

BÉGHIN, L. et al. Main characteristics and participation rate of European adolescents included in the HELENA study. Archives of Public Health, v. 70, n. 1, p. 1-11, 2012.

BEZERRA L.C. et al. Modelagem de Programas: da teoría à operacionalização. In: SAMICO I. et al. Avaliação em Saúde - bases conceituais e operacionais - Rio de Janeiro: Medbook, 2010.

BLUM, R.W. et al. Vulnerability, risk, and protection. Adolescent risk and vulnerability: Concepts and measurement, p. 50-72, 2001.

BÓGUS, C.M. A promoção da saúde como referencial para a formulação e desenvolvimento de políticas públicas saudáveis. Bol. Inst. Saúde, v. 34, p. 16-7, 2004.

BRASI L Constituição (1988). Constituição da República Federativa do Brasil. Brasília, DF: Senado; 1988.

BRASIL. Lei № 9.394, de 20 de dezembro de 1996. Estabelece as diretrizes e bases da educação nacional. Diário Oficial da União. 23 dez 1996.

BRASIL. Secretaria de Educação Fundamental. Parâmetros curriculares nacionais : terceiro e quarto ciclos do ensino fundamental: introdução aos parâmetros curriculares nacionais. - Brasília : MEC/SEF, 1998

BRASIL. Ministério da Saúde. Secretaria de Políticas de Saúde. Projeto Promoção da Saúde. As Cartas da Promoção da Saúde. Brasília: Ministério da Saúde, 2002.

BRASIL. Ministério da Saúde. Secretaria de Vigilância em Saúde. Política Nacional de Promoção da Saúde. Brasília: Ministério da Saúde, 2006. 
BRASI L. Ministério da Saúde. Ministério da Educação. Portaria Interministerial n.1010, de 8 de maio de 2006. Institui as diretrizes para a Promoção da alimentação adequada e saudável nas Escolas de educação infantil, fundamental e nível médio das redes públicas e privadas, em âmbito nacional. Diário Oficial da União de 9 de maio de 2006.

BRASIL. Decreto no. 6286 de 5 de dezembro de 2007. Institui o Programa Saúde na Escola - PSE, e dá outras providências. Diário Oficial União. 6 de dezembro de 2007.

BRASI L. Ministério da Saúde. Portaria № 154 de 24 de janeiro de 2008. Cria os Núcleos de Apoio à Saúde da Família - NASF. Diário Oficial da União de 25 de janeiro de 2008.

BRASIL Lei no 11.947 de 16 de junho de 2009. Conversão da medida provisória $n^{\circ} 455$, de 2008 dispõe sobre o atendimento da alimentação escolar e do programa dinheiro direto na escola aos alunos da educação básica e dá outras providências. Diário Oficial da União. 17 jun 2009.

BRASIL. Ministério da Saúde, Secretaria de Atenção à Saúde, Departamento de Atenção Básica. Orientações para a coleta e análise de dados antropométricos em serviços de saúde : Norma Técnica do Sistema de Vigilância Alimentar e Nutricional - SISVAN / - Brasília : Ministério da Saúde, 2011.

BRASIL Ministério da Saúde. Política Nacional de Atenção Básica. Brasília: Ministério da Saúde, 2012a. (Série B. Textos Básicos de Saúde)

BRASIL Ministério da Saúde. Política Nacional de Alimentação e Nutrição. Brasília: Ministério da Saúde, 2012b. (Série B. Textos Básicos de Saúde)

BRASIL. Ministério da Saúde. Secretaria de Vigilância em Saúde. Departamento de Vigilância de Doenças e Agravos não Transmissíveis e 
Promoção de Saúde. Vigitel Brasil 2012: vigilância de fatores de risco e proteção para doenças crônicas por inquérito telefônico. Brasília: Ministério da Saúde, 2013.

BRASIL. Ministério da Educação. RESOLUÇÃO № 26 DE 17 DE JUNHO DE 2013 Dispõe sobre o atendimento da alimentação escolar aos alunos da educação básica no âmbito do Programa Nacional de Alimentação Escolar PNAE. Disponível em [http:// http://www.fnde.gov.br/fnde/legislacao/resolucoes] acessado em 14 de agosto de 2013. Brasília: Ministério da Educação, 2013b.

BRENER N.D. et al. Youth risk behavior surveillance - selected steps communities, 2005. Morbidity and Mortality Weekly Report, v. 59, n. 2, p.116, 2007.

BROWN, T. et al. Prevention of obesity: a review of interventions. Obesity reviews, v. 8, n. s1, p. 127-130, 2007.

CAMELO, L.V. et al . Lazer sedentário e consumo de alimentos entre adolescentes brasileiros: Pesquisa Nacional de Saúde do Escolar (PeNSE), 2009. Cad. Saúde Pública, v. 28, n. 11, 2012.

CÁNDIDO, A.P.C. et al. Anthropometric methods for obesity screening in schoolchildren: the Ouro Preto Study. Nutr Hosp, v. 27, n. 1, p. 146-153, 2012.

CARDOSO, L.O. et al. Fatores socioeconômicos, demograficos, ambientais e comportamentais associados ao excesso de peso em adolescentes: uma revisão sistemática da literatura. Rev. bras. epidemiol, v. 12 , n. 3, p. 378403, 2009. 
CDC. The Centers for Disease Control and Prevention (CDC) Guidelines for school health programs to promote lifelong healthy eating. Journal of School Health, v. 67, p.9-26, 1997.

CDC. The Centers for Disease Control and Prevention (CDC) School health policies and programs study. SHPPS 2006. Disponível em http://www.cdc.gov/healthyyouth/cshp/index.htm

COLE, T. J. et al. What is the best measure of adiposity change in growing children: BMI, BMI\%, BMI Z-score or BMl centile? European journal of clinical nutrition, v. 59, n. 3, p. 419-425, 2005.

COUTINHO, J.G. et al. A organização da Vigilância Alimentar e Nutricional no Sistema Único de Saúde: histórico e desafios atuais. Rev. Bras Epidemiol, v. 12, n.4, p. 688-99, 2009.

COSTA F.L, CASTANHAR J.C. Avaliação de Programas Públicos: desafios conceituais e metodológicos. RAP, v.37, n.5, p.969-992, 2003.

DE ONIS M. et al. Development of a WHO growth reference for school-aged children and adolescents. Bulletin of the World Health Organization, v. 85, n. 9, p. 660-7, 2007.

DEMORY-LUCE, D. et al. Changes in food group consumption patterns from childhood to young adulthood: The Bogalusa Heart Study. Journal of the American Dietetic Association, v. 104, n. 11, p. 1684-1691, 2004.

DONABEDIAN, A. The Quality of Medical Care. Science, v. 200, n.4344 p. 856-864, 1978.

DONABEDI AN, A. The Definition of Quality and Approaches to Its Assessment [Explorations in Quality Assessment and Monitoring, vol. 1]. Ann Arbor: Health Administration Press, 1980. 
ENES, C.C; SLATER, B. Obesidade na adolescência e seus principais fatores determinantes. Rev. Bras. Epidemiol, v. 13, n. 1, p. 163-171, 2010.

FERREIRA, H.S.; LUCIANO, S.C.M. Prevalence of extreme anthropometric measurements in children from Alagoas, Northeastern Brazil. Revista de saude publica, v. 44, n. 2, p. 377-380, 2010.

FIGUEIREDO T.A.M. et al. A saúde na escola: um breve resgate histórico. Ciência \& Saúde Coletiva, v.15, n.2, p. 397-402, 2010.

FISBERG, M. Obesidade na Infância e Adolescência. In: M. Fisberg. Obesidade na infância e adolescência. São Paulo, Fixado Editorial BYK, p. 9-13, 1995.

FRACOLU, L. A. et al. Vigilância à Saúde: deve se constituir como política pública. Saúde Soc, v. 17, n. 2, p. 184-92, 2008.

GARCIA, R.C. Avaliação de Ações Govemamentais: pontos para um começo de conversa. Brasília, IPEA/CENDEC, out., 1997.

GOMES, F.S. et al. Influence of different body mass index cut-off values in assessing the nutritional status of adolescents in a household survey. Cademos de Saúde Pública, v. 25, n. 8, p. 1850-1857, 2009.

GOMES, F.S. et al. Antropometria como ferramenta de avaliação do estado nutricional coletivo de adolescentes; Anthropometry as a tool for assessing the nutritional status of adolescents. Rev. nutr, v. 23, n. 4, p. 591-605, 2010.

GRAHAM H.; POWER C. Childhood disadvantage and adult health: a lifecourse framework. London, Health Development Agency, 2004 
GRUNDY S.M. Multifactorial causation of obesity: implications for prevention. Am J Clin Nutr, v.67 n. 3, p. 563S-572S, 1998.

HARTZ, Z.M.A. Avaliação em saúde: dos modelos conceituais à prática na análise da implantação de programas. 1997.

HENRIQUE, F.C.S. et al. Tendência do campo de avaliação de intervenções públicas de alimentação e nutrição em programas de pós-graduação no Brasil: 1980-2004 Trends in graduate courses on the evaluation. Cad. Saúde Pública, v. 23, n. 12, p. 2972-2981, 2007.

HURRELMANN K; RICHTER M. Risk behaviour in adolescence: the relationship between developmental and health problems. Journal of Public Health, V.14, P. 20-28, 2006.

IBGE - Instituto Brasileiro de Geografia e Estatística. Síntese de indicadores sociais: Uma análise das condições de vida da população brasileira 2009. Instituto Brasileiro de Geografia e Estatística. 2009.

IBGE - Instituto Brasileiro de Geografia e Estatística. Censo Populacional 2010 - Primeiros resultados. Instituto Brasileiro de Geografia e Estatística. 2010.

IBGE - Instituto Brasileiro de Geografia e Estatística. Pesquisa de orçamentos familiares 2008-2009 - Antropometria e estado nutricional de crianças, adolescentes e adultos no Brasil. Rio de Janeiro; 2010a.

IBGE - Instituto Brasileiro de Geografia e Estatística. Pesquisa Nacional de Saúde do Escolar Avaliação do estado nutricional dos escolares do 9 o ano do ensino fundamental. Rio de Janeiro; 2010b.

IBGE - Instituto Brasileiro de Geografia e Estatística. Pesquisa Nacional de Saúde do Escolar. Rio de Janeiro; 2010c. 
IBGE - Instituto Brasileiro de Geografia e Estatística. Pesquisa Nacional por Amostra de Domicílios - 2011. Instituto Brasileiro de Geografia e Estatística. 2012.

IBGE - Instituto Brasileiro de Geografia e Estatística. Pesquisa Nacional de Saúde do Escolar. Rio de Janeiro; 2013.

IPEA - Instituto de Pesquisas Sociais Aplicadas Boletins - IPEA- Políticas Sociais: acompanhamento e análise - Vinte Anos da Constituição Federal Anexo Estatístico oo 17, 2009.

IPPOLITO-SHEPHERD, J. et al. Promoção da saúde no âmbito escolar: a iniciativa regional Escolas Promotoras da Saúde. In: Sociedade Brasileira de Pediatria. Escola promotora de saúde: manual. Rio de Janeiro, SBP, 2005.

JAGO, R. et al. Longitudinal associations between BMI, waist circumference, and cardiometabolic risk in US youth: Monitoring implications. Obesity, v. 21, n. 3, p. E271-E279, 2013.

Jaime P.C.; Lock K. Do school based food and nutrition policies improve diet and reduce obesity? Preventive Medicine, v. 48, p. 45 -53, 2009.

JAIME, P.C. et al. Ações de alimentação e nutrição na atenção básica: a experiência de organização no Governo Brasileiro; Food and nutrition actions in primary healthcare: the experience of the Brazilian government. Rev. nutr, v. 24, n. 6, p. 809-824, 2011.

J AI ME, P.C. et al. Brazilian obesity prevention and control initiatives. Obesity Reviews, v. 14, n. S2, p. 88-95, 2013. 
LEE, H. et al. US Trends in body mass index in adolescence and young adulthood in the United States: 1959-2002. Journal of Adolescent Health, v. 49, n. 6, p. 601-608, 2011.

LIMA G.Z. Saúde escolar e educação. São Paulo: Cortez; 1985.

LIMA M.L.O.F.; Medeiros J.J. Empreendedores de políticas públicas na implementação de programas governamentais. Rev. Adm. Pública, v.46, n. 5, p.1251-270, 2012.

LISSNER, L. et al. Secular trends in weight, height and BMl in young Swedes: The 'Grow up Gothenburg' Studies. Acta Paediatrica, v. 102, n. 3 , p. 314-317, 2013.

MANSON J .B. et al. Vigilância Nutricional. Genebra: WHO, 1984.

MENDES, R.; AKERMAN, M. Intersetorialidade: reflexões e práticas. Promoção da saúde e gestão local. São Paulo: Aderaldo \& Rothschild, p. 85-109, 2007.

MOURA J.B.V.S. et al. Perspectiva da epistemologia histórica e a escola promotora de saúde. História, Ciências, Saúde. v. 14, n. 2, p. 489-501, 2007.

OAKES JM. Macrosocial Determinants of Population Health. Am J Epidemiol. v. 167, n. 1518-1519, 2008.

OMS - Organização Mundial da Saúde. Escolas Promotoras de Saúde: modelo e guia para a ação. Washington, (D.C.): Opas. (Série HSS/Silos.), 1996.

PARRINO, C. et al. Secular trends in the prevalence of overweight and obesity in Sicilian schoolchildren aged 11-13 years during the last decade. PloS one, v. 7, n. 4, p. e34551, 2012. 
PEDEN, B.F.; KENISTON, A.H. Instructor's Manual to Accompany Adolescence: J ohn W. Santrock. McGraw-Hill, 1998.

PENTEADO, R.Z. et al. Do higienismo às ações promotoras de saúde: a trajetória em saúde vocal. Distúrbios da Comunicação, v. 17, n. 1, 2005.

ROLLS B.J. et al. Gender diferences in eating behavior and body weight regulation. Health Psicology, v. 10, n.2, p. 133-142, 1991.

RODRIGUES ARCE, V.A. et al. Integralidade do Cuidado: representações sociais das equipes de Saúde da Família do Distrito Federal. Saúde e Sociedade, v. 22, n. 1, 2013.

SCALES P. Reducing risks and building development assets: essential actions for promoting adolescent health. The J ournal of School Health, v. 69, n. 3, p. 13-19, 1999.

SILVA, P.L.B. (coord.) Modelo de Avaliação de Programas Sociais Prioritários: relatório final. Programa de Apoio à Gestão Social no Brasil. Campinas, NEPP-UNICAMP, 1999.

SILVA, J.B. da. et al. Estado nutricional de escolares do semi-árido do Nordeste brasileiro.Revista de Salud Pública, v. 11, n. 1, p. 62-71, 2009.

SILVA, S.F. (org). Redes de Atenção à Saúde: desafios da regionalização no SUS. Organizador. Campinas, SP: Saberes Editora, 2013.

SOARES B.S.A. et al. A escola promovendo hábitos alimentares saudáveis: uma proposta metodológica de capacitação para educadores e donos de cantina escolar. Cad. Saúde Pública, v. 24, n. S 2, p. S312-S322, 2008.

SONG, Y. et al. BMI-for-age Z-score distribution shifts among Chinese children: Gender disparity. Obesity, 2013. 
SRINIVASAN S.R. et al. Adolescent overweight is associated with adult overweight and related multiple cardiovascular risk factors: The Bogalusa Heart Study. Metabolism, v. 45, n. 2, p. 235-240, 1996.

STARFIELD B. Atenção Primária: equilíbrio entre necessidades de saúde, senviços e tecnologia. Brasília: Unesco, Ministério da Saúde, 2004.

UNICEF - The United Nations Children's Fund.. Guide for monitoring and evaluation. New York: Unicef, 1990.

UNICEF - The United Nations Children's Fund. The state of the world's children 2011. Adolescence: an age of opportunity. New York: UNI CEF, 2011.

WANG Y. Is obesity associated with early sexual maturation? A comparsion of the association in American bouys versus girls. Pediatrics, v.110,n.5, p.903-910, 2202.

WINDLE, M. et al. Healthy passages: A multilevel, multimethod longitudinal study of adolescent health. American J ournal of Preventive Medicine, v. 27, n. 2, p. 164172, 2004.

WHO. WORLD HEALTH ORGANI ZATION. Physical status: The use of and interpretation of anthropometry, Report of a WHO Expert Committee. 1995.

WHO. WORLD HEALTH ORGANI ZATION. Department of Nutrition for Health and Development. Nutrition-friendly schools initiative. Public Health Nutrition, v. 9, n. 5, p. 658-660, 2006 a.

WHO. WORLD HEALTH ORGANIZATION. WHO child growth standards: length/ height-for-age, weight-for-age, weight-for-length, weightfor-height and body mass index-for-age: methods and development. Geneva: WHO, 2006b. 
WHO. WORLD HEALTH ORGANI ZATION. WHO Growth reference data for 5-19 years. Geneva: WHO, 2007. Disponível em: http://www.who.int/growthref/who2007_bmi_for_age/en/ acessado em 15/07/2013.

WHO. WORLD HEALTH ORGANIZATION. Regional Office for Europe. (2012). Social Determinants of Health and Well-being Among Young People: Health Behaviour in School-aged Children (HBSC) Study: International Report from the 2009/2010 Survey. World Health Organization, Regional Office for Europe.

XIONG, K. et al. Analyses of body composition charts among younger and older Chinese children and adolescents aged 5 to 18 years. BMC public health, v. 12, n. 1, p. 835, 2012. 
Anexos 


\section{Anexo A: Lista de Portarias e Decreto do Programa Saúde na Escola}

- Decreto № 6.286, de 5 de dezembro de 2007: Institui o Programa Saúde na Escola - PSE, e dá outras providências.

- Portaria Interministerial MS/ME № 675, de 4 de junho de 2008: Institui a Comissão Intersetorial de Educação e Saúde na Escola.

- Portaria MS/GM № 1.861, DE 4 DE SETEMBRO DE 2008: Estabelece recursos financeiros pela adesão ao PSE para Municípios com equipes de Saúde da Família, priorizados a partir do Índice de Desenvolvimento da Educação Básica - IDEB, que aderirem ao Programa Saúde na Escola - PSE.

- Portaria Interministerial MS/ME № 1.399, DE 14 de novembro de 2008: Designa os membros para compor a Comissão Intersetorial de Educação e Saúde na Escola - CIESE instituída pela Portaria no 675, de 4 de junho de 2008.

- Portaria MS/GM № 2.931, de 4 de dezembro de 2008: Altera a Portaria № $1.861 / G M$, de 4 de setembro de 2008, que estabelece recursos financeiros pela adesão ao Programa Saúde na Escola - PSE e credencia Municípios para o recebimento desses recursos.

- Portaria MS/GM № 3.146, de 17 de dezembro de 2009: Estabelece recursos financeiros para Municípios com equipes de Saúde da Família, que aderirem ao Programa Saúde na Escola - PSE.

- Portaria MS/GM № 790, de 12 de abril de 2010: Altera a Portaria no 3.146/GM, de 17 de dezembro de 2009, que estabelece recursos financeiros pela adesão ao Programa Saúde na Escola (PSE).

- Portaria MS/GM № 1.537, de 15 de junho de 2010: Credencia Municípios para o recebimento de recursos financeiros pela adesão ao Programa Saúde na Escola - PSE, conforme a Portaria № 3.146/GM, de 17 de dezembro de 2009.

- Portaria Interministerial MS/MEC № 3.696, de 25 de novembro de 2010: Estabelece critérios para adesão ao Programa Saúde na Escola (PSE) para o ano de 2010 e divulga a lista de Municípios aptos para Manifestação de Interesse.

- Portaria Interministerial MS/MEC № 1.910, de 8 de agosto de 2011: Estabelece o Termo de Compromisso Municipal como instrumento para o recebimento de recursos financeiros do Programa Saúde na Escola (PSE).

- Portaria Interministerial MS/MEC № 1.911, de 8 de agosto de 2011: Altera a Portaria Interministerial no 3.696/MEC/MS, de 25 de novembro de 2010, que estabelece critérios para transferência de recursos aos Municípios 
credenciados ao Programa Saúde na Escola (PSE) e define lista de Municípios aptos a assinarem Termo de Compromisso Municipal.

- Portaria MS/GM N N 3.014, DE 20 DE DEZEMBRO DE 2011: Habilita Municípios e o Distrito Federal para o recebimento do repasse de recursos financeiros relativos ao Programa Saúde na Escola (PSE).

- Portaria MS/GM N 524, DE 26 DE MARÇO DE 2012: Habilita Municípios ao recebimento do repasse de recursos financeiros relativos ao Programa Saúde na Escola (PSE).

- Decreto № 6.286, de 5 de dezembro de 2007: Institui o Programa Saúde na Escola - PSE, e dá outras providências.

- Portaria Interministerial MS/ME № 675, de 4 de junho de 2008: Institui a Comissão Intersetorial de Educação e Saúde na Escola.

- Portaria MS/GM № 1.861, DE 4 DE SETEMBRO DE 2008: Estabelece recursos financeiros pela adesão ao PSE para Municípios com equipes de Saúde da Família, priorizados a partir do índice de Desenvolvimento da Educação Básica - IDEB, que aderirem ao Programa Saúde na Escola - PSE.

- Portaria Interministerial MS/ME № 1.399, DE 14 de novembro de 2008: Designa os membros para compor a Comissão Intersetorial de Educação e Saúde na Escola - CIESE instituída pela Portaria no 675, de 4 de junho de 2008.

- Portaria MS/GM № 2.931, de 4 de dezembro de 2008: Altera a Portaria № 1.861/GM, de 4 de setembro de 2008, que estabelece recursos financeiros pela adesão ao Programa Saúde na Escola - PSE e credencia Municípios para o recebimento desses recursos.

- Portaria MS/GM № 3.146, de 17 de dezembro de 2009: Estabelece recursos financeiros para Municípios com equipes de Saúde da Família, que aderirem ao Programa Saúde na Escola - PSE.

- Portaria MS/GM № 790, de 12 de abril de 2010: Altera a Portaria no 3.146/GM, de 17 de dezembro de 2009, que estabelece recursos financeiros pela adesão ao Programa Saúde na Escola (PSE).

- Portaria MS/GM № 1.537, de 15 de junho de 2010: Credencia Municípios para o recebimento de recursos financeiros pela adesão ao Programa Saúde na Escola - PSE, conforme a Portaria № 3.146/GM, de 17 de dezembro de 2009.

- Portaria Interministerial MS/MEC № 3.696, de 25 de novembro de 2010: Estabelece critérios para adesão ao Programa Saúde na Escola (PSE) para o 
ano de 2010 e divulga a lista de Municípios aptos para Manifestação de Interesse.

- Portaria Interministerial MS/MEC № 1.910, de 8 de agosto de 2011: Estabelece o Termo de Compromisso Municipal como instrumento para o recebimento de recursos financeiros do Programa Saúde na Escola (PSE).

- Portaria Interministerial MS/MEC № 1.911, de 8 de agosto de 2011: Altera a Portaria Interministerial no 3.696/MEC/MS, de 25 de novembro de 2010, que estabelece critérios para transferência de recursos aos Municípios credenciados ao Programa Saúde na Escola (PSE) e define lista de Municípios aptos a assinarem Termo de Compromisso Municipal.

- Portaria MS/GM N ${ }^{\circ}$ 3.014, DE 20 DE DEZEMBRO DE 2011: Habilita Municípios e o Distrito Federal para o recebimento do repasse de recursos financeiros relativos ao Programa Saúde na Escola (PSE).

- Portaria MS/GM N 524, DE 26 DE MARÇO DE 2012: Habilita Municípios ao recebimento do repasse de recursos financeiros relativos ao Programa Saúde na Escola (PSE).

- PORTARIA № 297, DE 28 DE FEVEREIRO DE 2013: Estabelece recursos do Bloco de Atenção de Média e Alta Complexidade Ambulatorial e Hospitalar a ser incorporado ao Teto Financeiro de Média e Alta Complexidade do Estado de Minas Gerais, em conformidade com o Programa de Reestruturação e Contratualização dos Hospitais Filantrópicos no âmbito do Sistema Único de Saúde (SUS).

- PORTARIA № 364, DE 8 DE MARÇO DE 2013: Redefine a Semana de Mobilização Saúde na Escola (Semana Saúde na Escola), de periodicidade anual, e o respectivo incentivo financeiro.

- PORTARIA № 1.302, DE 28 DE JUNHO DE 20131: Altera o prazo para o registro das informações das ações realizadas na Semana de Mobilização Saúde na Escola (Semana Saúde na Escola) junto aos Sistemas de Avaliação e Monitoramento do PSE.

- PORTARIA № 1.412, DE 10 DE JULHO DE 2013: Institui o Sistema de Informação em Saúde para a Atenção Básica (SISAB).

- PORTARIA INTERMINISTERIAL № 1.413, DE 10 DE JULHO DE 2013: Redefine as regras e critérios para adesão ao Programa Saúde na Escola (PSE) por Estados, Distrito Federal e Municípios e dispõe sobre o respectivo incentivo financeiro para custeio de ações.

- PORTARIA INTERMINISTERIAL № 15, DE 10 DE OUTUBRO DE 2013: Institui o Projeto Consultórios Itinerantes de Odontologia e de Oftalmologia, no 
âmbito do Programa Saúde na Escola - PSE e Programa Brasil Alfabetizado PBA, e dá outras providências.

- PORTARIA № 2.608, DE 31 DE OUTUBRO DE 2013: Define Municípios com adesão ao Programa Saúde na Escola de 2013 e os habilita ao recebimento de $20 \%$ (vinte por cento) do teto de recursos financeiros pactuados em Termo de Compromisso e dá outras providências

- PORTARIA № 3.210, DE 26 DE DEZEMBRO DE 2013: Inclui os Municípios de Glória (BA), Palmeira dos Índios (AL) e Paulo Frontin (PR) à lista dos Municípios que finalizaram a adesão ao Programa Saúde na Escola de 2013 e ao recebimento de $20 \%$ (vinte por cento) do teto de recursos financeiros pactuados em Termo de Compromisso. 


\title{
Anexo B: Parecer do Comitê de Ética em Pesquisa - COEP da Faculdade de Saúde Pública da Universidade de São Paulo.
}

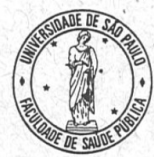 \\ COMITÊ DE ÉTICA EM PESQUISA - COEP \\ Faculdade de Saúde Pública \\ Universidade de São Paulo
}

OF.COEP $/ 350 / 11$

27 de setembro de 2011 .

Prezadas pesquisadora e orientadora,

O Comitê de Ética em Pesquisa da Faculdade de Saúde Pública da Universidade de São Paulo, analisou, de acordo com a Resolução n. ${ }^{\circ}$ 196/96 do Conselho Nacional de Saúde e suas complementares, o protocolo de pesquisa n. ${ }^{\circ} 2268$, intitulado "AVALIAÇÃO DA ADEQUAÇÃO DAS AÇÕES DE ALIMENTAÇÃO E NUTRIÇÃO NO PROGRAMA SAÚDE NA ESCOLA EM MUNICÍPIOS BRASILEIROS", do grupo III, sob responsabilidade da pesquisadora Ana Carolina Feldenheimer da Silva e orientação da Professora Patricia Constante Jaime, considerando-o APROVADO “AD REFERENDUM”.

Cabe lembrar que, de acordo com a Res. CNS 196/96, são deveres do(a) pesquisador(a): 1) Comunicar de imediato qualquer alteração no projeto e aguardar manifestação deste Comitê de Ética em Pesquisa para dar continuidade à pesquisa; 2) Manter sob sua guarda e em local seguro, pelo prazo de 5 (cinco) anos, os dados da pesquisa, contendo fichas individuais e todos os demais documentos recomendados pelo COEP, no caso eventual auditoria; 3) Comunicar formalmente a este Comitê por ocasião do encerramento da pesquisa; 4) Elaborar e apresentar relatórios parciais e final; 5) Justificar perante o COEP interrupção do projeto ou a não publicação dos resultados.

Atenciosamente,

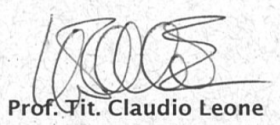

Coordenador do Comitê de Ética em Pesquisa - FSP/USP

IIm. ${ }^{\text {a Sr}}{ }^{\text {a }}$

Prof. $^{a}$ Assoc. Patricia Constante Jaime

Departamento de Nutrição

Faculdade de Saúde Pública da USP

Av. Dr. Arnaldo, 715 - Cerqueira César - CEP 01246-904 - São Paulo - SP Contato: (55 11) 30617779 | coep@fsp.usp.br | www.fsp.usp.br 


\section{Anexo C: Convite para participação no estudo}

Caro Gestor do Programa Saúde na Escola,

O Programa Saúde na Escola foi criando no ano de 2007 e é uma importante ação de saúde que reúne esforços das equipes de saúde e educação em mais de 4.000 municípios brasileiros. Como toda política pública, é importante que suas ações sejam estudadas e avaliadas de forma a gerar reflexões e melhorias das atividadades propostas para o programa.

O campo da alimentação é nutrição é uma importante ação do PSE presente nos componentes I e II.

Com essa perspectiva, estamos realizando uma pesquisa, que gerará uma tese de doutorado com base no Projeto "AVALAÇÃO DA ADEQUAÇÃO DAS AÇÕES DE ALIMENTAÇÃO E NUTRIÇÃO NO PROGRAMA SAÚDE NA ESCOLA EM MUNICÍPIOS BRASILEIROS" do Programa de Pós Graduação em Nutrição em Saúde Pública, da Faculdade de Saúde Pública da Universidade de São Paulo.

O projeto de pesquisa tem por objetivo conhecer como são desenvolvidas algumas ações do Programa Saúde na Escola.

O formulário foi elaborado para ser respondido pelo gestor da saúde responsável pelo programa mas pode ser discutido e compartilhado com os gestores da educação.

Os resultados da pesquisa poderão ajudar a qualificar as ações propostas e desenvolvidas nos municípios que desenvolvem as ações do PSE.

Os dados coletados são sigilosos e serão utilizados apenas para os fins da pesquisa.

Convido a todos a participar do estudo. O questionário está disponível no seguinte link:

http://formsus. datasus. gov.br/site/formulario.php?id_aplicacao=12045

e estará no ar até 31/08/2013.

Dúvidas, sugestões e críticas podem ser enviadas para este endereço.

Agradeço a colaboração, 


\title{
Anexo D: Formulário eletrônico disponibilizado aos gestores municipais do Programa Saúde na Escola
}

\author{
0809/13 Formsur \\ Rojwsing \\ verbox $3.0^{\circ}$ \\ Avaliação Açốes PSE \\ Caro Gestor do Programa Saúde na Escola: \\ O presente questionário é parte integrante do Projeto de pesquisa \\ intitulado: "AVALAÇÃO DA ADEQUAÇÃO DAS AÇÕES DE ALMENTAÇÃO E \\ NUTRIÇÃO NO PROGRAMA SAÚDE NA ESCOLA EM MUNICÍPIOS BRASILEIROS". O \\ formulário tem tempo de duração de cerca de 15 minutos. A sua colaboração é muito \\ importante para auxiliar a entender como as ações do Programa Saúde na Escola vem \\ sendo desenvolvida e como o PSE pode melhorar. \\ Este projeto tem o objetivo de Avaliar a adequação das ações de alimentação e \\ nutrição no Programa Saúde na Escola - PSE nos municipios convocados e que \\ aderiram ao PSE até o ano de 2012. Se o seu município aderiu em 2013, favor não \\ preencher o questionário. \\ Para tanto convidamos o Sr.(a) para que colabore com o nosso estudo preenchendo \\ as informações referentes ao seu município no formulário eletrônico disponibilizado \\ neste site. Os dados coletados serão utilizados para caracterizar as ações que foram \\ realizadas no período de implementação do Programa até a presente data. Os dados \\ aqui coletados serão utilizados especificamente para fins acadêmicos e os seus \\ resultados serão disponibilizados na Tese de Doutorado, que poderá ser consultada \\ por qualquer interessado, disponivel na biblioteca da Faculdade de Saúde Pública - \\ USP ou através dos pesquisadores envolvidos. Os resultados poderão ainda ser \\ publicados em artigos cientificos de revistas especializadas. \\ O preenchimento dos dados no sistema não acarretará em sanções nem ações focadas \\ sobre os municípios que colaborarem com o estudo. Será mantida a confidencialidade \\ de todos os participantes do estudo, não sendo revelado o nome dos informantes e \\ seus municípios de origem. Os resultados desse estudo contribuirão para o \\ planejamento futuras políticas além de contribuir para a avaliação de outros \\ programas governamentais. \\ Após ler as informações acima eu tenho os direitos de: \\ 1. Receber resposta a qualquer pergunta e esclarecimento sobre os \\ procedimentos, riscos, beneficios e outros relacionados à pesquisa; \\ 2. Retirar o consentimento a qualquer momento e deixar de participar do \\ estudo; \\ 3. Nẫo ser identificado e ser mantido o caráter confidencial das informações \\ relacionadas à privacidade. \\ 4. Procurar esdarecimentos com o Comitê de Ética em Pesquisa da Faculdade de \\ Saúde Pública da Universidade de São Paulo, no telefone 11 3061-7779 ou Av. Dr. \\ Arnaldo, 715 - Cerqueira César, São Paulo - SP, em caso de dúvidas ou notificação de \\ acontecimentos não previstos. \\ Pesquisador Responsável: Ana Carolina Feldenheimer da Silva \\ 1) Aceite em participar da pesquisa:
}

formsus.datasus.govbriksteltormuario php?d__aplicacao-12045 
ISm, aceto responder o formuldrib e portichar do estudo.

[NLo, n\$o scelo responder o formultrb e nem participar do estudo.

- Dados Institucionals

2) Estado:

3) Municipio:

4) E-mail:

5) Em que ano o municiplo aderiu ae DSE?

$$
\begin{aligned}
& \square^{2008} \\
& \square^{2009} \\
& \square^{2010} \\
& \square^{2011} \\
& \square^{2012} \\
& \square^{2013}
\end{aligned}
$$

6) Wocế é o gestor responsável pelo Pregrama Saúde na Escola no Municipio?

$1 \mathrm{Sim}$

1. No

7) Rrofissato:

$$
\begin{aligned}
& \text { 1 Medico } \\
& \text { [Enfermelo } \\
& \text { TOdontiogo } \\
& \text { [ Nutricionteta } \\
& \text { 1 Feloterapeuta } \\
& \text { I Terapeuta Ocupocional } \\
& \text { Peicodlogo } \\
& \text { [1] Foncaudidlogo } \\
& \text { | Assietente sock| } \\
& \text { Doutro }
\end{aligned}
$$

8) Em que setor da Secretaria de Saúde wock trabaha?

9) Nimero de escolas no municlpib:

10) Nímero de escolas vinculadas ao Programa no Municipio:

Caracterizaçăo da Atençbo Bdssica no Munikipio

11) Nímero de equipe de Estratégia Saúde da Familia:

12) Nímere de equlpe de Atençăe Bbska:

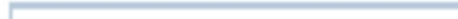

13) Nímero de equipe de ESF no PSE!

14) O Municlolo possul equipe de NasF? 


\section{$\square \operatorname{sim}$ \\ प1So}

15) O NaSF apóla as equipes de AB nas açōes do PSE?

प1Sm

$\square$ NSo

16) Come ocorre esse apoio?

$\square$ Matrikamento das aç̧es

A Atuaçto direta nas esooks

$\square$ Atendimento dos jovens comalguma demanda espochica de saude

Auxilo no planejamento das agbes das cqulpes nas escolas

VElo sel informar

17) Nos equipes de MaSF há nutrikionistas?

ISim, en todses

$\square^{5 \mathrm{Sm}}$ emporte delas

VISo, em nenhume

18) Quem săo os profissionais da saúde que attum no PSE?

Equpe de Atoncho Bdalca tradicional

$\square$ Equipe de Solde da fants

Equipe volante

$\square$ NASF

Doutice

Planejamento das açles

19) Data da 1a reuniso do GTI -:

20) Qual a conformaçäo inicial de GTI?

$$
\begin{aligned}
& \text { Drside } \\
& \square \text { etucacho } \\
& \text { D aceistênch sochal } \\
& \text { Deguranos allmentar e nutricions: } \\
& \text { Doutioe }
\end{aligned}
$$

21) O GTI realiza reuniōes com a equipe da alimentạ̧ăo escolar do municipio para điscussbo do cardbipio oferecido pela alimentaçào escolan?

$$
\square^{\mathrm{sm}}
$$

22) O GTI realizeu diagndstico para a implementaçb de Programa? :

$$
\begin{aligned}
& \square^{\text {Sim }} \\
& \square^{\text {NSo }} \\
& \square^{\text {Noo sei }}
\end{aligned}
$$

23) Qual a frequencia de reuribes do GTr?

$$
\begin{aligned}
& \square^{\text {Semenal }} \\
& \square^{\text {Qunnzenal }} \\
& \square^{\text {Mensal }} \\
& \square^{\text {Binestral }} \\
& \square_{\text {Thmestral }}^{\text {Semestral }} \\
& \square^{\text {Anual }}
\end{aligned}
$$


IO GTI nSio se reunlu no útimo ano

$1 \mathrm{~N}$ Lo sel

20) Quais proflssionais da educaçlo que atuam no PSE?

| Proteceores

Protesoor de educacho tleka

Pericdiogo

Agente de oducacto

loutioe

25) As aç̋̄es do PSE foram pactuadas no conselho municipal de saúde?

$15 \mathrm{Sm}$

$1 \mathrm{NLO}$

26) Se sim, sâe repactuadas anualmente?

$15 \mathrm{im}$

1 No

$1 \mathrm{Nos}$ sel

27) O GTI faz articulaçlo com outros setores para desenvolver as açeles nas escolas?

$1 \mathrm{Sim}$

No

28) Se sim, com quals setores?

| Organbagbes nto governamentsk

Universidades

Tecretarla Estadual de Solde

I Secretarla Estadual de Educactio

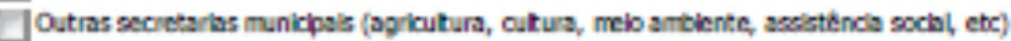

Entidodes relgibeas

| Assockodes comunthrias

Extensto nural

loubce

\footnotetext{
Atuaçso do nutricionista no municiplo

29) HS nutricionista atuando no municipio? :

$1 \mathrm{Sin}$

No

30) Quantos nutricionistas atuam no municipio?

Nonhum

11

125

16-10

$10-20$

$120-50$

Inale de 50

31) Se sim, ende atua?

Saúde - gertio

II Educacho - gestho

Allmentactio esoolar

- Atenctio sside

loestio de programes
} 
Materlals de apolo para as açoles

32) O municipio recebeu os materiais enviados pelo Ministérib da Educaçbo para apolar as açōes de promoçäo da alimentaçăe saudável:

A Ábum serkdo "o que é vits saudiver"

Thanul Operadonal para Promoctio da Almentacto Saudtrel nas Eacolas

I Revieza Cench Haje

No fol recebido nenhum meterbl

33) O municipio desenvolveu alguma ficha padräo para avaliaço das condiçbes de saúde dos educandos?

$$
\begin{array}{r}
\mathrm{Nim} \\
\mathrm{NOO}
\end{array}
$$

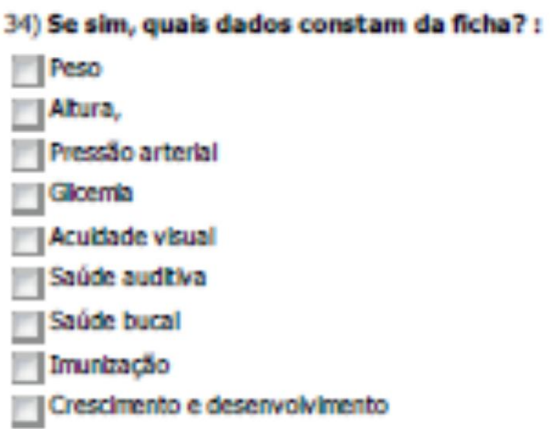

34) Se sim, quais dades constam da ficha? :

Peso

Ahurs,

| Precelo arterial

IGoemla

IAculade vieusl

| lSaúde audtiva

ISaúde bucal

Imunbacto

Cresclmento e desenvolvimento

Açbes de allmentaçâo e nutrikșo

35) O municipio desenvolvia aç̧es de avaliaça do estado nutricional dos escolares como atividade de rotina antes do PSE ser implementado?

$$
\begin{aligned}
& \text { ISm } \\
& \text { N No } \\
& \text { No sel }
\end{aligned}
$$

36) Se sim, quen desenvolvia as acbles?

Isaúde,

Educscilo

Dotros setores

37) Quem desenvolvia a açăo na escola?

1 Protecoores

Alunos

[ Funclondirice da escols (alem doe professores)

Empresa teveribada

Wutricionleta da alimentaçso escolar

poutros

38) Quem desenvolvía a açăo na saúde?

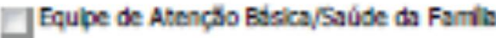

Proflesionsls do NASF

poutros 
39) Como o municipio se organiza para a aç̆o? :

$\square$ Equipe de SF cuids das escolas do teritbrio

$\square$ Equipe volante

Equlpe de saude espocitos para as agobes do PSE

$\square$ Equipe Atençio Bdalca/Saúde da Famils cobre escolas dentro e fora do seu temitório

40) Onde as ações șo reallizadas? :

$\square$ Esoob
$\square^{\text {Ues }}$
$\square^{\text {Hosplal }}$
$\square^{\text {Contro de espech lidsde }}$
$\square^{\text {Outro espapo da comunidsde }}$

- Componente I - avallaçẩo das condị̧bes de saúde

41) A ESF em parcería com a equipe da escola realiza avaliaçbo do estado nutricional dos escolares?

$\square \mathrm{sm}$

प1\%o

42) Se sim, quais profisskenais desenvelvem a açbo?

43) Se sim, com qual periodicidade?

Mensal

Dinestral

Thimestral

प Semestal

DAnual

4) A equipe realiza a classincaçbo do estado nutricional?

$\square \mathrm{Sm}$

1No

45) Os casos de đesnutrikb̆o e excesso de peso sầ encaminhados para algum serviço de sabude?

$$
\square^{\mathrm{Sm}}
$$

46) Se sim, para qual?

$$
\begin{aligned}
& \text { Atençlo Basica } \\
& \square \text { Ambulatorilo de espechaldade } \\
& \square \text { Hosplal } \\
& \square \text { Outros pontos da Rede de Saúde }
\end{aligned}
$$

47) HS um fluxe de encaminhamento para a UBS de educandes diagnosticados com baike peso ou excesso de peso?

$$
\square^{\mathrm{Sm}}
$$

45) Os dados sảo registrados em algum słbtema de informaçbo?

$$
\square^{\mathrm{sm}}
$$

49) Se sim, qual sistema?

$$
\begin{aligned}
& \square \text { SISvan } \\
& \square \text { SIMEC } \\
& \square \text { Setem Propro do Municpio } \\
& \square \text { Outro }
\end{aligned}
$$




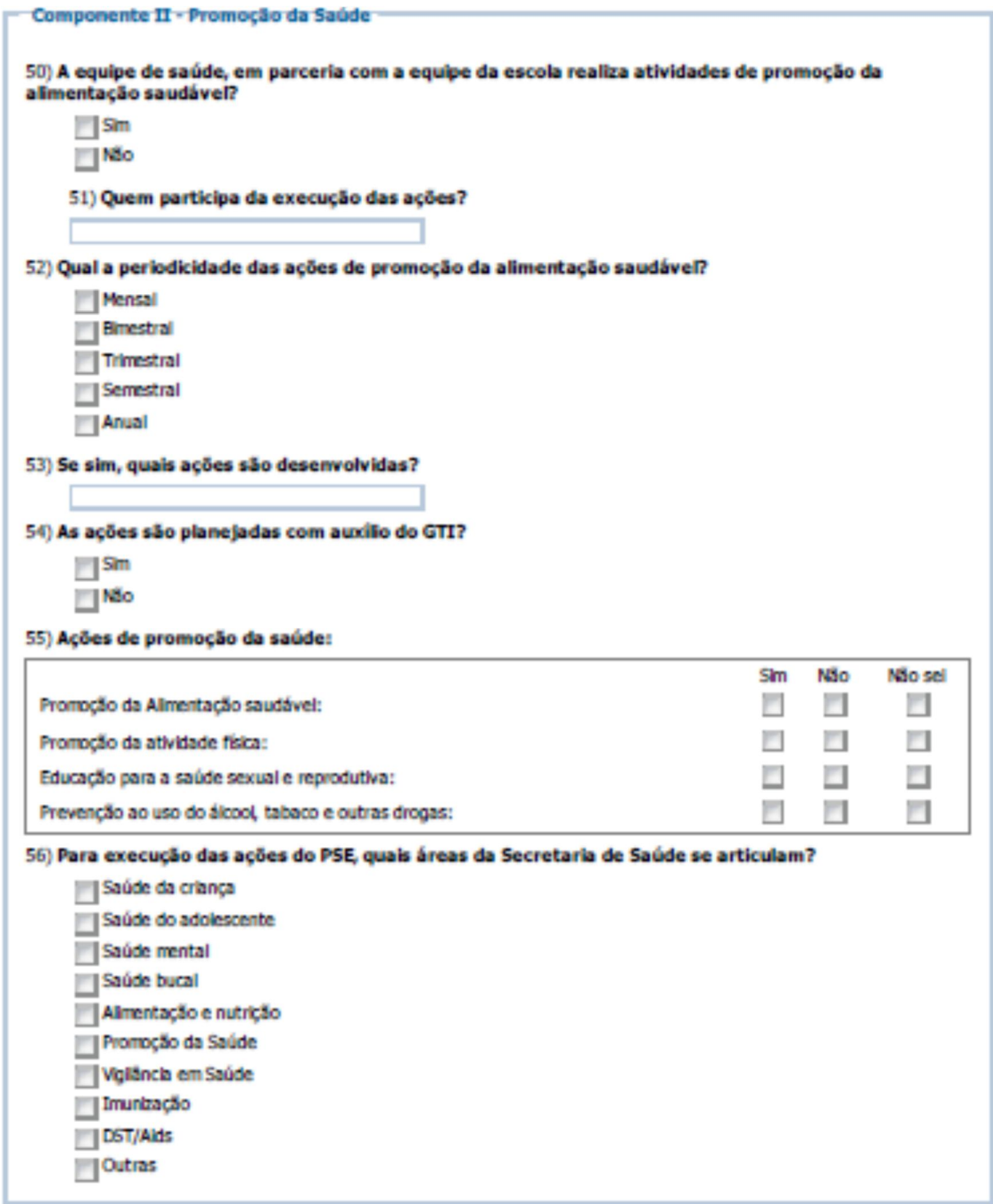

Semana Saúde na Escola 2012

57) O municipio reallrou a semana Saúde na escola no ano de 2012?

$$
\square^{\text {Sim }}
$$

58) Quais atividades foram realizadas na Semana Saúde na Escola 2012/:

Athidades efucatives de promoçto da almentaç̧o saudivel e modes de vida ssudives: Athidades cetucatives sobre a temetca da saide sexial, sáse reprodutva, prevençto DST/Aids:

Sm NSo NSo se:

$\square \square \square$ Allikade ceducatives sobre a tenítica da side 
Atbilades educativas sobre a temitka dos rbocs do uso de áloool tabsca, cracke outras drogas: Atbilades educativas sobre diversidade sexual, bulyhg, homofobla, dacriminaglo e preconcek $\alpha$

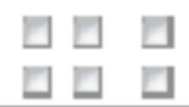

59) Qual a sua opintio sobre a reallzaç̇ólo da Semana Saúde na Escola?

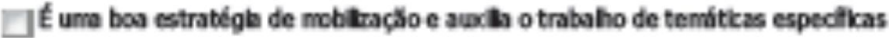

Atrapaha as atividades da eqube de saude por conta da moblizaçlo

Tem baba adesto das escolns e fovers

$\square$ Aurda na dhulgaç̆o do PSE e de suas ağbes

TIlosel

Doutro

60) Qual?

\section{1) Comentárlos e sugestồes!}


Anexo E: Medianas dos valores de peso e altur a, segundo sexo e ano, comparados com os valores de referência da OMS 2007 e Pesquisa de Orçamentos Familiares- 2008/ 9.

Tabela 9 - Distribuição da mediana da altura de indivíduos do sexo masculino, segundo idade. SISVAN (anos 2008 a 2012), Pesquisa Nacional de Orçamentos Familiares e Valores da População de referência proposta pela OMS. Brasil, 2014.

\begin{tabular}{cccccccc}
\hline & POF & SISVAN & SISVAN & SISVAN & SISVAN & SISVAN & WHO \\
& $\mathbf{2 0 0 8 / 9}$ & $\mathbf{2 0 0 8}$ & $\mathbf{2 0 0 9}$ & $\mathbf{2 0 1 0}$ & $\mathbf{2 0 1 1}$ & $\mathbf{2 0 1 2}$ & $\mathbf{2 0 0 7}$ \\
\hline 7 anos & 124,9 & 121 & 122 & 122 & 122 & 123 & 121,7 \\
8 anos & 129,7 & 126 & 127 & 127 & 128 & 128 & 127,3 \\
9 anos & 135,2 & 132 & 132 & 132 & 132,5 & 133 & 132,6 \\
10 anos & 139,9 & 136 & 137 & 138 & 138 & 138 & 137,8 \\
11 anos & 143,6 & 141 & 142 & 144 & 143 & 143 & 143,1 \\
12 anos & 151 & 146 & 147 & 149 & 148 & 149 & 149,1 \\
13 anos & 157,5 & 152 & 153 & 155 & 155 & 156 & 156,0 \\
14 anos & 164,1 & 158 & 160 & 161 & 161 & 162 & 163,2 \\
15 anos & 167,8 & 163 & 164 & 165 & 165 & 165 & 169,0 \\
16 anos & 170 & 165 & 166 & 168 & 167 & 167 & 172,9 \\
17 anos & 171,8 & 166 & 167 & 169 & 169 & 168 & 175,2 \\
18 anos & 172,6 & 167 & 168 & 169 & 168 & 169 & 176,1 \\
\hline
\end{tabular}

Tabela 10- Distribuição da mediana da altura de indivíduos do sexo feminino, segundo idade. SISVAN (anos 2008 a 2012), Pesquisa Nacional de Orçamentos Familiares e Valores da População de referência proposta pela OMS. Brasil, 2014.

\begin{tabular}{cccccccc}
\hline & POF & SISVAN & SISVAN & SISVAN & SISVAN & SISVAN & WHO \\
& $2008 / 9$ & 2008 & 2009 & 2010 & 2011 & 2012 & 2007 \\
\hline 7 anos & 123,3 & 120 & 121 & 122 & 122 & 122 & 120,8 \\
8 anos & 129,4 & 126 & 126 & 127 & 127 & 128 & 126,6 \\
9 anos & 135 & 132 & 132 & 133 & 133 & 134 & 132,5 \\
10 anos & 140,4 & 138,2 & 138 & 140 & 139 & 140 & 138,6 \\
11 anos & 147,5 & 144 & 145 & 146 & 146 & 146 & 145,0 \\
12 anos & 153 & 150 & 150 & 152 & 152 & 152 & 151,2 \\
13 anos & 157 & 153 & 154 & 155 & 155 & 155 & 156,4 \\
14 anos & 159,1 & 155 & 156 & 156 & 156 & 157 & 159,8 \\
15 anos & 160 & 157 & 156 & 157 & 157 & 157 & 161,7 \\
16 anos & 160,3 & 157 & 157 & 157 & 158 & 158 & 162,5 \\
17 anos & 160,5 & 158 & 158 & 158 & 158 & 158 & 162,9 \\
18 anos & 161,1 & 158 & 158 & 158 & 158 & 158 & 163,1 \\
\hline
\end{tabular}


Tabela 11 - Distribuição da mediana de peso de indivíduos do sexo masculino, segundo idade. SISVAN (anos 2008 a 2012), Pesquisa Nacional de Orçamentos Familiares e Valores da População de referência proposta pela OMS. Brasil, 2014.

\begin{tabular}{cccccccc}
\hline & POF & SISVAN & SISVAN & SISVAN & SISVAN & SISVAN & WHO \\
& 2008 & 2008 & 2009 & 2010 & 2011 & 2012 & 2007 \\
7 anos & 25,1 & 22,7 & 23 & 23 & 23,2 & 23,8 & 22,9 \\
8 anos & 27,7 & 25 & 25 & 25,7 & 26 & 26,1 & 25,5 \\
9 anos & 31,6 & 28,1 & 28,1 & 28 & 28,8 & 29 & 28,2 \\
10 anos & 33,4 & 30,4 & 31 & 31,7 & 31,6 & 32 & 31,2 \\
11 anos & 36,8 & 33,4 & 34 & 35,35 & 35,5 & 35 & 34,7 \\
12 anos & 42 & 36,5 & 37,9 & 39 & 39,5 & 39,15 & 39,0 \\
13 anos & 47,4 & 41 & 42 & 44,5 & 45 & 45 & 44,4 \\
14 anos & 52,3 & 47 & 48 & 50 & 50 & 50 & 50,6 \\
15 anos & 57 & 52 & 53 & 54 & 53,65 & 54 & 56,4 \\
16 anos & 60,1 & 55 & 55,7 & 57,9 & 56,5 & 57,2 & 61,3 \\
17 anos & 63,1 & 57 & 58 & 59,45 & 60 & 59 & 64,9 \\
18 anos & 65,3 & 60 & 59 & 61 & 60 & 60,35 & 67,4 \\
\hline
\end{tabular}

Tabela 12 - Distribuição da mediana de peso de indivíduos do sexo feminino, segundo idade. SISVAN (anos 2008 a 2012), Pesquisa Nacional de Orçamentos Familiares e Valores da População de referência proposta pela OMS. Brasil, 2014.

\begin{tabular}{lccccccc}
\hline & POF & SISVAN & SISVAN & SI SVAN & SISVAN & SISVAN & WHO \\
& $2008 / 9$ & 2008 & 2009 & 2010 & 2011 & 2012 & 2007 \\
7 anos & 24,9 & 22 & 22,5 & 23 & 23 & 23 & 22,5 \\
8 anos & 27,7 & 25 & 25 & 25,6 & 26 & 26 & 25,1 \\
9 anos & 31,7 & 28,4 & 28,3 & 28,6 & 29 & 29,4 & 28,3 \\
10 anos & 34,3 & 32 & 32 & 33 & 32,8 & 33,1 & 31,9 \\
11 anos & 39,5 & 36 & 36 & 38,3 & 38 & 38 & 36,3 \\
12 anos & 44,2 & 40,5 & 40,9 & 43 & 43,3 & 43 & 41,2 \\
13 anos & 47,9 & 45 & 45 & 47 & 47,5 & 47,9 & 46,0 \\
14 anos & 50 & 48 & 48,5 & 50 & 50 & 50 & 50,0 \\
15 anos & 52,6 & 50 & 50 & 52 & 52 & 52,5 & 52,8 \\
16 anos & 53,3 & 52 & 52 & 53,5 & 54 & 55 & 54,7 \\
17 anos & 54,1 & 53 & 53,2 & 55 & 56 & 56 & 55,8 \\
18 anos & 55,4 & 54 & 55 & 56,5 & 57 & 57,4 & 56,5 \\
\hline
\end{tabular}




\section{Anexo F: Distribuição de desvios nutricionais (baixo peso, sobrepeso e obesidade) segundo idade e sexo, de indivíduos acompanhados SI SVAN no anos de 2008 a 2012.}

Tabela 13 - Distribuição percentual de desvios nutricionais (baixo peso, sobrepeso e obesidade) segundo idade e sexo, de indivíduos acompanhados SISVAN no ano de 2008. Brasil, 2014.

\begin{tabular}{ccccccc}
\hline \multirow{2}{*}{$\begin{array}{c}\text { Idade } \\
\text { (anos) }\end{array}$} & \multicolumn{2}{c}{ Baixo peso (\%) } & \multicolumn{2}{c}{ Sobrepeso (\%) } & \multicolumn{2}{c}{ Obesidade (\%) } \\
\cline { 2 - 7 } & masculino & feminino & masculino & feminino & masculino & feminino \\
\hline 7 & 5,77 & 5,07 & 23,34 & 20,42 & 10,07 & 7,05 \\
8 & 6,53 & 4,61 & 24,63 & 23,17 & 11,12 & 8,5 \\
9 & 5,17 & 4,26 & 24,96 & 23,86 & 11,45 & 9,39 \\
10 & 5,3 & 5,7 & 24 & 23,23 & 9,77 & 6,83 \\
11 & 4,82 & 5,73 & 22,26 & 22,8 & 8,56 & 6,3 \\
12 & 7,25 & 5,8 & 19,87 & 22,48 & 6,76 & 5,17 \\
13 & 7,12 & 4,54 & 17,24 & 20,92 & 5,16 & 4,79 \\
14 & 7,16 & 3,84 & 17,41 & 20,88 & 3,62 & 4,49 \\
15 & 5,72 & 3,79 & 16,91 & 19,11 & 3,85 & 4,14 \\
16 & 6,13 & 3,52 & 14,03 & 19,11 & 2,87 & 4,55 \\
17 & 6,52 & 3,09 & 11,69 & 20,25 & 2,46 & 4,97 \\
18 & 3,74 & 2,36 & 9,97 & 22,07 & 1,71 & 5,3 \\
\hline
\end{tabular}

Tabela 14 - Distribuição percentual de desvios nutricionais (baixo peso, sobrepeso e obesidade) segundo idade e sexo, de indivíduos acompanhados SISVAN no ano de 2009. Brasil, 2014.

\begin{tabular}{ccccccc}
\hline \multirow{2}{*}{$\begin{array}{c}\text { Idade } \\
\text { (anos) }\end{array}$} & \multicolumn{2}{c}{ Baixo peso (\%) } & \multicolumn{2}{c}{ Sobrepeso (\%) } & \multicolumn{2}{c}{ Obesidade (\%) } \\
\cline { 2 - 7 } & masculino & feminino & masculino & feminino & masculino & feminino \\
\hline 7 & 5,66 & 5,3 & 23,25 & 20,31 & 9,91 & 7,4 \\
8 & 6,16 & 4,87 & 2,86 & 22,65 & 10,25 & 7,94 \\
9 & 5,77 & 5,34 & 25,46 & 24,1 & 11,58 & 9,11 \\
10 & 5,52 & 4,7 & 27,23 & 26,61 & 12,56 & 9,43 \\
11 & 4,44 & 5,42 & 24,41 & 23,79 & 11,57 & 7,12 \\
12 & 5,2 & 4,89 & 23,49 & 23,24 & 9,11 & 5,65 \\
13 & 6,32 & 4,8 & 20,74 & 21,74 & 7,32 & 5,41 \\
14 & 6,17 & 4 & 17,19 & 21,9 & 4,93 & 4,54 \\
15 & 5,38 & 3,54 & 16,24 & 20,52 & 4,54 & 4,18 \\
16 & 5,56 & 3,14 & 14,75 & 21 & 3,63 & 4,66 \\
17 & 4,48 & 3 & 12,72 & 22,53 & 3,01 & 5,23 \\
18 & 6,89 & 2,14 & 11,8 & 24,03 & 2,84 & 6,79 \\
\hline
\end{tabular}


Tabela 15 - Distribuição percentual de desvios nutricionais (baixo peso, sobrepeso e obesidade) segundo idade e sexo, de indivíduos acompanhados SISVAN no ano de 2010. Brasil, 2014.

\begin{tabular}{ccccccc}
\hline \multirow{2}{*}{$\begin{array}{c}\text { Idade } \\
\text { (anos) }\end{array}$} & \multicolumn{2}{c}{ Baixo peso (\%) } & \multicolumn{2}{c}{ Sobrepeso (\%) } & \multicolumn{2}{c}{ Obesidade (\%) } \\
\cline { 2 - 7 } & masculino & feminino & masculino & feminino & masculino & feminino \\
\hline 7 & 5,07 & 4,13 & 23,88 & 23,04 & 10,34 & 8,52 \\
8 & 4,69 & 3,96 & 24,88 & 24,72 & 11,07 & 8,66 \\
9 & 4,57 & 4,05 & 25,09 & 26,56 & 11,46 & 9,42 \\
10 & 4,36 & 3,89 & 28,54 & 30,23 & 13 & 11,62 \\
11 & 4,5 & 3,39 & 29,56 & 29,45 & 12,86 & 10,61 \\
12 & 4,39 & 2,99 & 25,58 & 28,14 & 10,78 & 8,14 \\
13 & 5,45 & 3,99 & 23,32 & 26,44 & 7,64 & 7,14 \\
14 & 5,98 & 3,12 & 20,49 & 25,63 & 6,16 & 6,12 \\
15 & 4,48 & 2,74 & 18,3 & 26,56 & 5,09 & 6,63 \\
16 & 4,35 & 2,39 & 16,2 & 25,8 & 3,9 & 6,5 \\
17 & 5,21 & 1,89 & 15,13 & 28,47 & 4,09 & 7,23 \\
18 & 5,49 & 1,87 & 12,96 & 30,03 & 3,96 & 8,94 \\
\hline
\end{tabular}

Tabela 16 - Distribuição percentual de desvios nutricionais (baixo peso, sobrepeso e obesidade) segundo idade e sexo, de indivíduos acompanhados SISVAN no ano de 2011. Brasil, 2014.

\begin{tabular}{ccccccc}
\hline \multirow{2}{*}{$\begin{array}{c}\text { Idade } \\
\text { (anos) }\end{array}$} & \multicolumn{2}{c}{ Baixo peso (\%) } & \multicolumn{2}{c}{ Sobrepeso (\%) } & \multicolumn{2}{c}{ Obesidade (\%) } \\
\cline { 2 - 7 } & masculino & feminino & masculino & feminino & masculino & feminino \\
\hline 7 & 5,36 & 4,00 & 27,08 & 24,72 & 12,25 & 10,19 \\
8 & 5,35 & 4,16 & 27,67 & 28,19 & 13,21 & 11,12 \\
9 & 4,91 & 4,28 & 28,71 & 28,18 & 13,82 & 10,55 \\
10 & 5,57 & 4,96 & 29,83 & 28,60 & 14,30 & 11,40 \\
11 & 4,44 & 4,68 & 30,33 & 29,10 & 13,39 & 11,63 \\
12 & 5,31 & 4,14 & 28,56 & 31,37 & 12,40 & 11,18 \\
13 & 5,50 & 3,47 & 24,49 & 28,81 & 9,87 & 9,24 \\
14 & 5,50 & 3,83 & 23,60 & 27,11 & 7,75 & 7,09 \\
15 & 4,65 & 2,75 & 18,19 & 26,21 & 6,14 & 7,07 \\
16 & 5,82 & 2,31 & 15,90 & 27,86 & 5,41 & 7,43 \\
17 & 5,53 & 2,52 & 16,65 & 30,79 & 4,54 & 8,70 \\
18 & 5,09 & 1,89 & 15,08 & 31,77 & 5,48 & 9,67 \\
\hline
\end{tabular}


Tabela 17 - Distribuição percentual de desvios nutricionais (baixo peso, sobrepeso e obesidade) segundo idade e sexo, de indivíduos acompanhados SISVAN no ano de 2012. Brasil, 2014.

\begin{tabular}{ccccccc}
\hline \multirow{2}{*}{$\begin{array}{c}\text { Idade } \\
\text { (anos) }\end{array}$} & \multicolumn{2}{c}{ Baixo peso (\%) } & \multicolumn{2}{c}{ Sobrepeso (\%) } & \multicolumn{2}{c}{ Obesidade (\%) } \\
\cline { 2 - 7 } & masculino & feminino & masculino & feminino & masculino & feminino \\
\hline 7 & 4,83 & 4,27 & 28,39 & 25,55 & 13,50 & 11,21 \\
8 & 5,13 & 3,86 & 30,07 & 29,22 & 15,38 & 12,93 \\
9 & 4,57 & 4,25 & 30,25 & 30,10 & 14,22 & 12,49 \\
10 & 5,04 & 4,49 & 29,38 & 28,53 & 13,78 & 10,54 \\
11 & 4,97 & 4,39 & 28,77 & 29,88 & 12,16 & 10,41 \\
12 & 5,45 & 4,00 & 27,02 & 29,80 & 9,82 & 9,86 \\
13 & 5,72 & 2,97 & 24,80 & 28,44 & 8,54 & 8,42 \\
14 & 5,01 & 2,65 & 20,55 & 27,22 & 6,90 & 7,27 \\
15 & 5,59 & 2,78 & 18,58 & 27,33 & 5,98 & 7,19 \\
16 & 5,10 & 2,01 & 17,56 & 28,82 & 6,10 & 7,36 \\
17 & 3,56 & 2,03 & 16,40 & 30,65 & 6,03 & 8,58 \\
18 & 4,77 & 1,64 & 14,39 & 33,26 & 3,66 & 9,92 \\
\hline
\end{tabular}




\section{Currículo Lattes}




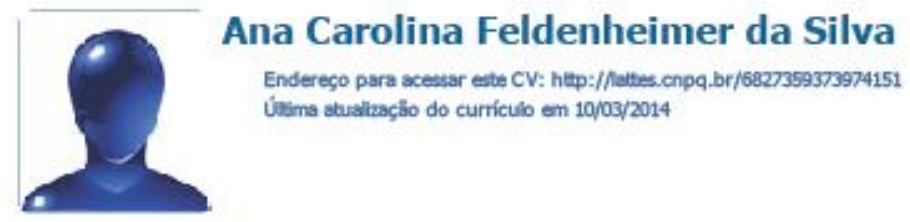

Atualmente é Consultora Nacional de Alimentação e Nutrição da Organização Pan-Americana da Saúde (OPAS/OMS). Possui graduação em Nutrição pela Universidade de São Paulo (2004), Especialização em Nutrição na Infância pelo Departamento de Pediatria da Unifesp - SP (2006), Especialização em Gestão de Políticas de Alimentação e Nutrição pela Fiocruz Brasilia (2009) e mestrado em Saúde Pública pela Universidade de São Paulo (2007). Atuou como consultora técnica da Coordenação-Geral da Política de Alimentação e Nutrição do Departamento de Atenção Básica do Ministério da Saúde entre os anos de 2008 a 2013. Tem experiência na área de Nutrição, com ênfase em Análise Nutricional de População, atuando principalmente nos seguintes temas: crianças, gestantes, epidemiologia e análise do estado nutricional de populaçães. (Texto informado pelo autor)

\section{Identificação}

Nome Ana Carolina Feldenheiner da Silva

Nome em citaçôes bibliográficas SILVA, ACF; Silva, Ana Carolina Feldenheimer da;Siva, Ana Carolna Feldenheimer;SILVA, A C F

\section{Endereço}

Endereço Profissional Mnistério da Saúde, Coordenação Geral de Alimentação e Nutrição - DAB/SAS, SAF Sul, Quadra 2, Lote 5/6, Edff́cio Premium- Torre II, Auditónio, Sala 8 SAF SU

$70070-600$ - Brasita, DF - Brasit

URL da Homepage: www.saude.gov.br/nutricao

\section{Formação acadêmica/titulação}

\begin{tabular}{|c|c|}
\hline 2010 & $\begin{array}{l}\text { Doutorado em andamento em Nutricao em Saude Publica. } \\
\text { Faculdade de Saúde Pública-USP. } \\
\text { Títuba: Programa Saúde na Escola: Análise da gestão local, ações de } \\
\text { alimentaçäo e nutriçäo e estado nutricional dos escolares brasileiros., } \\
\text { Orientador: (9) Profa Dra Patricia Constant Jaime. }\end{array}$ \\
\hline $2005-2007$ & $\begin{array}{l}\text { Mestrado em Saúde Pública (Conceito CAPES 5). } \\
\text { Universidade de Säo Paulo, USP, Brasil. } \\
\text { Títuba Redes de Apoio Social emgestantes de baixa renda do munićpio de Säo } \\
\text { Paubo e sua influência sobre o peso ao nascer,Ano de Obtenção: } 2007 . \\
\text { Orientador: Maria Helena D'Aquino Benício. } \\
\text { Bobista do(a): Conseho Nacional de Desenvolvimento Cientifico e Tecnológico, } \\
\text { CNPq, Brasil. } \\
\text { Palavras-chave: Redes de Apoio; gestantes; peso ao nascer. } \\
\text { Grande área: Cências da Saúde / Área: Saúde Coletiva / Subárea: Saúde } \\
\text { Pública. } \\
\text { Grande Área: Cểncias da Saúde / Área: Nutrição. }\end{array}$ \\
\hline $2008-2009$ & $\begin{array}{l}\text { Especialização em Gestão de Políticas de Almentaçäo e Nutrição. } \\
\text { FUndaçäo Oswaldo Cruz. } \\
\text { Títub: Protocolb de atendimento de adolescentes com excesso de peso na } \\
\text { atençäo básica. } \\
\text { Orientador: Janine Gubert Coutinho. }\end{array}$ \\
\hline
\end{tabular}




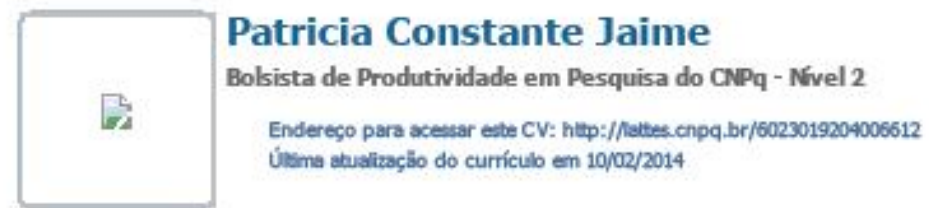

Nutricionista. Professora associada do Departamento de Nutrição da Faculdade de Saúde Pública (FSP) da Universidade de São Paulo (USP). Mestre e Doutora em Saúde Pública pela FSP/USP. PósDoutora em Epidemiologia Nutricional pelo Núcleo de Pesquisas Epidemiológicas em Nutrição e Saúde - NUPENS / USP e em Políticas Públicas de Alimentação e Nutrição pela London School of Hygiene and Tropical Medicine, Reino Unido. Atual Coordenadora da Coordenação Geral de Alimentação e Nutrição / DAB / SAS do Ministério da Saúde. Tem experiência no campo da alimentação e nutrição em saúde coletiva, atuando principalmente nos seguintes temas: avaliação de programas e políticas de alimentação e nutrição, consumo alimentar de grupos populacionais, intervenções nutricionais e promoçāo da alimentação saudável. Bolsista Produtividade em Pesquisa do $\mathrm{CNPq}-\mathrm{Pq} 2$. (Texto informado pelo autor)

Identificação

\begin{tabular}{ll}
\hline Nome & Patricia Constante Jaime \\
Nome em citações bibliográficas & JAIME, P. C.;]aime, Patricia Constante;]aime PC;]JAIME, PATRICIA C;]JAIME, \\
& PATRÄ CIA CONSTANTE;]AIME, P C;]AIME, P.C.
\end{tabular}

\title{
Endereço
}

Endereço Profissional Universidade de Säo Paub, Faculdade de Saúde Pública.

Avenida Dr. Arnaldo, $7152^{\circ}$ andar (Departamento de Nutrição)

Cerqueira Cesar

01246-904 - Sao Paulo, SP - Brasit

Telefone: (11) 30717866

\author{
Formação acadêmica/titulação \\ $2010 \quad$ Livre-docência. \\ Faculdade de Saúde Pública / USP. \\ Títub: Intervenção no ambiente de trabalho para prevenção do ganho de peso \\ corporal: delineamento e avaliação., Ano de obtenção: 2010. \\ $2007-2008$ \\ Pós-Doutorado. \\ London School of Hygiene and Tropical Medicine. \\ Bolsista do(a): Intemational Nutrition Foundation. \\ Grande área: Ciências da Saúde / Área: Nutrição. \\ Grande Área: Cências da Saúde / Área: Saúde Coletiva / Subárea: Saúde \\ $2002-2003$ \\ Pública. \\ Pós-Doutorado. \\ Núcleo de Pesquisas Epiderriológicas em Nutrição e Saúde da USP. \\ Grande área: Cências da Saúde / Área: Saúde Coletiva / Subảrea: \\ Epiderriologia / Especialidade: Epidemiologia Nutricional. \\ Grande Área: Cênccias da Saúde / Área: Saúde Coletiva / Subárea: \\ Epiderriologia. \\ $1999-2001$ \\ Doutorado em Saúde Pública (Conceito CAPES 5). \\ Universidade de Säo Paulo, USP, Brasil. \\ Títulb: Correçöes em medidas de consumo alimentar: aplicaçäo na análise da \\ correlação do consumo de cákio, proteína e energia coma densidade mineral \\ óssea em horrens adultos e idosos, Ano de obtenção: 2001.
}

